Domestic Sales Mix of Plug-In Electric Vehicles by Trim Variant and Vehicle Characteristics

Energy Systems Division 


\section{About Argonne National Laboratory}

Argonne is a U.S. Department of Energy laboratory managed by UChicago Argonne, LLC under contract DE-AC02-06CH11357. The Laboratory's main facility is outside Chicago, at 9700 South Cass Avenue, Lemont, Illinois 60439. For information about Argonne and its pioneering science and technology programs, see www.anl.gov.

\section{DOCUMENT AVAILABILITY}

Online Access: U.S. Department of Energy (DOE) reports produced after 1991 and a growing number of pre-1991 documents are available free at OSTI.GOV (http://www.osti.gov/), a service of the US Dept. of Energy's Office of Scientific and Technical Information.

\section{Reports not in digital format may be purchased by the public from the National Technical Information Service (NTIS):}

U.S. Department of Commerce

National Technical Information Service

5301 Shawnee Road

Alexandria, VA22312

www.ntis.gov

Phone: (800) 553-NTIS (6847) or (703) 605-6000

Fax: (703) 605-6900

Email: orders@ntis.gov

\section{Reports not in digital format are available to DOE and DOE contractors} from the Office of Scientific and Technical Information (OSTI):

U.S. Department of Energy

Office of Scientific and Technical Information

P.O. Box 62

Oak Ridge, TN 37831-0062

www.osti.gov

Phone: (865) 576-8401

Fax: (865) 576-5728

Email: reports@osti.gov

\section{Disclaimer}

This report was prepared as an account of work sponsored by an agency of the United States Government. Neither the United States Government nor any agency thereof, nor UChicago Argonne, LLC, nor any of their employees or officers, makes any warranty, express or implied, or assumes any legal liability or responsibility for the accuracy, completeness, or usefulness of any information, apparatus, product, or process disclosed, or represents that its use would not infringe privately owned rights. Reference herein to any specific commercial product, process, or service by trade name, trademark, manufacturer, or otherwise, does not necessarily constitute or imply its endorsement, recommendation, or favoring by the United States Government or any agency thereof. The views and opinions of document authors expressed herein do not necessarily state or reflect those of the United States Government or any agency thereof, Argonne National Laboratory, or UChicago Argonne, LLC. 
ANL/ESD-21/5

\section{Domestic Sales Mix of Plug-In Electric Vehicles by Trim Variant and Vehicle Characteristics}

by

Rebecca H. Schwartz ${ }^{1,2}$, Matthews Cribioli, ${ }^{1,3}$, and David Gohlke ${ }^{1}$

${ }^{1}$ Energy Systems Division, Argonne National Laboratory

${ }^{2}$ Brown University

${ }^{3}$ University of California, Irvine

October 2021 


\section{TABLE OF CONTENTS}

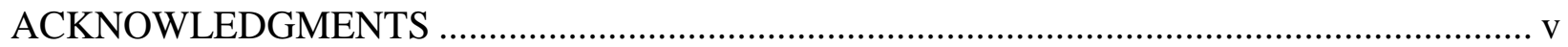

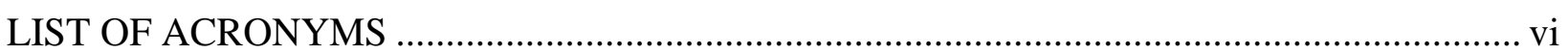

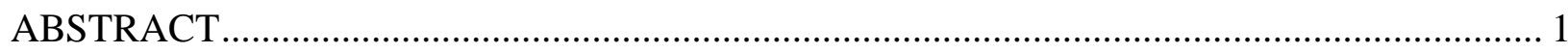

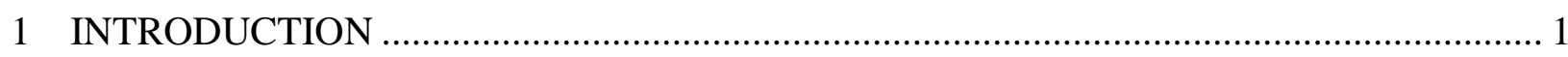

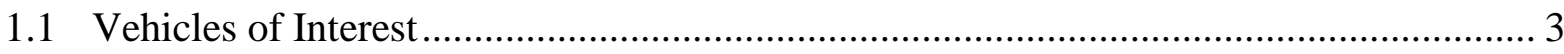

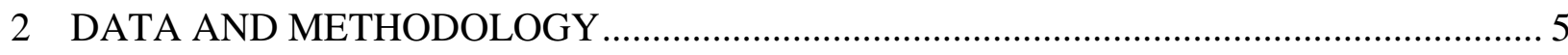

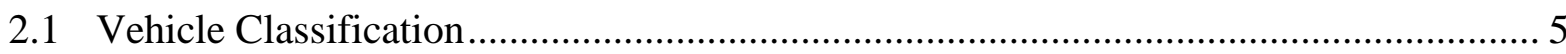

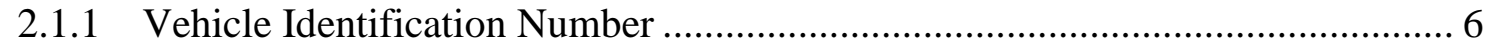

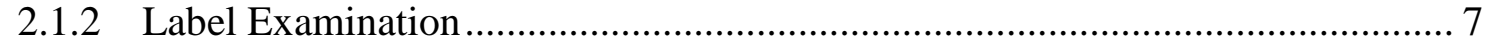

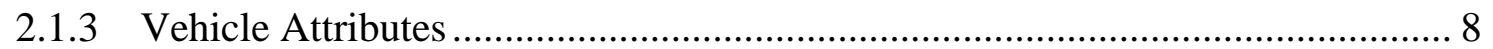

2.1.4 Other Identifiers Not Used .................................................................... 8

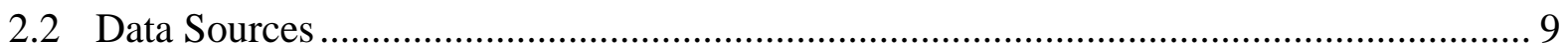

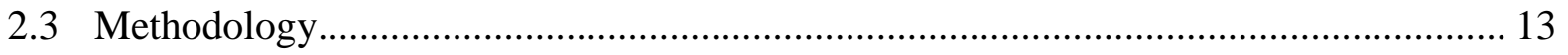

2.3.1 Quantification of Sales Shares by Model .................................................. 13

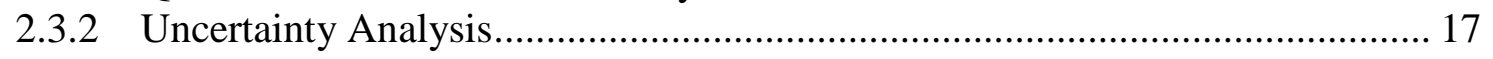

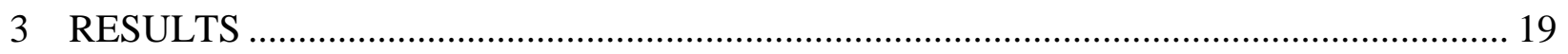

3.1 Vehicle-Specific Results ............................................................................... 21

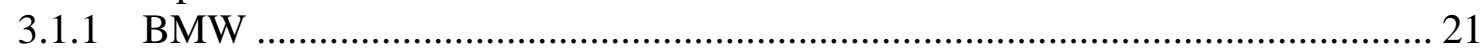

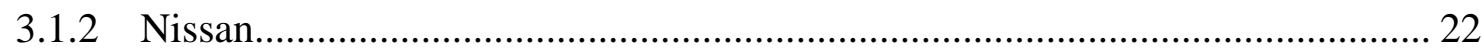

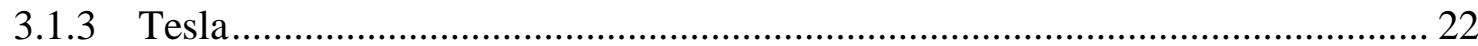

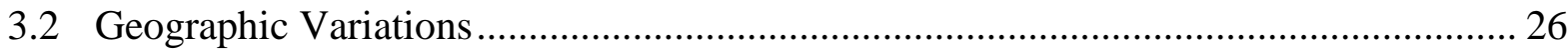

3.2.1 Tesla All-Wheel Drive ............................................................................ 26

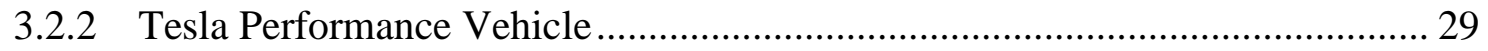

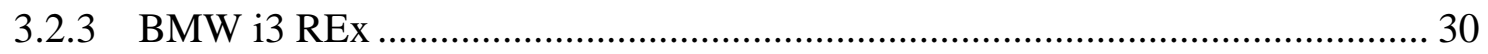

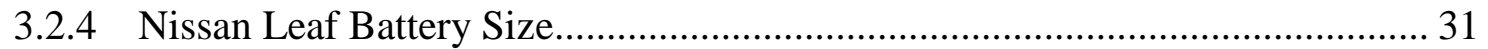

3.2.5 Chevrolet Volt Emission Package .............................................................. 32

3.2.6 Volvo XC60 Assembly Location............................................................... 33

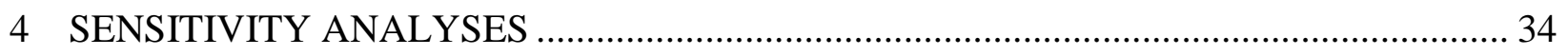

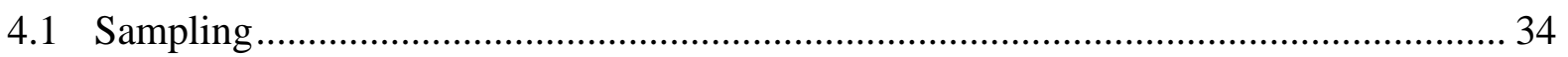

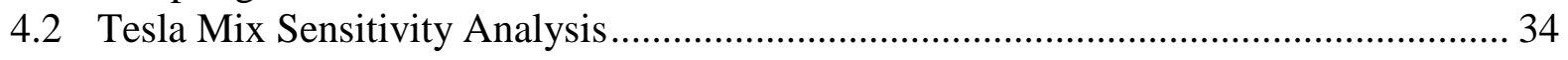

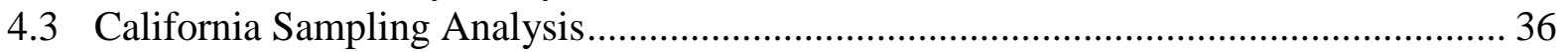

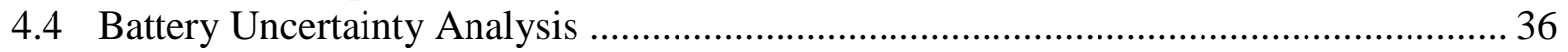

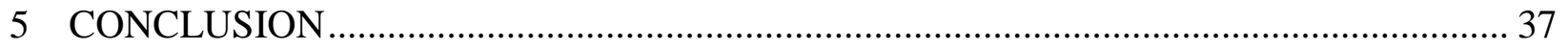

APPENDIX A: Detailed Estimated Trim Variant Distributions ............................................. 38

APPENDIX B: Share of Tesla Models by Trim Variant ....................................................... 46

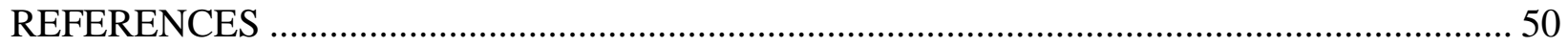




\section{FIGURES}

1 Vehicle Characteristic Detail Level of 2016 Tesla Models ................................................. 5

2 States with PEV Registration Data Used in this Analysis .................................................... 11

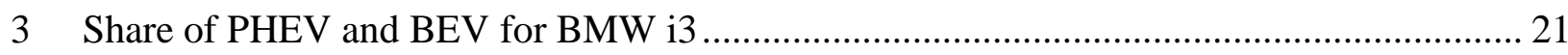

4 Yearly Distribution of Nissan Leaf by Battery Size .......................................................... 22

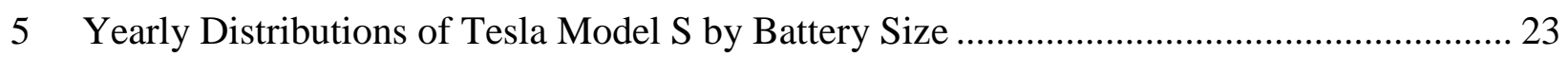

6 Yearly Distributions of Tesla Model X by Battery Size......................................................... 23

7 Yearly Distributions of Tesla Model 3 and Model Y by Battery Size .................................. 24

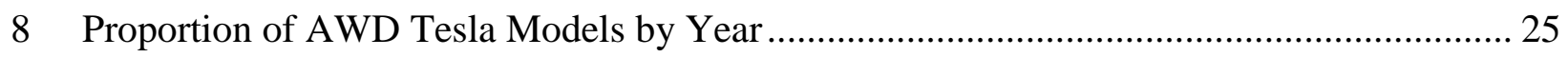

9 Proportion of Performance Tesla Models by Year ............................................................ 25

10 Share of MY2015-17 Tesla Model S and MY2018-20 Tesla Model 3 with AWD by

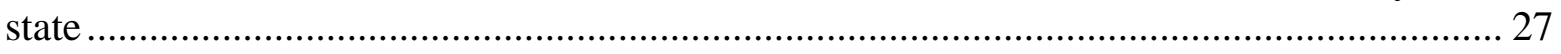

11 Share of MY2015-20 Tesla Model S with performance trim by state .................................. 29

12 Share of MY2014-20 BMW i3 with range extender (REx) by state .................................. 30

13 Share of MY2016, 2019 and 2020 Nissan Leaf in dataset with largest available battery ..... 31

14 Share of MY2013-19 Chevrolet Volt in dataset with low-emissions package ..................... 32

15 Share of MY2018-19 Volvo XC60 assembled in Sweden by state ..................................... 33

\section{TABLES}

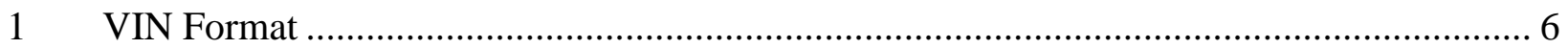

2 VIN Descriptors for Each Distinguishable Make and Model of PEV …………................ 7

3 Domestic and International Vehicle Registration Data Sources ......................................... 10

$4 \quad$ Vehicle Makes and Models Considered in this Analysis ................................................... 14

5 Sales-weighted Average Vehicle Characteristics for Each PEV Make and Model ............. 20

6 Predictive Model Coefficients for AWD for Certain Non-Performance Tesla Models...... 28

7 Impacts of Tesla Sensitivity Analyses on Total Battery Capacity ………………............... 35

A1 Audi A3 e-tron Trim Variant Distribution .................................................................. 38

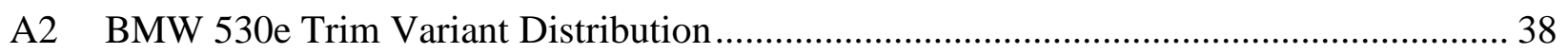

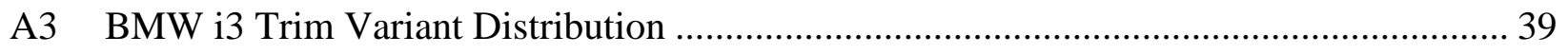

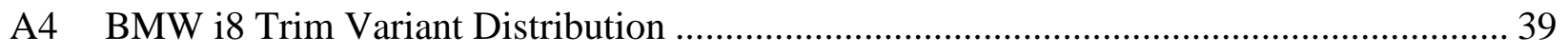

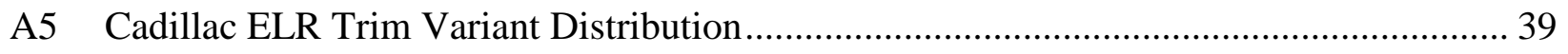

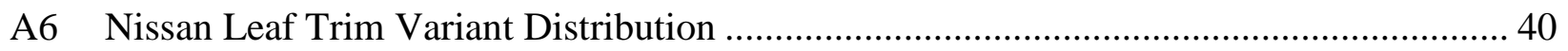




\section{TABLES (CONT.)}

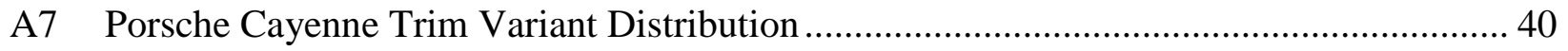

A8 Porsche Panamera Trim Variant Distribution .................................................... 41

A9 Porsche Taycan Trim Variant Distribution ........................................................... 41

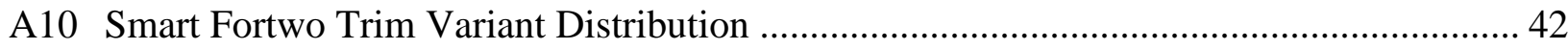

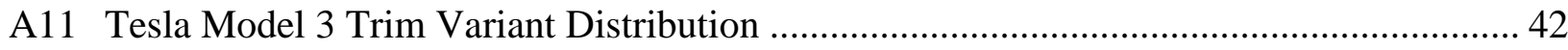

A12 Tesla Model S Trim Variant Distribution ................................................................ 43

A13 Tesla Model X Trim Variant Distribution................................................................... 45

A14 Tesla Model Y Trim Variant Distribution............................................................. 45

B1 Tesla Model S Trim Variant Distribution .............................................................. 46

B2 Tesla Model X Trim Variant Distribution................................................................ 48

B3 Tesla Model 3 Trim Variant Distribution ................................................................... 49

B4 Tesla Model Y Trim Variant Distribution...................................................................... 49 


\section{ACKNOWLEDGMENTS}

This activity was supported by the Vehicle Technologies Office, Office of Energy Efficiency and Renewable Energy, United States Department of Energy. This work was supported in part by the U.S. Department of Energy, Office of Science, Office of Workforce Development for Teachers and Scientists (WDTS) under the Science Undergraduate Laboratory Internships Program (SULI).

The authors thank Tom Wenzel of Lawrence Berkeley National Laboratory, Conor Gately and Lily Perkins-High of the Metropolitan Area Planning Council, Cesar Cuevas at the California Air Resources Board, Brett Williams and Nick Pallonetti of the Center for Sustainable Energy, and Atlas Public Policy for detailed registration data. The authors thank Joann Zhou and Luke Rush of Argonne National Laboratory for supplying vehicle sales data.

This report was prepared as an account of work sponsored by an agency of the United States government. Neither the United States government nor any agency thereof, nor any of their employees, makes any warranty, express or implied, or assumes any legal liability or responsibility for the accuracy, completeness, or usefulness of any information, apparatus, product, or process disclosed or represents that its use would not infringe privately owned rights. Reference herein to any specific commercial product, process, or service by trade name, trademark, manufacturer, or otherwise does not necessarily constitute or imply its endorsement, recommendation, or favoring by the United States government or any agency thereof. The views and opinions of authors expressed herein do not necessarily state or reflect those of the United States government or any agency thereof. 


\section{LIST OF ACRONYMS}

\begin{tabular}{|c|c|}
\hline ANL & Argonne National Laboratory \\
\hline BEV & Battery Electric Vehicle \\
\hline CVRP & Clean Vehicle Rebate Program \\
\hline CUV & Crossover Utility Vehicle \\
\hline DCFC & Direct-Current Fast Charging \\
\hline DOE & Department of Energy \\
\hline EPA & Environmental Protection Agency \\
\hline GWh & gigawatt-hour \\
\hline $\mathrm{kWh}$ & kilowatt-hour \\
\hline MAPC & Metropolitan Area Planning Council \\
\hline MSRP & Manufacturer's Suggested Retail Price \\
\hline MY & Model Year \\
\hline NHTSA & National Highway Traffic Safety Administration \\
\hline OEM & Original Equipment Manufacturer \\
\hline PEV & Plug-in Electric Vehicle \\
\hline PHEV & Plug-in Hybrid Electric Vehicle \\
\hline RWD & Real-Wheel Drive \\
\hline SUV & Sport Utility Vehicle \\
\hline TSN & Typschlüsselnummer \\
\hline SUV & Sport Utility Vehicle \\
\hline VIN & Vehicle Identification Number \\
\hline vPIC & Vehicle Product Information Catalog \\
\hline Wh & watt-hour \\
\hline WMI & World Manufacturer Identifier \\
\hline ZEV & Zero-Emission Vehicle \\
\hline
\end{tabular}




\title{
DOMESTIC SALES MIX OF PLUG-IN ELECTRIC VEHICLES BY TRIM VARIANT AND VEHICLE CHARACTERISTICS
}

\begin{abstract}
As plug-in electric vehicles (PEVs) take up a larger share of the United States vehicle market, their variety increases as well. Since many electric vehicle manufacturers offer multiple PEV trim variants, the distribution of vehicle characteristics such as battery capacity, all-electric range, electricity consumption, and curb weight cannot be determined by sales data alone. Sales data and vehicle registration data were analyzed to quantify and map the trim variant distribution of PEV models from nine automakers. With this information, we quantify national sales-weighted characteristics of fourteen different models over ten years, including battery capacity, fuel economy, and vehicle weight. We find a positive correlation between share of all-wheel drive variants for Tesla vehicles and average annual snowfall, and general uniformity nationwide in other vehicle characteristics. The estimated trim variant distributions will be useful in informing decisions regarding materials recycling and EV impact on the energy grid, and this study found that the total installed battery capacity in PEV in the U.S. was $76 \mathrm{GWh}$ through 2020.
\end{abstract}

\section{INTRODUCTION}

In the last decade, plug-in electric vehicles (PEVs) have represented increasingly larger market shares of both the domestic and global vehicle market (Cohen 2020; BloombergNEF 2020), growing from just 17,000 passenger vehicles worldwide in 2010 to 7.2 million in 2019 (IEA 2020b). With more electric vehicles on the road, their impacts on emissions, energy consumption, and materials usage increase and become more complicated to track. As sales have increased, the market of battery electric vehicles (BEVs) and plug-in hybrid electric vehicles (PHEVs) has diversified, and electric vehicle manufacturers now offer a variety of vehicle models. Even within a single model, automakers are now offering multiple variants to satisfy consumer demand, with variations in driving range and vehicle performance. Increasing variety complicates the calculation of PEV metrics since variables such as battery capacity, fuel economy, and range can no longer be calculated purely from sales data at the model level for models with multiple variants. This report examines available multiple data sources to estimate the trim variant distribution of PEV models that have significant differences in battery capacity and efficiency. From these trim variant distributions, we estimate the average vehicle battery capacity and average range for each model to better understand the use and impacts of the PEV market. This report outlines the methodology used to estimate the sales mix of various PEV models in order to track trends in vehicle characteristics, and presents estimates of trim variant mix of U.S. sales for fourteen models of PEV dating back to 2011. 
In general, the initial point of information about the vehicles comes from quarterly sales reports directly from the original equipment manufacturers (OEMs). These reports are often presented at the model-level, enabling comparison of different vehicle powertrains and body types, but rarely data with higher resolution. After the initial sales, registration data can be used to understand the vehicle stock. In the United States, vehicles are registered at the state level, and while aggregated registration databases exist (e.g. IHS Markit 2021), they often do not present the level of detail necessary for analysis of electric vehicles. Understanding the distribution of electric vehicle characteristics is critical for quantifying their environmental impacts, as electricity used for PEVs is not tracked at the point of sale, like gasoline-fueled vehicles. Additionally, the vast majority of PEVs use lithium-ion batteries and understanding the total capacity of cells on the road can potentially be used for electricity grid management and ultimately improve projections of future materials recycling flows (Xu et al. 2020; Wei et al. 2021). From an analytical perspective, knowledge of the mix of trim variants can help inform vehicle purchase choice models to better understand and forecast consumer preferences.

Other reports have informally looked into the mix of different vehicle trim variants, but not systematically across all electric vehicle models. Prior to vehicle sale, OEMs register Vehicle Identification Numbers (VINs) for vehicles they plan to produce with the National Highway Transportation Safety Administration (NHTSA) in order to accommodate future recalls (NHTSA 2008). This set of VINs is housed in a recall database hosted by NHTSA (NHTSA 2021b). Although the tool is intended to be used to determine if a vehicle has been recalled, it also lets the user know if the vehicle's VIN has been registered with NHTSA by manufacturers. The Twitter account @Model3VINs used this recall information to find which VINs had been registered for the Tesla Model 3 and estimate the production output, starting in mid-2017 (Model 3 VINs 2020). By early-2018, the tracker was also quantifying all-wheel drive (AWD) and in 2019 the tracker also presented international VINs as the Model 3 began to be sold outside the United States (Shahan 2018; Model3VINs.com 2019). Journalists from Bloomberg used this tool to determine the rate of Tesla Model 3 production by generating potential VINs and seeing if they were registered with the database (Randall 2019). However, this method was not used in this report since manufacturers can register VINs of vehicles that are not produced and sent to market or those sold internationally. At an aggregate level, vehicle recall data has been used to estimate trim variant distribution of the BMW i3 and the production rate of the Tesla Model 3. In 2017, BMW issued a recall on the i3 due to fault in the fuel tank vent line, impacting $76 \%$ of the i3 sold to that time (Cole 2017). As this only affected the range-extended PHEV version of the $\mathrm{i3}$, this reveals the ratio of BEV to PHEV for the i3 for model year (MY) 2014 to early 2017. The website Tesla-info.com has gathered information from sales listings of over 120,000 used Tesla vehicles, from MY2013 to MY2021 (Tesla Info 2021). Because used vehicle listings are not necessarily representative of all vehicles, we do not reproduce their methodology to estimate total sales shares.

We have identified 20 models of PEV which have multiple trim variants in the FuelEconomy.gov database provided by the U.S. Department of Energy (DOE) and the U.S. Environmental Protection Agency (EPA) from MY2011 to MY2021 (DOE and EPA 2021). Of these, eighteen have identifying information in their VIN, as determined from VIN decoders providers by the NHTSA Product Information Catalog and Vehicle Listing (NHTSA 2021a). In this study we analyze PEV sales mixes of several vehicle models through the end of 2020 using vehicle registration data from nineteen states and the District of Columbia. By decoding the 
VINs from the state's registration data, sales mix can be better understood. Where VIN decoding is insufficient to completely determine the trim variant mix, we supplement our analysis of U.S. registration with international registration data. We use this information to find the salesweighted average fuel efficiency, battery capacity, driving range, and curb weight for each model. We believe this study is the first study to use vehicle registration data to systematically estimate trim variant distributions of electric vehicles.

\subsection{VEHICLES OF INTEREST}

In this report, we pay particular focus to Tesla vehicles due to their high volume and wide range of trim variants. Tesla is the largest electric vehicle manufacturer both globally and domestically, with $18 \%$ of global electric vehicle market (Lambert 2020) and $79 \%$ of the domestic electric vehicle market (Lambert 2021b) during the 2020 sales year. As of January 2021, Tesla sells four car models: Model S, Model X, Model 3, and the Model Y. The Model S, a large luxury sedan, began domestic sales in 2012, the Model X, a luxury sports utility vehicle (SUV), began domestic sales in 2015 (Durbin 2015), the Model 3, a mid-sized car, began domestic sales in 2017, and the Model Y, a crossover utility vehicle (CUV), began domestic sales in 2020 (Lambert 2019b). The Model 3 has rapidly grown to be the top-selling Tesla vehicle. Intended for mass market distribution, the Tesla Model 3 has become the best-selling electric vehicle in the world since its release in 2017. At 365,000 vehicles sold worldwide in 2020, the Model 3 makes up 12\% of the global electric vehicle market (Lambert 2021a). Because Tesla makes up such a large volume of the electric vehicle market, having an accurate model of the Tesla sales mix allows for better estimations of total energy consumption, electricity consumption, and upstream electricity emissions from Tesla vehicles. Without the data for Tesla vehicles, precise estimations of the impact of electric vehicles cannot be reached. Estimations of Tesla's impact remain imprecise since the company releases sales numbers only at the model level in its quarterly reports (Tesla 2021), but the following methodology produces the most accurate and detailed estimation to date.

The Nissan Leaf was the first prominent mainstream battery electric vehicle sold in the United States, and has sold a total of over 150,000 in the U.S. since 2011 (ANL 2021). Since its release in 2010, the total range has increased from 73 miles to up to 226 miles, as per EPA testing, due to an increase in battery size from $24 \mathrm{kWh}$ to $62 \mathrm{kWh}$. However, as the battery size has increased, Nissan has made multiple battery sizes available for purchase, leading to uncertainty in total battery size and average range.

Beyond the Tesla and Nissan models, several other vehicles have been offered with multiple variants which can be distinguished in the EPA/DOE FuelEconomy.gov data (DOE and EPA 2021). The BMW i3 is available as a full-electric BEV and with a gasoline-fueled rangeextender. BMW does not distinguish between the two in its quarterly (previously monthly) sales reports, and so classification of these two vehicles needs to be determined. The BMW 530e and BMW 330e each have the xDrive package which improves performance but reduces all-electric range and fuel economy. The roadster and coupe variants of the BMW i8 are also distinguishable by VIN, but do not differ in any key metrics in the FuelEconomy.gov database and only have slightly different curb weights. 
Porsche has released multiple versions of the Panamera and Cayenne with and without 'turbo' packages, which have lower fuel efficiency and reduced range. Porsche has also released multiple battery sizes in the all-electric Taycan starting in MY2020, though these are generally not distinguishable by VIN. Since MY2011, the Smart Fortwo has been offered for sale with modest differences in electricity consumption for the coupe and cabriolet trims. The 2016 Cadillac ELR had a Sport variant with improved performance and reduced fuel economy. The 2016 Audi A3 e-tron was released with an 'ultra' variant with lower profile wheels to reduce rolling resistance for improved efficiency and all-electric range. In model year (MY) 2021, Ford released the Mustang Mach-E with multiple performance levels and battery sizes, Audi released two variants of the e-tron with modest differences in fuel efficiency and range, and Volkswagen released multiple distinguishable packages of the ID.4. These MY2021 vehicles do not have sufficient registrations to date for an analysis of their sales mix. 


\section{DATA AND METHODOLOGY}

\subsection{VEHICLE CLASSIFICATION}

For each model year, we can explore the sales mix of vehicles at different levels of detail. In this report, we consider four levels of detail used in this report, with Figure 1 demonstrating these levels visually: the OEM level (shown in orange), the model level (shown in yellow), the VIN level (shown in blue), and the trim variant level (shown in green). Within each variant, the vehicles may be sold at different trim levels, such as comfort packages; these are not included in our analysis unless they change the performance characteristics of the vehicle. One minor complication is that the sales data is generally counted within a calendar year, but registration information is typically counted by model year. The results presented in this analysis are generally at the model-year level.

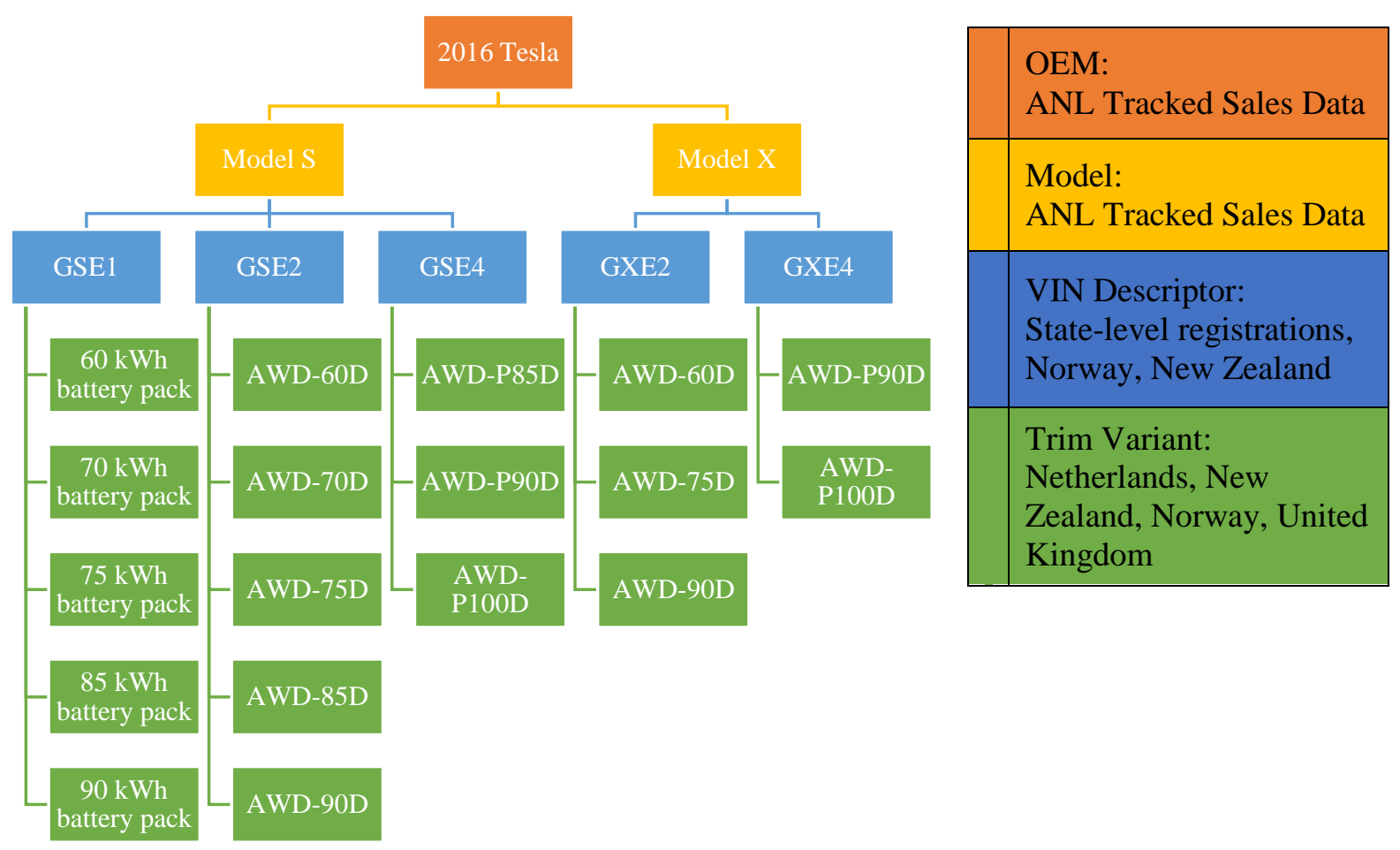

\section{FIGURE 1 Vehicle Characteristic Detail Level of 2016 Tesla Models}

Argonne National Laboratory (ANL) tracks and aggregates monthly PEV sales data in the United States at the automaker and model levels (ANL 2021), with data ultimately sourced from quarterly OEM announcements. The VIN data is enough to distinguish the trim variants for nearly all vehicle models in this study, with the exception of the MY2017 BMW i3, MY2020 Porsche Taycan, and Tesla models after 2015. The VIN specifies performance level but does not give sufficient information to know the battery capacity for the Porsche Taycan. For Tesla models released after August 2015, a VIN can map onto a small number of potential EPAcertified trim variants. Figure 1 represents a schematic showing the labeling hierarchy of 2016 
Teslas. Within a single VIN descriptor for these Tesla vehicles, performance characteristics such as motor power output and AWD capability are known, but the total all-electric range is not uniquely determined. In order to determine the sales mix of different variants, we looked at label data where registration information specified this information.

\subsubsection{Vehicle Identification Number}

This analysis relies on VIN decoding to estimate the sales mix of each variant for each model. The VIN is a 17-digit number which has digits that describe different aspects of the vehicle (NHTSA 2015). Each vehicle brand uses a slightly different decoding scheme, but for all brands, the first three characters are the World Manufacturer Identifier (WMI), the ninth digit is the check digit, used to identify the validity of the VIN, the tenth digit shows the model year, and the 12th through 17th digits represent a unique vehicle serial number. As these serial numbers can potentially be linked to personally identifiable information, no analysis has been taken on the last 6 digits of the VIN. The fourth through eighth digits of the VIN are determined by the manufacturer and describe key vehicle characteristics. This is summarized in Table 1.

\section{TABLE 1 VIN Format}

\begin{tabular}{|l|l|l|l|l|l|l|}
\hline Digits & $1-3$ & $4-8$ & 9 & 10 & 11 & $12-17$ \\
\hline Identifier & WMI & $\begin{array}{l}\text { Vehicle } \\
\text { Descriptor } \\
\text { Section }\end{array}$ & Check Digit & Model Year & Plant & $\begin{array}{l}\text { Serial } \\
\text { Number }\end{array}$ \\
\hline
\end{tabular}

The digits from the vehicle descriptor section (digits 4-8) identify the variants of interest in this analysis. We refer to the specific set of digits necessary to uniquely identify the trim variants as the VIN descriptor, which we denote with three or four alphanumeric characters. Table 2 shows the set of VIN descriptors for each electric vehicle model in this analysis. For convenience, we present the VIN descriptor with the model year digit (digit 10). For example, for Tesla, the descriptor FSH1 refers to a MY2015 [F] Tesla Model $[S]$ that has a high capacity battery $[H]$ and a single motor [1]. Likewise, a Nissan Leaf with descriptor $K B B$ refers to a model year $2020[K]$ vehicle with a $62 \mathrm{kWh}$ battery $[B]$ and the S-level trim $[B]$, while a Smart Fortwo with descriptor $D K 9$ refers to a MY2013 [D] vehicle with a convertible body-type $[K]$ and an electric motor [9]. This table also shows the first eight digits of the VIN, with asterisks marking values that are not the same for all variants. Note that Table 2 is not exhaustive of all models of PEV, nor even of all MY for a given model, if there is not information in the VIN distinguishing multiple trim variants. 
TABLE 2 VIN Descriptors for Each Distinguishable Make and Model of PEV

\begin{tabular}{|c|c|c|c|}
\hline Model & MY & VIN descriptor digits & VIN8 \\
\hline Audi A3 e-tron & 2016 & 10-4-5: Series, Engine type & $\mathrm{WAU} * \mathrm{PBFF}$ \\
\hline Audi e-tron & 2021 & 10-4-7: Series, Model & WA1*AAGE \\
\hline BMW i3 & $2014-21$ & 10-4-5-6: General vehicle descriptor & $\mathrm{WBY} * \star \star \mathrm{C}^{\star}$ \\
\hline BMW i8 & $2019-20$ & 10-4-6: General vehicle descriptor & WBY2Z*C* \\
\hline BMW 330e & 2021 & 10-5-6: General vehicle descriptor & $\begin{array}{l}\text { WBA5 } P^{*} C^{*} \\
\text { 3MW } P^{*} J^{\star}\end{array}$ \\
\hline BMW 530e & $2018-21$ & 10-4-5-6: General vehicle descriptor & $\mathrm{WBA}^{\star \star \star \star \star \star \star ~}$ \\
\hline Cadillac ELR & 2016 & 10-4-5: Line, Series & $1 \mathrm{G} 6 \mathrm{R} \star 1 \mathrm{E} 4$ \\
\hline Chevrolet Volt & 2011-19 & 10-4-5: Line, Series & $1 \mathrm{G} 1 \mathrm{R} * 6 * *$ \\
\hline Ford Mustang Mach E & 2021 & 10-6-7-8: Line, Series, Engine type & 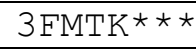 \\
\hline Nissan Leaf & $2016,19-21$ & 10-4-7: Engine type, Body type & $1 \mathrm{~N} 4 * \mathrm{Z}^{* \star \star}$ \\
\hline Porsche Cayenne & $2020-21$ & 10-4-5: Body type, Fuel & $\mathrm{WP} 1 * \star 2 \mathrm{AY}$ \\
\hline Porsche Panamera & $2018-21$ & 10-4-5: Body type, Fuel & $\mathrm{WP} 0 * \star 2 \mathrm{~A} 7$ \\
\hline Porsche Taycan & $2020-21$ & 10-4-5: Body type, Fuel & $\mathrm{WPO} * \star 2 \mathrm{Y} 1$ \\
\hline Smart Fortwo & $2011,13-19$ & 10-5-6: General vehicle descriptor & WME**9** \\
\hline Tesla Model 3 & $2017-21$ & 10-4-7-8: Line, Fuel, Motor/drive unit & $5 Y J 3 E^{*} E^{\star}$ \\
\hline Tesla Model S & $\begin{array}{l}2012-13 \\
2014-15 \\
2015-21\end{array}$ & $\begin{array}{l}\text { 10-4-7-8: Line, Charger, Motor \& Battery } \\
\text { 10-4-7-8: Line, Battery type, Motor/drive unit } \\
\text { 10-4-7-8: Line, Fuel, Motor/drive unit }\end{array}$ & $5 Y J S A * \star \star$ \\
\hline Tesla Model X & $2016-21$ & 10-4-7-8: Line, Fuel, Motor/drive unit & $5 \mathrm{YJXC} \mathrm{E}^{\star}$ \\
\hline Tesla Model Y & $2020-21$ & 10-4-7-8: Line, Fuel, Motor/drive unit & $5 \mathrm{YJYG}^{\star} \mathrm{E}^{\star}$ \\
\hline Volkswagen ID.4 & 2021 & 10-4-5: Series, Engine type & $\begin{array}{l}\mathrm{WVG}^{*} * \mathrm{PE} 2 \\
1 \mathrm{~V} 2 * * \mathrm{PE} 2\end{array}$ \\
\hline Volvo XC60 & $2018-21$ & 10-5-8: Engine, Trim & $\begin{array}{l}Y V 4 B^{*} 0 D^{*} \\
L Y V B * 0 D^{\star}\end{array}$ \\
\hline
\end{tabular}

For BMW and Smart, the vehicle descriptor section is generated as a whole, rather than designating a specific vehicle characteristic. There are two separate WMIs for the MY2021 BMW 330e and Volkswagen ID.4, representing alternate assembly locations available for sale in the United States. Likewise, the MY2018 and MY2019 Volvo XC60 indicate assembly locations in both Europe and China. Over time the information carried in the VIN descriptor may change. For example, prior to 2020, the Nissan Leaf VIN gave information about the battery size, but not the specific trim level (S, SV, or SL). In the FuelEconomy.gov database, the SV and SL trims each have modestly higher electricity consumption rates and reduced range compared to the $S$ trim. Starting with MY2020, those trims can be ascertained from digit 7. For the Tesla Model S, prior to August 2015, the battery size was signified by digit 7, explicitly showing high- and lowcapacity batteries. Starting in August 2015, this information was removed from the VIN, being replaced by a signifier for electricity as a fuel type.

\subsubsection{Label Examination}

Label examination was only used in determining trim variant mix for Tesla Models within each VIN descriptor. While VIN decoding may not give the exact trim variant for Tesla models, label examination does, but label examination itself cannot be used to determine the 
domestic trim variant distribution since none of the domestic data retrieved in this study contained labels.

Although only the data from Norway, United Kingdom, New Zealand, and the Netherlands provide information at the label level, these labels can be used to deduce the exact trim of the vehicle sold. For example, a MY2018 vehicle with the label SP85D would be a Model S Performance vehicle with Dual motors and an $85 \mathrm{kWh}$ battery. Since the introduction of the Model 3, and beginning in 2019 for the Model S and Model X, trim variants do not explicitly contain the battery size or number of motors, but the trim variant name such as LR (Long Range) or P (Performance) only corresponds to one battery type for each make, model, and year.

Although label examination is a relatively straight-forward process there are two main issues that complicate its usage. Unlabeled and mislabeled vehicle trims have the potential to skew data. In this study, unlabeled and mislabeled data was removed from analysis, including vehicles with invalid VINs. Combining label data with VIN data where possible can be used to sort out mislabeled products such as those incorrectly marked performance or dual motor. Of the 138,640 international vehicles surveyed, only 1,260 vehicles (less than 1\%) were removed for being unlabeled, under-labeled, or mislabeled.

The other complication is more abstract. Because there may be variation between the domestic sales mix and the international sales mix, a variety of sensitivity analyses have been applied to show the robustness of the results. Further examinations of sensitivity analysis can be found in the Results section.

\subsubsection{Vehicle Attributes}

When a specific label is not presented, but other information is, this information can potentially be used as a proxy to determine the label. Vehicle registrations from New York State include the unladen weight of the vehicle (NYS DMW 2021). This can be used to estimate the fraction of vehicles with different battery capacities, though there are data gaps and the curb weight does not give a perfect one-to-one correspondence with a specific trim variant or battery size. The Massachusetts Vehicle Census run by the Metropolitan Area Planning Council (MAPC) also cataloged vehicle registration data from 2009 through 2014 (MAPC 2016). This data includes MSRP (Manufacturer's Suggested Retail Price) and vehicle weight. The MSRP can be cross-referenced against prices of these vehicles to find the battery size, and the weight can be used to identify all-wheel drive models in late 2014. Using MSRP and vehicle weight, the Massachusetts sales mix could be accurately measured to the variant level, even in the absence of VIN or label information.

\subsubsection{Other Identifiers Not Used}

Germany presents aggregated registration data by year, based on the vehicle "Typschlüsselnummer" (TSN), a three-character code specifying model, body type, motor, and fuel source (KBA 2021). This data describes vehicles with the level of detail gained from a VIN but does not reveal specific trim variant distributions for later models.

Vehicle recall also has the potential to determine trim variant distribution. If only a portion of models are recalled, the fraction of recalled vehicles may correspond to a specific trim. Alternatively, the recall may specify the number of vehicles for each variant. Japanese 
Tesla recalls on the Model S and Model X can be used to estimate the distribution of models by engine type, but this appears to be equivalent to the VIN descriptor level (MLIT 2017). Since this study only uses international data if it is as detailed as the trim variant level, the German registration data and Japanese recall data will not be used to determine trim variant distributions.

\subsection{DATA SOURCES}

Electricity consumption rates, all-electric driving range, battery capacity, and curb weight were tracked for all models examined. The fuel efficiency and driving range data came from FuelEconomy.gov, a database of vehicle attributes maintained by the DOE and the EPA (DOE \& EPA 2021). Since this report is focused on PEV attributes, the driving range and fuel efficiency metrics of PHEVs used are from electric power alone, not gasoline. The fuel efficiency metric used was combined electricity consumption and the range used was the combined range from cities and highways. Battery capacity was more difficult to track, since many electric vehicle manufacturers do not release total battery capacity as one of their vehicle metrics and battery capacity statistics may refer to accessible battery capacity as opposed to total battery capacity (Lambert, 2016). This could lead to an underreporting of the total installed battery capacity of vehicles on the road.

Battery capacities were cross-referenced across three websites: Car and Driver magazine (Car and Driver 2021), Electric Vehicle Database (Electric Vehicle Database 2021), EV Specifications (EV Specifications 2021), and Teslawissen.ch (Bolli 2021). If these websites listed conflicting information, the battery capacity listed the most frequently was the one used. Curb weight comes from the Canadian Vehicle Specifications database (CARSP 2021), Car and Driver magazine, EV Specifications, and vehicle specification sheets directly from the OEMs.

Sales data for each model has been gathered as part of a long-standing project tracking electric and hybrid vehicles by Argonne National Laboratory (ANL 2021). Through June 2018, data was collected from the HybridCars.com sales dashboard, and data was collected from the monthly scorecard at InsideEVs.com through 2019. There is currently no freely available source aggregating all PEV sales data, so currently this data is processed from Wards Auto. For all historical sources of sales data, sales are presented at the make and model level, within a given month.

Decoding information for the VIN for each vehicle comes from NHTSA's Product Information Catalog and Vehicle Listing (vPIC), a consolidated platform that presents data collected from manufacturer reported data (NHTSA 2021a). Information about the VINs is submitted to NHTSA for each model year by each OEM, as per VIN reporting requirements of 49 CFR Part 565.7. This data is frequently updated several times as new models are released and additional trims are created; we use the most frequent decoding report for each model year.

In order for a data set to be useful in determining the PEV sales mix, it must contain at least one of three descriptors: VIN, trim variant, or vehicle attributes such as horsepower, weight, or MSRP. Every dataset used in this study contains at least one of these key descriptors. In this analysis, we used registration data from 20 states and the District of Columbia, supplementing this with data from Germany, Japan, the Netherlands, Norway, New Zealand, and the United Kingdom (U.K.). Table 3 displays the contents of each dataset, and this data is graphically 
summarized in Figure 2. The geography marker represents the finest spatial resolution available for the data, which is typically presented by zip code or by county for U.S. data, if at all. Datasets with discrete data present the characteristics of interest for individual, identifiable vehicles, as opposed to aggregated across the whole state or country. Complete data presents all electric vehicles within the jurisdiction, while incomplete data only includes a subset of the electric vehicles, for example because it comes from emissions testing of PHEVs or only in specific counties, or only a sample of specific vehicle makes rather than all PEVs. VINs with the first eight digits are sufficient for this analysis, though some jurisdictions do present the full 17-digit VIN for each registered vehicle. A VIN's tenth digit provides the vehicle model year. When the VIN is absent, the initial registration year can be used to estimate for model year.

TABLE 3 Domestic and International Vehicle Registration Data Sources

\begin{tabular}{|c|c|c|c|c|c|c|c|c|c|}
\hline Location & 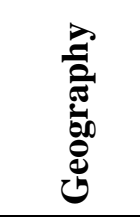 & 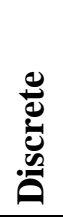 & 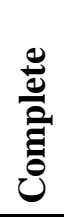 & 苔 & 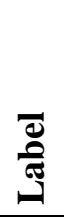 & 葛 & 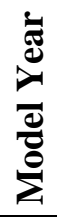 & 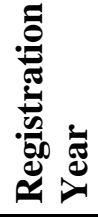 & Last Update \\
\hline California & None & $\checkmark$ & & $\checkmark$ & & & $\checkmark$ & $\checkmark$ & $10 / 31 / 2020$ \\
\hline Colorado & Zip & $\checkmark$ & $\checkmark$ & $\checkmark$ & & & $\checkmark$ & $\checkmark$ & $3 / 1 / 2021$ \\
\hline Connecticut & Zip & $\checkmark$ & $\checkmark$ & $\checkmark$ & & & $\checkmark$ & $\checkmark$ & $1 / 4 / 2018$ \\
\hline District of Columbia & County & $\checkmark$ & $\checkmark$ & $\checkmark$ & & & $\checkmark$ & $\checkmark$ & $1 / 6 / 2020$ \\
\hline Florida & County & & $\checkmark$ & & $\checkmark$ & & & $\checkmark$ & $12 / 31 / 2020$ \\
\hline Massachusetts & Zip & $\checkmark$ & $\checkmark$ & $\checkmark$ & & $\checkmark$ & $\checkmark$ & $\checkmark$ & $11 / 08 / 2019$ \\
\hline Michigan & Zip & $\checkmark$ & $\checkmark$ & $\checkmark$ & & & $\checkmark$ & $\checkmark$ & $8 / 20 / 2019$ \\
\hline Minnesota & Zip & $\checkmark$ & $\checkmark$ & $\checkmark$ & & & $\checkmark$ & $\checkmark$ & $2 / 1 / 2020$ \\
\hline Montana & County & $\checkmark$ & $\checkmark$ & $\checkmark$ & & & $\checkmark$ & $\checkmark$ & $2 / 19 / 2020$ \\
\hline New Jersey & Zip & $\checkmark$ & $\checkmark$ & $\checkmark$ & & & $\checkmark$ & $\checkmark$ & $6 / 30 / 2020$ \\
\hline New Mexico & Zip & $\checkmark$ & & $\checkmark$ & & & $\checkmark$ & $\checkmark$ & $3 / 18 / 2021$ \\
\hline New York & Zip & $\checkmark$ & $\checkmark$ & $\checkmark$ & & $\checkmark$ & $\checkmark$ & $\checkmark$ & $6 / 1 / 2021$ \\
\hline North Dakota & None & $\checkmark$ & & $\checkmark$ & & & $\checkmark$ & & $3 / 19 / 2021$ \\
\hline Ohio & County & $\checkmark$ & & $\checkmark$ & & & $\checkmark$ & $\checkmark$ & $3 / 19 / 2021$ \\
\hline Oregon & Zip & $\checkmark$ & $\checkmark$ & $\checkmark$ & & & $\checkmark$ & $\checkmark$ & $7 / 20 / 2020$ \\
\hline South Dakota & None & $\checkmark$ & & $\checkmark$ & & & $\checkmark$ & $\checkmark$ & $3 / 19 / 2021$ \\
\hline Tennessee & County & $\checkmark$ & $\checkmark$ & $\checkmark$ & & & $\checkmark$ & $\checkmark$ & $12 / 31 / 2020$ \\
\hline Texas & None & $\checkmark$ & & $\checkmark$ & & & $\checkmark$ & $\checkmark$ & $4 / 1 / 2019$ \\
\hline Vermont & Zip & $\checkmark$ & $\checkmark$ & $\checkmark$ & & & $\checkmark$ & $\checkmark$ & $6 / 30 / 2020$ \\
\hline Virginia & County & $\checkmark$ & $\checkmark$ & $\checkmark$ & & & $\checkmark$ & $\checkmark$ & $12 / 31 / 2019$ \\
\hline Washington & Zip & $\checkmark$ & $\checkmark$ & $\checkmark$ & & $\checkmark$ & $\checkmark$ & $\checkmark$ & $3 / 15 / 2021$ \\
\hline Wisconsin & Zip & $\checkmark$ & $\checkmark$ & $\checkmark$ & & & $\checkmark$ & $\checkmark$ & $12 / 31 / 2020$ \\
\hline Germany & & & & & & $\checkmark$ & & $\checkmark$ & $1 / 1 / 2020$ \\
\hline Japan & & & & & & $\checkmark$ & $\checkmark$ & & $1 / 10 / 2019$ \\
\hline The Netherlands & & $\checkmark$ & $\checkmark$ & & $\checkmark$ & $\checkmark$ & & $\checkmark$ & $1 / 22 / 2021$ \\
\hline New Zealand & & $\checkmark$ & $\checkmark$ & $\checkmark$ & $\checkmark$ & & $\checkmark$ & $\checkmark$ & $2 / 8 / 2021$ \\
\hline Norway & & $\checkmark$ & $\checkmark$ & $\checkmark$ & $\checkmark$ & & $\checkmark$ & $\checkmark$ & $1 / 29 / 2021$ \\
\hline United Kingdom & & & $\checkmark$ & & $\checkmark$ & & $\checkmark$ & & $12 / 9 / 2020$ \\
\hline
\end{tabular}




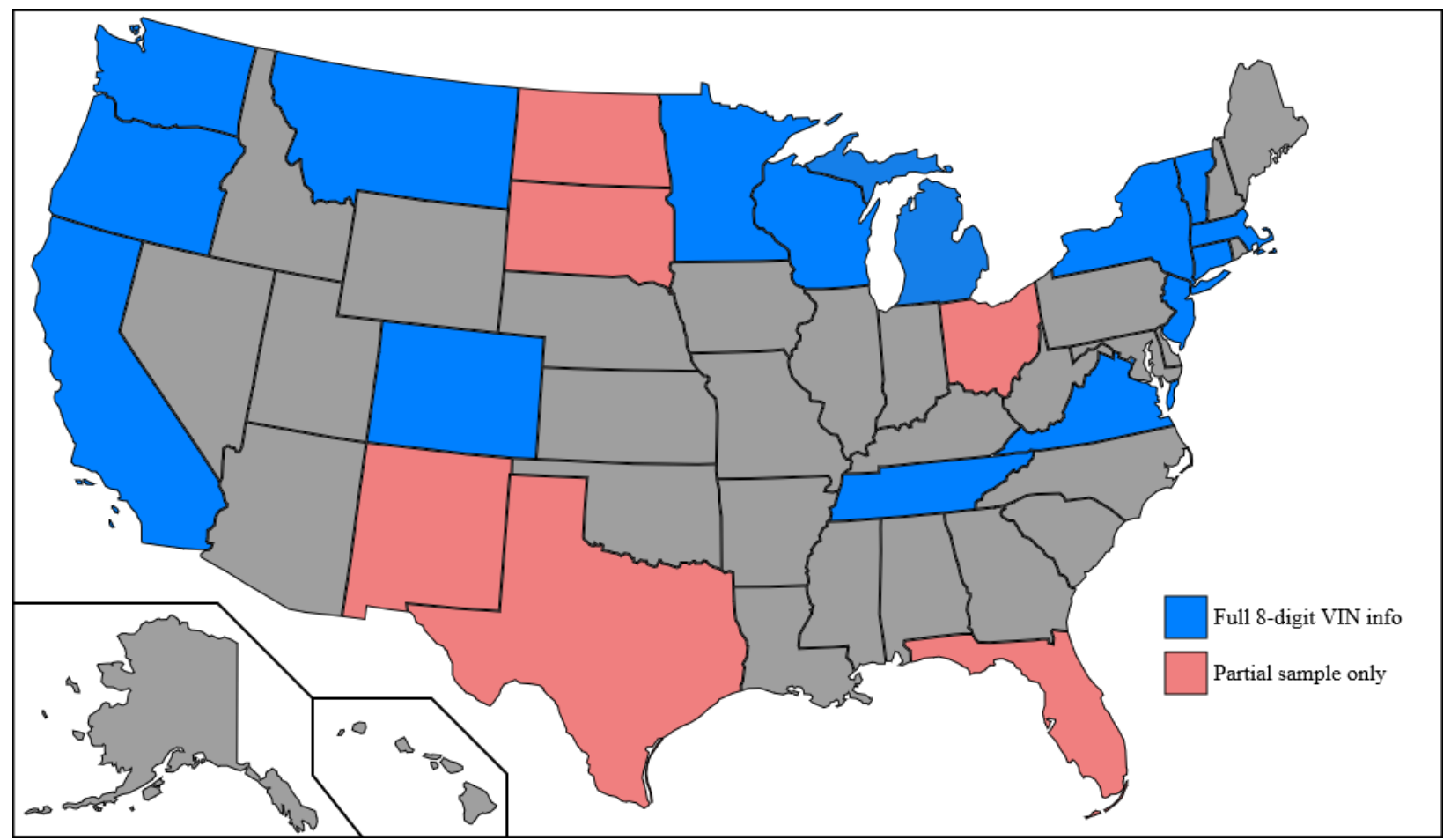

FIGURE 2 States with PEV Registration Data Used in this Analysis

Both domestic and international registration data were collected for this study. New York publishes full data sets for all registered vehicles monthly (NYS DMW 2021). Washington publishes similar data for electric vehicles registered in the state (WA DOL 2021). Data for Massachusetts was supplied by MAPC coming from the Massachusetts Registry of Motor Vehicles (MAPC, private communication, April 2021). Data for Texas came from emissions and safety inspections (Tom Wenzel, private communication, February 2021). Data for California came from vehicles registered in the Clean Vehicle Rebate Project (CVRP), supplied by the California Air Resources Board (CARB, private communication, June 2021). Washington DC has published the VINs of vehicles related to required emissions testing (Open Data DC 2021). Bernalillo County, New Mexico publishes similar data, though BEV and new PHEVs are not required to test, and so only a few models from Table 2 are included in the data (City of Albuquerque 2021). For North Dakota, Ohio, and South Dakota, the status of vehicle titles can be checked online (ND DOT 2021; OH BMV 2021; SD Cars 2021). Valid registrations were found by comparing a list of all possible VINs against these online databases. However, it was not feasible to extract registration data for models with many different VIN possibilities, nor was it greatly beneficial to extract data for models with few registrations in the state, and so we only gathered information from these states for a few models, namely the Nissan Leaf, Model S, Model 3, and BMW i3.

The other states listed in Table 3 and Figure 2 were retrieved from Atlas EV Hub, an online platform that contains a wealth of electric vehicle data including VINs (Atlas 2021): Colorado, Connecticut, Montana, Michigan, Minnesota, New Jersey, Oregon, Tennessee, Vermont, Virginia, and Wisconsin. Not every state available on Atlas EV Hub was used since some datasets did not contain requisite vehicle identifiers such as VIN, trim variant, or MSRP 
data. Most notably, Florida also does not share sufficiently detailed information on the Atlas EV hub for this analysis, except for determining the share of BMW i3 REx. For the state of California, the Atlas EV Hub data does not have full VIN information, while data from the CVRP does include sufficient VIN information for a variant-focused analysis. However, the data from the California CVRP may skew toward vehicles purchased by lower-income households and not be representative of all electric vehicles registered in the state. The Center for Sustainable Energy examined participation in the CVRP, finding high participation, but variances by county, model, and over time were observed (Williams et al. 2015). For the present analysis, we compared the prices of vehicles in the data set from the CVRP with all vehicles registered from the Atlas EV Hub, using the MSRP of the base trim for each make and model. We find that the average MSRP is $11 \%$ lower for vehicles that we include in our analysis (i.e., from the CVRP), relative to the full set of electric vehicle registrations in the state. This may also be indicative of consumer choice of lower-cost trim variants, and thus we note this caveat in assessing the trim mix of each make and model.

Although PEV sales information is not available at the level of necessary detail for every state, the mix of states for which data is available spans coast to coast, including both relatively urban and rural states. Including California, which alone accounts for nearly half of the domestic electric vehicle market (Boudette 2019; NREL 2020; Alliance for Automotive Innovation 2021), we have registration data for seven of the ten largest markets for electric vehicles in the United States. In particular, we include registration information from eight of the other eleven states which follow California's Zero-Emission Vehicle (ZEV) requirements under section 177 of the Clean Air Act (CARB 2019; Berman 2020). The Southeast and Southwest are underrepresented by the states in this data set, but we make the assumption that the states included for analysis, nonetheless, provide a representative picture of PEV sales nationwide.

International data was only used to estimate the trim variant mix of Tesla models, since the VIN information provided by the domestic data was detailed enough to estimate the sales mix of the other vehicle brands. Tesla registration data was taken from the Netherlands, New Zealand, Norway, and the United Kingdom (GOV.UK 2020; Edvardsen 2021; RDW 2021; NZTA 2021). The U.K. and the Netherlands data contains trim variant information, and Norway and the New Zealand data contains both VIN and trim variant data. Data from Germany and Japan gives aggregated vehicle characteristics, but not trim variant information (KBA 2020; MLIT 2019).

Vehicle sales listings were considered as a potential source of VINs for this analysis. The website Tesla-info.com has compiled 77,000 historical listings for used Teslas in the United States, each of which by definition was manufactured and sold (Tesla Info 2021). Similarly, VinAudit has a VIN directory which includes active and historical sales listings for most lightduty vehicles (VinAudit 2021). While this type of data is potentially useful for our analysis, it was not included for three main analytical reasons. First, we do not know how representative used vehicle sales listings are for the entire set of registered vehicles; it is possible that vehicles with certain characteristics are more likely to be sold more frequently. Relatedly, we do not know how complete the sales database is, and it may also bias toward specific types of vehicles. Finally, VINs from sales listings were not included because they may be duplicative with the other registration data by state, leading to double-counting. While this is also a concern for the state-level data, we expect the interstate transfer of vehicles to be a minor error in our variant estimation. 


\subsection{METHODOLOGY}

\subsubsection{Quantification of Sales Shares by Model}

For all makes and models listed in Table 2 through MY2020, the number of vehicles having each VIN descriptor was aggregated from each source of domestic VIN (or VINequivalent) data. While VIN information for many MY2021 vehicles exists, there is not yet a large enough sample of these vehicles to be considered representative. This set of registration data was compared with initial sales to see how representative our sample is. Table 4 shows the estimated fraction of initial vehicle sales included in our analysis. As noted above, we do not explicitly account for differences in model year and sales year, but this only has a very minor impact on the calculation of confidence intervals. We also present the range of the most relevant characteristics for each vehicle across all variants, namely the all-electric driving range, electricity consumption rate, battery capacity, and curb weight. Certain models with no discernable difference in these four characteristics are not shown in Table 4, such as the Chevrolet Volt, the Volvo XC60, or the MY2011 Smart Fortwo.

For most of the vehicles listed in Table 4, the VIN descriptor is sufficient for each of the EPA-distinguished variants. The $2017 \mathrm{BMW}$ i3 BEV exists with both a $22 \mathrm{kWh}$ and $33 \mathrm{kWh}$ battery, but there is no clear distinguishing information to compare sales of the two. Using active sales listings from Cars.com and CarGurus.com, we find 5 listings for the 60 Ah variant, and 51 listings for the 94 Ah variant (Cars.com 2021; CarGurus.com 2021). As described in the previous section, sales data is not necessarily representative of the full market, and without the VIN to rely on, there could also be issues with mislabeling the vehicle characteristics. Nonetheless, we will use this ratio to determine the mix of vehicles for the 2017 BMW i3 BEV.

The BMW i3 had two trim variants from 2014 to 2016, and four trim variants from 2018 to 2020. Unlike other models, the BEV i3 and the PHEV i3 can generally be distinguished by model name in registration data. For consistency in analysis, we use the VIN descriptor to determine the mix, rather than the nominal label, which also enables comparative analysis of the i3 and the i3s.

The EPA database notes differences in the fuel economy of the different trim levels for the 2019 Nissan Leaf, however, this is not noted in the VIN until the 2020 model year. Therefore, we use the VIN analysis to find the split between the $40 \mathrm{kWh}$ and $62 \mathrm{kWh}$ batteries, and then assume the same ratio for the 62-kWh base and premium trims for 2019. The MY2020 Porsche Taycan Turbo and Turbo S models are distinct in the FuelEconomy.gov database, but not by VIN. We assume that these two vehicles have the same market share.

The Tesla vehicles are more complicated than these particular examples and will be given additional attention. For MY2012 and MY2013, the information from the VIN is more detailed than that in the FuelEconomy.gov database. In these model years, digit 7 of the VIN corresponds to the onboard charger, ranging from $10 \mathrm{~kW}$ capability to $20 \mathrm{~kW}$ plus direct-current fast charging (DCFC). Digit 8 corresponds to both the drive unit and the battery, and so designates both battery capacity and the performance level. For both years, the FuelEconomy.gov database does not distinguish the charger, and there is no record for the performance variant of the nominally$85 \mathrm{kWh}$ Model S, but each of these can be distinguished using the VIN. 
TABLE 4 Vehicle Makes and Models Considered in this Analysis

\begin{tabular}{|c|c|c|c|c|c|c|c|c|c|}
\hline Model & $\begin{array}{c}\text { Vehicle count } \\
\text { in dataset }\end{array}$ & $\begin{array}{c}\text { Total } \\
\text { estimated sales }\end{array}$ & $\begin{array}{l}\text { Estimated \% } \\
\text { of U.S. sales }\end{array}$ & $\begin{array}{c}\text { Number of } \\
\text { EPA-listed } \\
\text { variants }\end{array}$ & $\begin{array}{c}\text { VIN } \\
\text { sufficient } \\
?\end{array}$ & $\begin{array}{c}\text { All-electric } \\
\text { range } \\
\text { (miles) }\end{array}$ & $\begin{array}{c}\text { Electricity } \\
\text { consumption } \\
\text { (Wh/mile) }\end{array}$ & $\begin{array}{c}\text { Battery } \\
\text { capacity } \\
(\mathbf{k W h})\end{array}$ & $\begin{array}{l}\text { Curb weight } \\
\text { (lb) }\end{array}$ \\
\hline \multicolumn{10}{|l|}{2012} \\
\hline Tesla Model S & 2229 & 2400 & $93 \%$ & 1 & $\checkmark$ & 265 & 380 & 81.5 & 4650 \\
\hline \multicolumn{10}{|l|}{2013} \\
\hline Smart Fortwo & 591 & 900 & $64 \%$ & 2 & $\checkmark$ & 68 & 320 & 17.6 & 2110 \\
\hline Tesla Model S & 14220 & 19400 & $73 \%$ & 3 & $\checkmark$ & $139-265$ & $350-380$ & $61-81.5$ & $4410-4650$ \\
\hline \multicolumn{10}{|l|}{2014} \\
\hline BMW i3 & 4488 & 6100 & $74 \%$ & 2 & $\checkmark$ & $72-81$ & $270-290$ & 21.6 & $2860-3130$ \\
\hline Smart Fortwo & 1444 & 2600 & $56 \%$ & 2 & $\checkmark$ & 68 & 320 & 17.6 & $2090-2140$ \\
\hline Tesla Model S & 14150 & 16800 & $84 \%$ & 3 & $\checkmark$ & $208-265$ & $350-380$ & $61-81.5$ & $4410-4940$ \\
\hline \multicolumn{10}{|l|}{2015} \\
\hline BMW i3 & 5173 & 11000 & $47 \%$ & 2 & $\checkmark$ & $72-81$ & $270-290$ & 21.6 & $2860-3130$ \\
\hline Smart Fortwo & 1060 & 1400 & $74 \%$ & 2 & $\checkmark$ & 68 & 315 & 17.6 & $2090-2140$ \\
\hline Tesla Model S & 18354 & 26200 & $70 \%$ & 8 & & $210-270$ & $330-380$ & $61-85.6$ & $4410-4960$ \\
\hline \multicolumn{10}{|l|}{2016} \\
\hline Audi A3 e-tron & 1712 & 4300 & $40 \%$ & 2 & $\checkmark$ & $16-17$ & $380-400$ & 8.8 & 3620 \\
\hline BMW i3 & 2017 & 7600 & $26 \%$ & 2 & $\checkmark$ & $72-81$ & $270-290$ & 21.6 & $2860-3130$ \\
\hline Cadillac ELR & 191 & 500 & $36 \%$ & 2 & $\checkmark$ & $36-40$ & $390-430$ & 16.5 & $2090-2140$ \\
\hline Nissan Leaf & 9011 & 14000 & $64 \%$ & 2 & & $84-107$ & $296-300$ & $24-30$ & $3310-3340$ \\
\hline Tesla Model S & 16624 & 30200 & $55 \%$ & 13 & & $210-315$ & $320-380$ & $71.2-102.4$ & $4470-4940$ \\
\hline Tesla Model X & 9760 & 19600 & $50 \%$ & 5 & & $200-289$ & $360-390$ & $75-102.4$ & $5190-5480$ \\
\hline \multicolumn{10}{|l|}{2017} \\
\hline BMW i3 & 4342 & 6300 & $69 \%$ & 3 & & $81-114$ & $270-300$ & $21.6-33.2$ & $2870-3230$ \\
\hline Smart Fortwo & 383 & 500 & $70 \%$ & 2 & $\checkmark$ & $57-58$ & $310-330$ & 17.6 & $2360-2380$ \\
\hline Tesla Model S & 12415 & 26500 & $47 \%$ & 8 & & $210-335$ & $320-350$ & $75-102.4$ & $4410-4940$ \\
\hline Tesla Model X & 7579 & 21700 & $35 \%$ & 6 & & $200-295$ & $360-390$ & $75-102.4$ & $5190-5530$ \\
\hline
\end{tabular}


TABLE 4 (Cont.)

\begin{tabular}{|c|c|c|c|c|c|c|c|c|c|}
\hline Model & $\begin{array}{c}\text { Vehicle count } \\
\text { in dataset }\end{array}$ & $\begin{array}{c}\text { Total } \\
\text { estimated sales }\end{array}$ & $\begin{array}{l}\text { Estimated \% } \\
\text { of U.S. sales }\end{array}$ & $\begin{array}{c}\text { Number of } \\
\text { EPA-listed } \\
\text { variants } \\
\end{array}$ & \begin{tabular}{|c|} 
VIN \\
sufficient \\
$?$ \\
\end{tabular} & $\begin{array}{c}\text { All-electric } \\
\text { range } \\
\text { (miles) }\end{array}$ & $\begin{array}{c}\text { Electricity } \\
\text { consumption } \\
(\mathrm{Wh} / \mathrm{mile}) \\
\end{array}$ & $\begin{array}{c}\text { Battery } \\
\text { capacity } \\
(\mathbf{k W h}) \\
\end{array}$ & $\begin{array}{c}\text { Curb weight } \\
\text { (lb) }\end{array}$ \\
\hline \multicolumn{10}{|l|}{2018} \\
\hline BMW i3 & 2595 & 6100 & $42 \%$ & 4 & $\checkmark$ & $97-114$ & $286-310$ & 33.2 & $2960-3280$ \\
\hline BMW 530e & 3502 & 9700 & $36 \%$ & 2 & $\checkmark$ & $15-16$ & 490 & 9.2 & $4270-4390$ \\
\hline Porsche Panamera & 445 & 1400 & $33 \%$ & 6 & $\checkmark$ & $14-16$ & $590-670$ & 14.1 & $4790-5310$ \\
\hline Smart Fortwo & 775 & 1200 & $65 \%$ & 2 & $\checkmark$ & $57-58$ & $310-330$ & 17.6 & $2360-2380$ \\
\hline Tesla Model 3 & 72678 & 115100 & $63 \%$ & 4 & $\checkmark$ & $260-310$ & $259-289$ & $65-79.5$ & $3690-4100$ \\
\hline Tesla Model S & 8982 & 25100 & $36 \%$ & 4 & $\checkmark$ & $259-335$ & $326-346$ & $75-102.4$ & $4410-4940$ \\
\hline Tesla Model X & 8678 & 20900 & $41 \%$ & 3 & $\checkmark$ & $238-295$ & $362-395$ & $75-102.4$ & $5310-5530$ \\
\hline \multicolumn{10}{|l|}{2019} \\
\hline BMW i3 & 1978 & 4900 & $41 \%$ & 4 & $\checkmark$ & $126-153$ & $298-320$ & 42.2 & $2970-3310$ \\
\hline BMW i8 & 454 & 1100 & $41 \%$ & 2 & $\checkmark$ & 18 & 490 & 11.7 & $3500-3670$ \\
\hline BMW 530e & 2500 & 6300 & $40 \%$ & 2 & $\checkmark$ & $15-16$ & 460 & 9.2 & $4270-4390$ \\
\hline Nissan Leaf & 8432 & 12400 & $68 \%$ & 2 & $\checkmark$ & $150-226$ & $302-323$ & $40-62$ & $3430-3830$ \\
\hline Porsche Panamera & 103 & 1100 & $10 \%$ & 6 & & 16 & $650-660$ & 14.1 & $4780-5310$ \\
\hline Smart Fortwo & 224 & 700 & $33 \%$ & 2 & $\checkmark$ & $57-58$ & $310-330$ & 17.6 & $2360-2380$ \\
\hline Tesla Model 3 & 44331 & 142800 & $31 \%$ & 6 & & $220-310$ & $254-289$ & $53.6-79.5$ & $3550-4100$ \\
\hline Tesla Model S & 2484 & 16200 & $15 \%$ & 7 & & $249-370$ & $303-347$ & $75-102.4$ & $4770-4940$ \\
\hline Tesla Model X & 3363 & 18600 & $18 \%$ & 5 & & $238-325$ & $350-428$ & $75-102.4$ & $5310-5530$ \\
\hline \multicolumn{10}{|l|}{2020} \\
\hline BMW i3 & 206 & 1500 & $14 \%$ & 4 & $\checkmark$ & $126-153$ & $298-320$ & 42.2 & $2970-3310$ \\
\hline BMW i8 & 13 & 200 & $7 \%$ & 2 & $\checkmark$ & 18 & 490 & 11.7 & $3500-3670$ \\
\hline BMW 530e & 203 & 2700 & $8 \%$ & 2 & $\checkmark$ & $19-21$ & 470 & 12 & $4270-4390$ \\
\hline Nissan Leaf & 2170 & 9600 & $23 \%$ & 6 & $\checkmark$ & $149-226$ & $304-323$ & $40-62$ & $3540-3950$ \\
\hline Porsche Cayenne & 127 & 2000 & $6 \%$ & 4 & $\checkmark$ & $12-14$ & $710-760$ & 14.1 & $5160-5680$ \\
\hline Porsche Panamera & 46 & 600 & $8 \%$ & 6 & $\checkmark$ & 16 & $650-660$ & 14.1 & $4760-5390$ \\
\hline Porsche Taycan & 414 & 4400 & $9 \%$ & 2 & & $192-203$ & $487-499$ & 93.4 & $4950-5130$ \\
\hline Tesla Model 3 & 30482 & 91200 & $33 \%$ & 8 & & $220-330$ & $240-299$ & $53.6-80.5$ & $3550-4100$ \\
\hline Tesla Model S & 2043 & 14400 & $14 \%$ & 5 & & $287-402$ & $289-347$ & $75-102.4$ & $4770-4940$ \\
\hline Tesla Model X & 3161 & 18000 & $18 \%$ & 5 & & $258-351$ & $322-428$ & $75-102.4$ & $5310-5530$ \\
\hline Tesla Model Y & 11290 & 61800 & $18 \%$ & 3 & & $291-316$ & $279-304$ & 74 & 4420 \\
\hline
\end{tabular}


For Tesla models starting in MY2014, we use international registration data to determine the trim variant frequency. The EPA and DOE's Fuel Economy database (DOE and EPA 2021) lists 98 distinct Tesla trim variants through 2020, differentiated by battery capacity, number of motors, and performance level. These trims will be the ones used in this report. While there is slight variation in the trim names between countries (the Netherlands, for instance, denotes performance vehicles in a parameter different from the variant), it is relatively easy to match trim variant names across datasets.

Since the domestic registration data provides the most accurate description of the U.S. electric vehicle market, it was used to determine the relative frequency of each VIN descriptor for a given model and model year. International data was used to find the distribution of Tesla trims within a given VIN descriptor. For all vehicle models examined, domestic data was weighted solely by the size of individual samples in determining distribution.

Using international data, the distribution of trim variants for each VIN descriptor was determined. Label trim variants were identified in the data from the Netherlands, New Zealand, Norway and the United Kingdom. These data sets are complete, listing all vehicles registered in each country. Each trim variant maps onto a specific VIN descriptor, and so we can quantify the distribution of trim variants within a given VIN descriptor. Norway and New Zealand additionally contain VIN information, which allows for cross-validation of the trim variants present within a given VIN descriptor. For Germany, the TSN appears to be linked directly to the VIN, rather than the trim variants, and thus analysis of aggregated registration numbers by TSN does not give additional information about the variant mix of each VIN descriptor. Likewise, Japanese recall data specifies type, but not at a sufficiently disaggregated level for variant analysis. In our baseline analysis, we estimate the mix of trim variants within each VIN descriptor for the domestic market using the relative shares from the international data. In determining this mix, we weight each country by the number of Tesla models sold in a given year, as a country with more sales is likely to be more representative of the total market.

We acknowledge that using international data to represent the domestic market has shortcomings. The challenges with using international Tesla data are important to note but not impossible to overcome. Notable international Tesla sales began later in Europe than in the United States, with notable sales in the Netherlands and Norway beginning in 2013, and in the United Kingdom beginning in 2014. Relatedly, the Tesla sales mix skews more expensive when the OEM enters a new market to maximize profit from pent-up demand (Guess 2018). Additionally, New Zealand and the U.K. have right-hand drive models, which may have been released at a different trim distribution than the left-hand drive models sold in the U.S. (Tesla 2014). Fortunately, by considering only individual VIN descriptors, as opposed to the entire set of Tesla sales in a given year, we can generally account for these differences in the overall sales mix. The Model 3, Tesla's more affordable vehicle intended for mass market, did not begin robust sales in Europe until 2019, two years after the release of Model 3 in the United States, and production has yet to begin in Europe for the Model Y. Therefore analysis using European data sources excludes the MY2018 Model 3 and the MY2020 Model Y.

To confirm validity of this approach, we compared to the trim variant distribution as derived from international registration data with curb weight data from New York state vehicle registrations (NYS DMW 2021). The curb weight data used by New York rarely agrees exactly with the data presented in this report (e.g. Table 4 or in Appendix A). Therefore, it is not feasible 
to define trim variants simply by matching the corresponding weight. However, it is possible to examine the distribution of curb weights in the New York registration database for each VIN descriptor to estimate the relative shares of each trim variant. In general, there is fair agreement between the New York data and international data. The New York data exhibits a tendency to have somewhat larger batteries (and hence longer all-electric driving ranges) on average for the Model S and Model 3 and slightly smaller batteries for the Model X than the international data.

The 2020 Model Y only has three variants, a long range AWD, a performance AWD, and a performance AWD with 22-inch wheels. Performance vehicles can be distinguished via VIN analysis and trim variant distribution will be split evenly between the two performance models. Methods to quantify how robust the results are to uncertainty will be discussed further in the Results section of this report. The 2018 Model 3 trim variants are more complicated to discern. The dual motor models have the same trim variants as the 2019 dual motor models, so the trim variant relative frequencies from 2019 were used for the 2018 models as well. The single motor models were harder to estimate. There were two single motor Model 3 variants: Mid-Range and Long Range. The Mid-Range was only sold between October 2018 and March 2019 (Lambert 2019a). Using this limited sales window and average vehicle pricing data gleaned from Tesla quarterly investor reports the 2018 Model 3 trim distribution was estimated (Tesla 2018; Tesla 2019). Full results can be found in Appendix A.

The MY2019-21 Tesla Model S and MY2020-21 Tesla Model Y each have sales offerings with multiple wheel sizes. The smaller wheels grant better fuel economy and allelectric range, but are sometimes viewed to have lower performance than the larger wheels (Gurskiy 2019). This is also true for the Karma GS-6 and Karma Revero, which are in the FuelEconomy.gov database with multiple wheel sizes, but not clearly distinguishable by VIN, and not considered in this analysis. Within this analysis, we assume all wheel sizes to have equal sales shares within each trim variant. There are reasons to believe that the smaller wheel sizes should have larger shares - there is typically a price premium for the larger wheels and they reduce all-electric range - but as these vehicles are in the luxury segment, consumers are likely to be less price sensitive and may not weight different vehicle attributes the same as in the mass market (Greene and Liu 2012; Brooker et al. 2015).

\subsubsection{Uncertainty Analysis}

In determining the overall mix of each vehicle variant, we need to consider both systematic and sampling errors. For each model, we have VIN-level information for between $4 \%$ and $93 \%$ of the total sales. Due to lack of information across the entire domestic market, we assume that vehicles sold in states in our data set are nationally representative. It is possible that we have a data set that is systematically skewed away from the national average because of the states we examined. We examined the variance in VIN distributions by state, to have an estimation of variance in states not sampled. In general, we find that states tend to have similar variant mixes. Results for specific vehicles are described in greater detail in Section 3.2.

From a socio-economic perspective, of the sixteen states for which complete PEV registration data was available, five were at or below the national average of vehicle miles traveled (VMT) and six had median household income below the national median income (Zhou et al. 2020). While more of the states had average VMT and median household income higher than the national statistics, the existence of states both above and below the national 
average VMT and median household income supports our claim that this data is somewhat representative of the whole country.

In this analysis, we know how many vehicles of each model were sold in a given year, and we are counting distinct registrations to determine the overall mix of these variants. This is similar to determining margin of error for polls and surveys. However, our sampling for each vehicle is a relatively large proportion of the total number of vehicles sold, and we are sampling without replacement, so we must perform a correction to account for a finite population. To quantify our expected shares of each variant in the broader population and determine confidence intervals, we use the hypergeometric distribution. We assume ab initio that any combination of vehicle trims is potentially possible, and find the probability of each initial possibility of yielding the measured sales mix. Dyer and Pierce (1993) note that using a Polya (beta-binomial) prior distribution increases the conservativeness of the estimate, but also note that they expect close agreement in the posterior distribution regardless of prior distribution. By comparing these probabilities, we quantify the expected value for each trim mix. This also has the effect of shifting the expected value slightly from the observed value; for example, a variant with no observations in the sampled data set may still exist in the larger data set, and has an expected value greater than zero (albeit small).

For the Tesla vehicles with trims not uniquely determined by VIN descriptor, we consider a further sensitivity analysis with different mixes of the trim variants. Beyond the baseline scenario, which uses the international sales-weighted mix, we consider four alternative scenarios: 1) a scenario in which all trims are selected to maximize all-electric range, and 2) a scenario in which all trims are selected to minimize all-electric range, 3) a scenario in which the weighting is proportional to the number of total vehicles registered in the country, rather than the number of Tesla vehicles, and 4) a scenario in which all trims are evenly split. 


\section{RESULTS}

Table 5 displays the weighted-average battery capacity, average vehicle range, and average fuel efficiency for electric vehicle models tested. The distributions of each of the trim variants for each model can be found listed by model in Appendix A, along with a complete list of the metrics for each trim variant.

Table 5 includes fourteen different models, spanning both BEVs and PHEVs, from MY2011 to MY2020. The Audi A3 e-tron, BMW i8, BMW 530e, Cadillac ELR, Porsche Cayenne, and Porsche Panamera are PHEV models. The BMW i3 is available as a BEV or as a range-extended PHEV. The Nissan Leaf, Porsche Taycan, Smart Fortwo, Tesla Model 3, Tesla Model S, Tesla Model X, and Tesla Model Y are BEV. PHEVs typically have a lower electric driving range due to their smaller battery size and the expectation that gasoline can supplement electricity to fuel longer journeys, and they generally have higher fuel consumption rates (Gohlke and Zhou 2021). For most of the specific vehicle models, all-electric range has increased over time, as has battery capacity and curb weight. Section 3.1 will explore the top selling models in more detail: BMW i3, Nissan Leaf, and the four Tesla models. Section 3.2 considers regional variations in the trim mix, highlighting all-wheel drive drivetrains, and preferences in powertrain options. 
TABLE 5 Sales-weighted Average Vehicle Characteristics for Each PEV Make and Model

\begin{tabular}{|c|c|c|c|c|}
\hline Model & $\begin{array}{c}\text { All-Electric } \\
\text { Range (mile) }\end{array}$ & $\begin{array}{l}\text { Electricity consumption } \\
\text { (Wh/mile) }\end{array}$ & $\begin{array}{c}\text { Battery capacity } \\
(\mathrm{kWh})\end{array}$ & $\begin{array}{l}\text { Curb weight } \\
\text { (lb) }\end{array}$ \\
\hline MY16 Audi A3 e-tron & 16.1 & 398 & 8.8 & 3620 \\
\hline MY14 BMW i3 & 75.0 & 283 & 21.6 & 3040 \\
\hline MY15 BMW i3 & 74.1 & 285 & 21.6 & 3070 \\
\hline MY16 BMW i3 & 73.7 & 286 & 21.6 & 3080 \\
\hline MY17 BMW i3 & 100.5 & 297 & 32.9 & 3160 \\
\hline MY18 BMW i3 & 101.9 & 304 & 33.2 & 3160 \\
\hline MY19 BMW i3 & 135.4 & 312 & 42.2 & 3180 \\
\hline MY20 BMW i3 & 138.2 & 310 & 42.2 & 3160 \\
\hline MY19 BMW i8 & 18.0 & 490 & 11.7 & 3630 \\
\hline MY20 BMW i8 & 18.0 & 490 & 11.7 & 3580 \\
\hline MY18 BMW 530e & 15.5 & 476 & 9.2 & 4330 \\
\hline MY19 BMW 530e & 15.5 & 474 & 9.2 & 4320 \\
\hline MY20 BMW 530e & 19.6 & 504 & 12.0 & 4350 \\
\hline MY16 Cadillac ELR & 38.8 & 402 & 17.1 & 4070 \\
\hline MY16 Nissan Leaf & 98.5 & 299 & 27.8 & 3290 \\
\hline MY19 Nissan Leaf & 175.3 & 309 & 48.3 & 3580 \\
\hline MY20 Nissan Leaf & 185.8 & 313 & 51.9 & 3750 \\
\hline MY20 Porsche Cayenne & 13.8 & 716 & 14.1 & 5210 \\
\hline MY18 Porsche Panamera & 15.5 & 610 & 14.1 & 4880 \\
\hline MY19 Porsche Panamera & 14.0 & 651 & 14.1 & 4840 \\
\hline MY20 Porsche Panamera & 14.0 & 651 & 14.1 & 4840 \\
\hline MY20 Porsche Taycan & 199.5 & 491 & 93.4 & 5050 \\
\hline MY13 Smart Fortwo & 68.0 & 320 & 17.6 & 2110 \\
\hline MY14 Smart Fortwo & 68.0 & 320 & 17.6 & 2100 \\
\hline MY15 Smart Fortwo & 68.0 & 315 & 17.6 & 2100 \\
\hline MY17 Smart Fortwo & 57.9 & 313 & 17.6 & 2370 \\
\hline MY18 Smart Fortwo & 57.9 & 313 & 17.6 & 2370 \\
\hline MY19 Smart Fortwo & 57.9 & 311 & 17.6 & 2370 \\
\hline MY18 Tesla Model 3 & 305.7 & 274 & 78.2 & 3930 \\
\hline MY19 Tesla Model 3 & 265.9 & 271 & 66.1 & 3800 \\
\hline MY20 Tesla Model 3 & 283.6 & 265 & 68.1 & 3830 \\
\hline MY12 Tesla Model S & 265.0 & 380 & 81.5 & 4650 \\
\hline MY13 Tesla Model S & 247.0 & 372 & 76.1 & 4580 \\
\hline MY14 Tesla Model S & 254.0 & 376 & 78.5 & 4650 \\
\hline MY15 Tesla Model S & 258.1 & 348 & 79.0 & 4480 \\
\hline MY16 Tesla Model S & 266.3 & 341 & 80.2 & 4750 \\
\hline MY17 Tesla Model S & 273.0 & 332 & 81.7 & 4740 \\
\hline MY18 Tesla Model S & 282.4 & 329 & 84.1 & 4810 \\
\hline MY19 Tesla Model S & 322.6 & 324 & 94.9 & 4860 \\
\hline MY20 Tesla Model S & 371.9 & 306 & 102.4 & 4890 \\
\hline MY16 Tesla Model X & 253.4 & 372 & 84.9 & 5290 \\
\hline MY17 Tesla Model X & 263.4 & 373 & 88.0 & 5300 \\
\hline MY18 Tesla Model X & 272.5 & 378 & 91.8 & 5390 \\
\hline MY19 Tesla Model X & 294.2 & 374 & 97.8 & 5420 \\
\hline MY20 Tesla Model X & 328.7 & 350 & 102.4 & 5440 \\
\hline MY20 Tesla Model Y & 313.1 & 281 & 74.0 & 4420 \\
\hline
\end{tabular}




\subsection{VEHICLE-SPECIFIC RESULTS}

\subsubsection{BMW}

The BMW i3 is offered as both an all-electric BEV and a range-extended PHEV. The share of BEV peaked around 33\% in its initial year (MY2014), before shifting more predominantly to the PHEV in 2016. This analysis finds that 74\% of MY2014 to MY2016 vehicles were PHEV. This aligns closely with data from NHTSA, where approximately $76 \%$ of BMW i3 sold through January 2017 were PHEV (Cole 2017), as per the comparison of recalled PHEV with total sales data. MY2016 was the final year with the $22 \mathrm{kWh}$ battery; since 2016, the share of BEV has increased in each year, alongside the all-electric range. The average curb weight of the i3 increased from $3040 \mathrm{lb}$ in MY2014 to $3180 \mathrm{lb}$ in MY2019, before dropping to $3160 \mathrm{lb}$ in MY2020. The curb weight is directly linked to the sales composition for the i3. In each year, the PHEV is approximately $300 \mathrm{lb}$ heavier than the corresponding BEV due to the additional weight of the combustion powertrain. Additionally, the battery weight has grown, with the MY2020 i3 BEV being over 100 lb heavier than the original MY2014 model.

\section{PHEV/BEV Share for BMW i3}

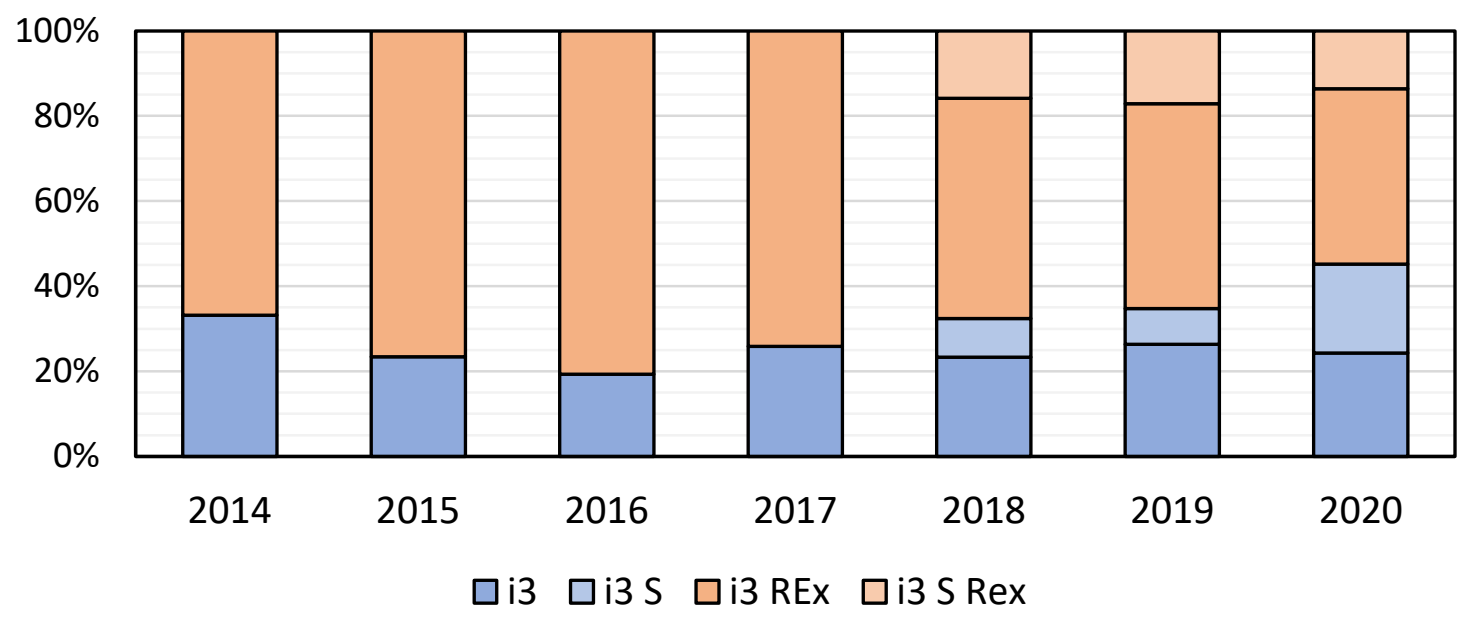

\section{FIGURE 3 Share of PHEV and BEV for BMW i3}

While the vehicle size has increased, the electrical efficiency of the vehicle has declined somewhat. The sales-weighted electricity consumption increased from 283 to $310 \mathrm{Wh} / \mathrm{mi}$ from 2014 to 2020 . For each of the four individual trim variants, the energy consumption rate has increased, likely due to the increased mass of the vehicle. 


\subsubsection{Nissan}

Because the Nissan Leaf was the first prominent BEV produced in the U.S. and has experienced substantial changes in battery size since its release, we discuss its yearly distribution by battery size in more depth.

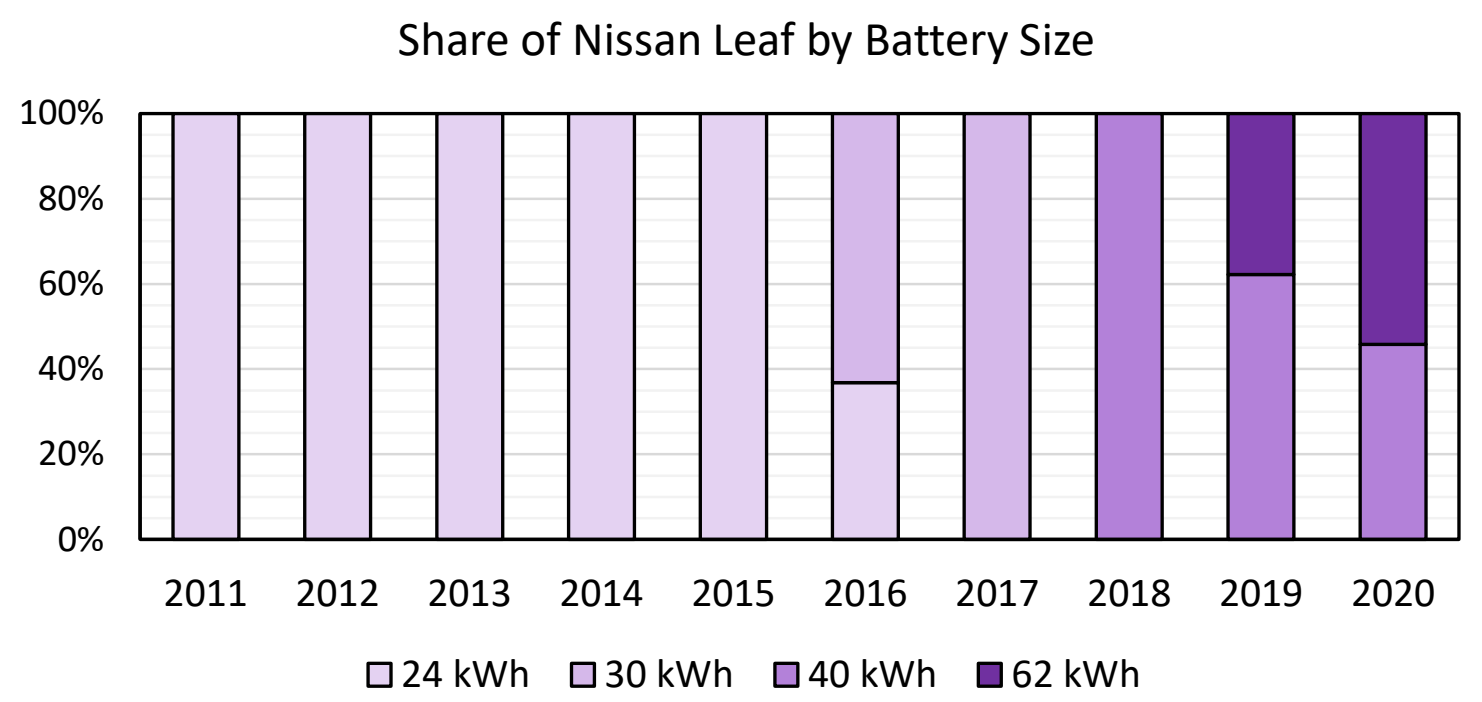

FIGURE 4 Yearly Distribution of Nissan Leaf by Battery Size

Figure 4 displays the yearly distribution of battery size within Nissan Leaf vehicles. The Leaf has increased its average battery size annually since 2015. 2016 was the transition between the $24 \mathrm{kWh}$ battery and the $30 \mathrm{kWh}$ battery; MY2015 was all $24 \mathrm{kWh}$ batteries, and MY2017 had only $30 \mathrm{kWh}$ batteries. However, 2019 and 2020 sales both have a mix of $62 \mathrm{kWh}$ and $40 \mathrm{kWh}$ batteries. This continued mix of battery sizes shows that consumers are taking advantage of the choice between a lower capacity and higher capacity battery.

Like the BMW i3, efficiency has decreased as weight and battery capacity have grown. The 2011 Nissan Leaf started at $340 \mathrm{Wh} / \mathrm{mi}$, which was improved to $290 \mathrm{Wh} / \mathrm{mi}$ by 2013, before gradually increasing to a sales-weighted average of $313 \mathrm{Wh} / \mathrm{mi}$ in 2020 . Likewise, the vehicle mass changed from a curb weight of $3370 \mathrm{lb}$ in 2011 down to $3260 \mathrm{lb}$ in 2013 and up to an average of $3750 \mathrm{lb}$ in 2020 .

\subsubsection{Tesla}

Because Tesla vehicles have both the highest sales and the largest batteries, their trim distributions were examined by battery size, performance, and all-wheel drive (AWD) capabilities in the following figures. Figures displaying the yearly distribution of Tesla models by trim alone can be found in Appendix B.

From 2012 to 2020, the sales-weighted electricity consumption for Tesla Model S dropped from $380 \mathrm{Wh} / \mathrm{mi}$ to $306 \mathrm{Wh} / \mathrm{mi}$. Over the same time the EPA-rated all-electric driving range increased from 265 miles to 372 miles. Unlike the BMW i3 and the Nissan Leaf, this improvement in vehicle fuel economy occurred while the vehicle increased in mass. The average 
curb weight of the Tesla Model S increased from $4650 \mathrm{lb}$ to $4890 \mathrm{lb}$, due to an increase in the total battery size and the shift from rear-wheel drive (RWD) to all-wheel drive (AWD)

drivetrains.

Share of Tesla Model S by Battery Size

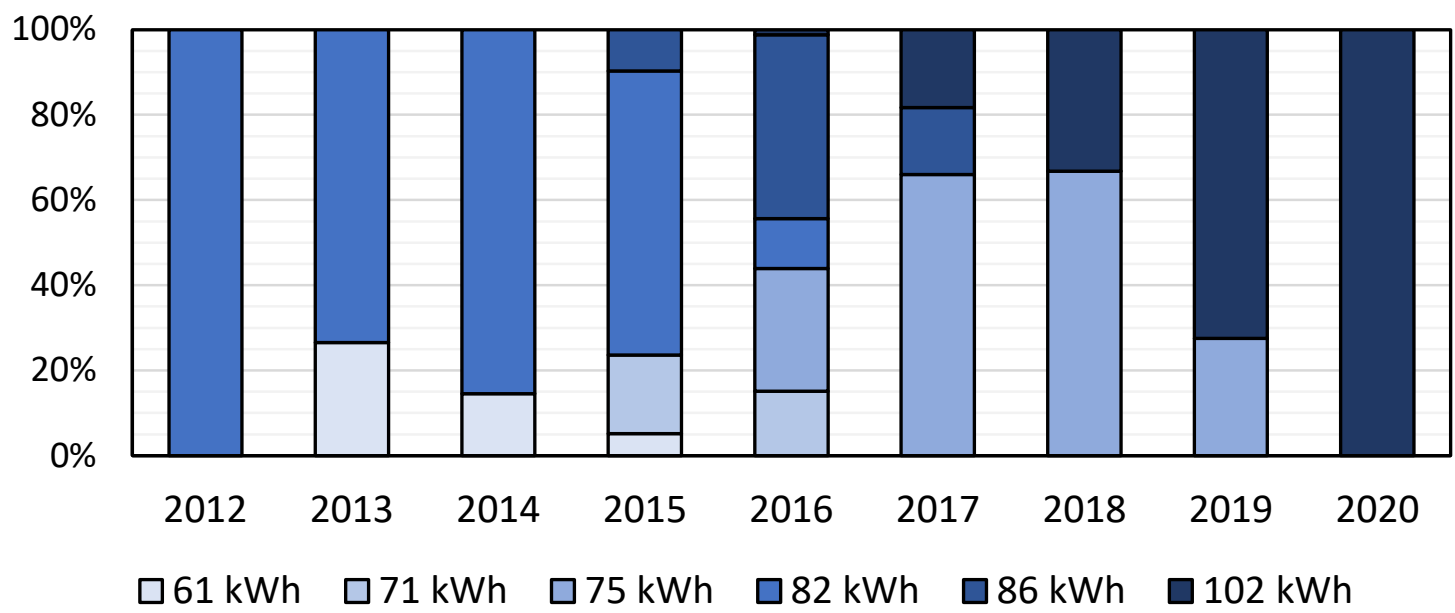

\section{FIGURE 5 Yearly Distributions of Tesla Model S by Battery Size}

Figure 5 displays the yearly distributions of the battery sizes of the Tesla Model S. Tesla increased its number of batteries through 2016 and then decreased the number of battery offerings beginning in 2017. The average battery size has grown from $81.5 \mathrm{kWh}$ to $102.4 \mathrm{kWh}$, while the number of battery size options has decreased in recent years. The decrease in Model S options corresponds to the release of the Tesla Model 3, a cheaper vehicle intended for mass market. All 2020 trims contain the large $100 \mathrm{kWh}$ battery, and all vehicles sold are either long range or performance (see Appendices A and B). While the Model S accounted for 100\% of Tesla vehicles prior to 2016, it accounted for only 6.5\% of Tesla sales in 2020.

Share of Tesla Model X by Battery Size

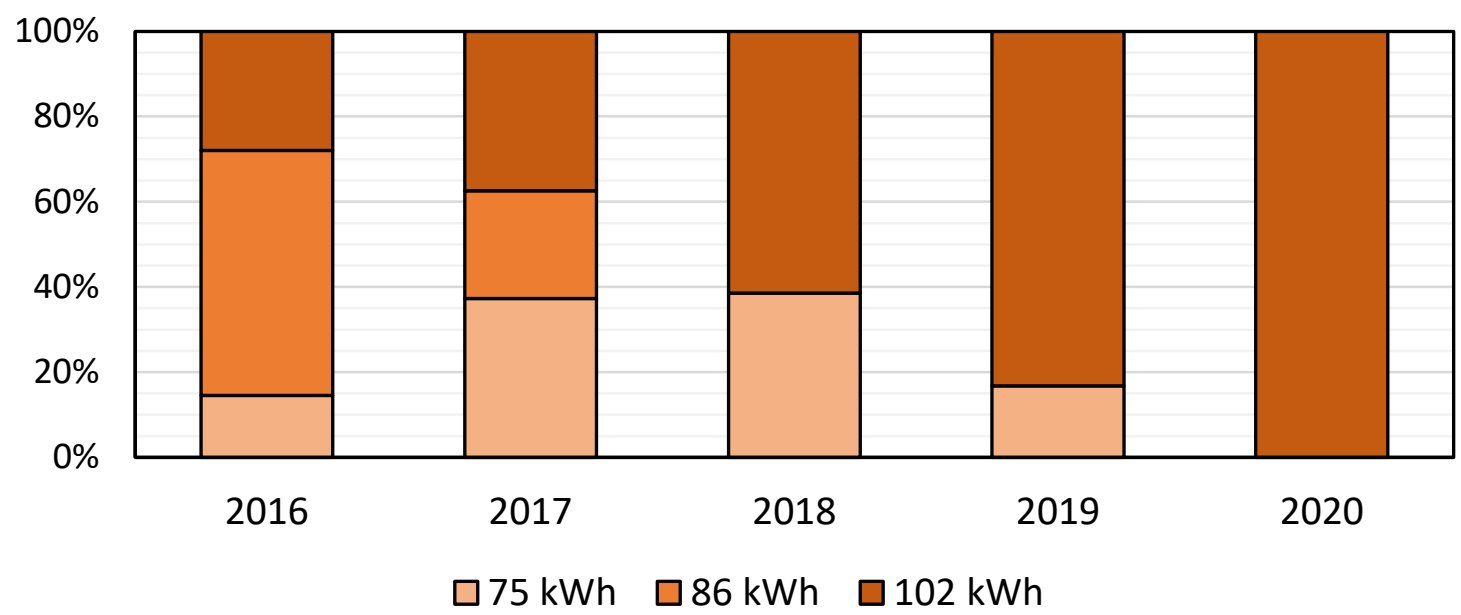

FIGURE 6 Yearly Distributions of Tesla Model X by Battery Size 
The Tesla Model X follows similar trends to the Model $\mathrm{S}$ but has had fewer trim options and battery sizes since its release in 2016, as shown in Figure 6. The average all-electric range of the Model X has increased from 253 miles to 329 miles from 2016 to 2020, while the energy consumption rate improved from $372 \mathrm{Wh} / \mathrm{mi}$ to $350 \mathrm{Wh} / \mathrm{mi}$. Like the Model S, the standard battery size of the Model X increased annually and the 2020 sales mix only contained long range or performance models with the long-range $(102 \mathrm{kWh})$ battery.

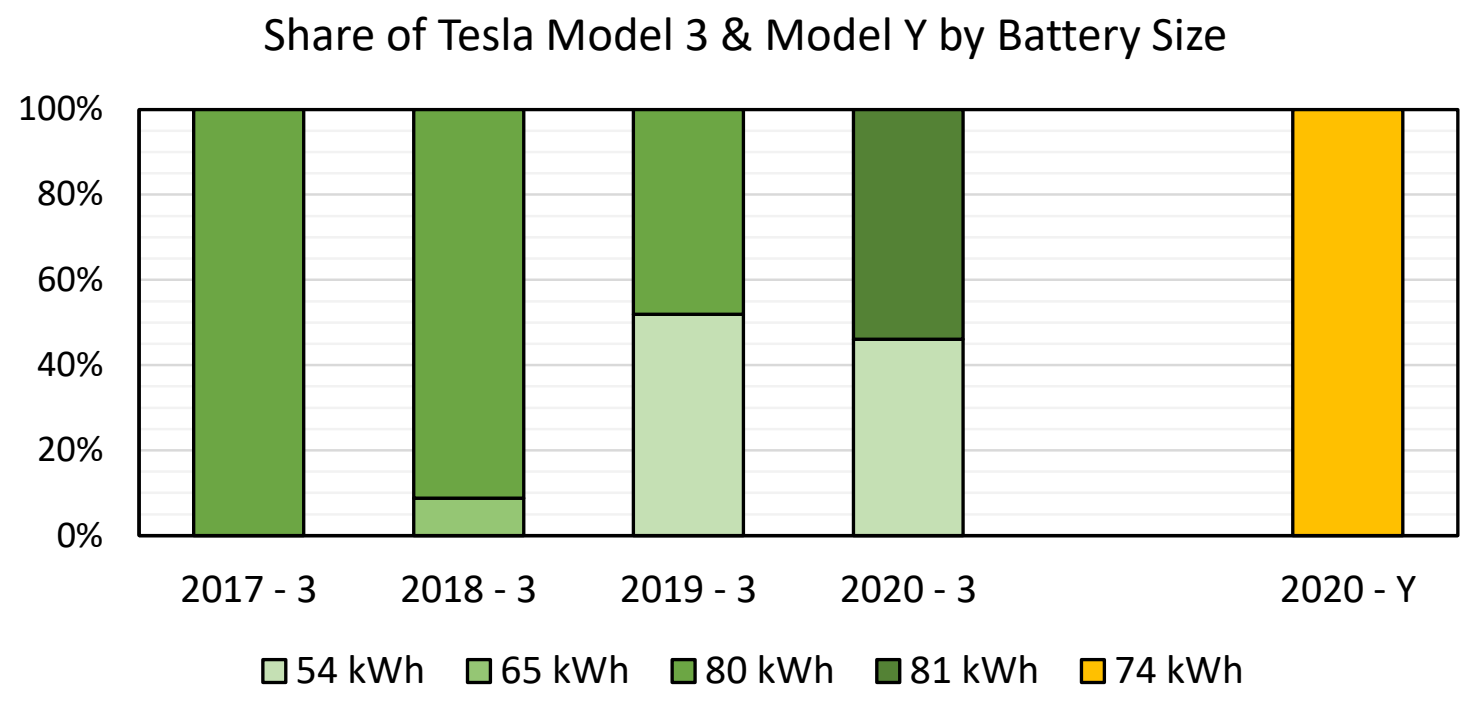

FIGURE 7 Yearly Distributions of Tesla Model 3 and Model Y by Battery Size

The Tesla Model 3 was released in 2017 with the intention to be a mass-market vehicle, rather than a luxury vehicle. Unlike the Model S and the Model X, the Tesla Model 3's average battery size in 2020 is lower than the average battery size during its release in 2017, as shown in Figure 7. Upon release, the initial builds exclusively included a long-range battery. Average energy efficiency of the Model 3 has nearly remained constant since 2017, with the electricity consumption rate decreasing from $268 \mathrm{Wh} / \mathrm{mi}$ to a sales-weighted average value of $265 \mathrm{Wh} / \mathrm{mi}$. Individual trim variants have improved over time, with the long range variant dropping from $268 \mathrm{Wh} / \mathrm{mi}$ in 2017 to $259 \mathrm{Wh} / \mathrm{mi}$ in 2020 and the long range AWD variant dropping from 289 to $280 \mathrm{Wh} / \mathrm{mi}$ from 2018 to 2020 . Additionally, the introduction of variants with smaller batteries has improved average fuel economy. The MY2021 Model 3 Standard Range Plus RWD is the single most fuel efficient vehicle in the FuelEconomy.gov database at $237 \mathrm{Wh} / \mathrm{mi}$ (DOE and EPA 2021). This improvement in fuel economy at the variant level has been countered by the increase in sales shares of lower-efficiency performance models.

Since the Tesla Model Y was released in 2020, there is only one year of Model Y sales data, as shown in Figure 7. Like the Model 3, only long-range trims with one battery size were available during its first year of production. The Model $\mathrm{Y}$ is intended for the mass market as is the Model 3. 


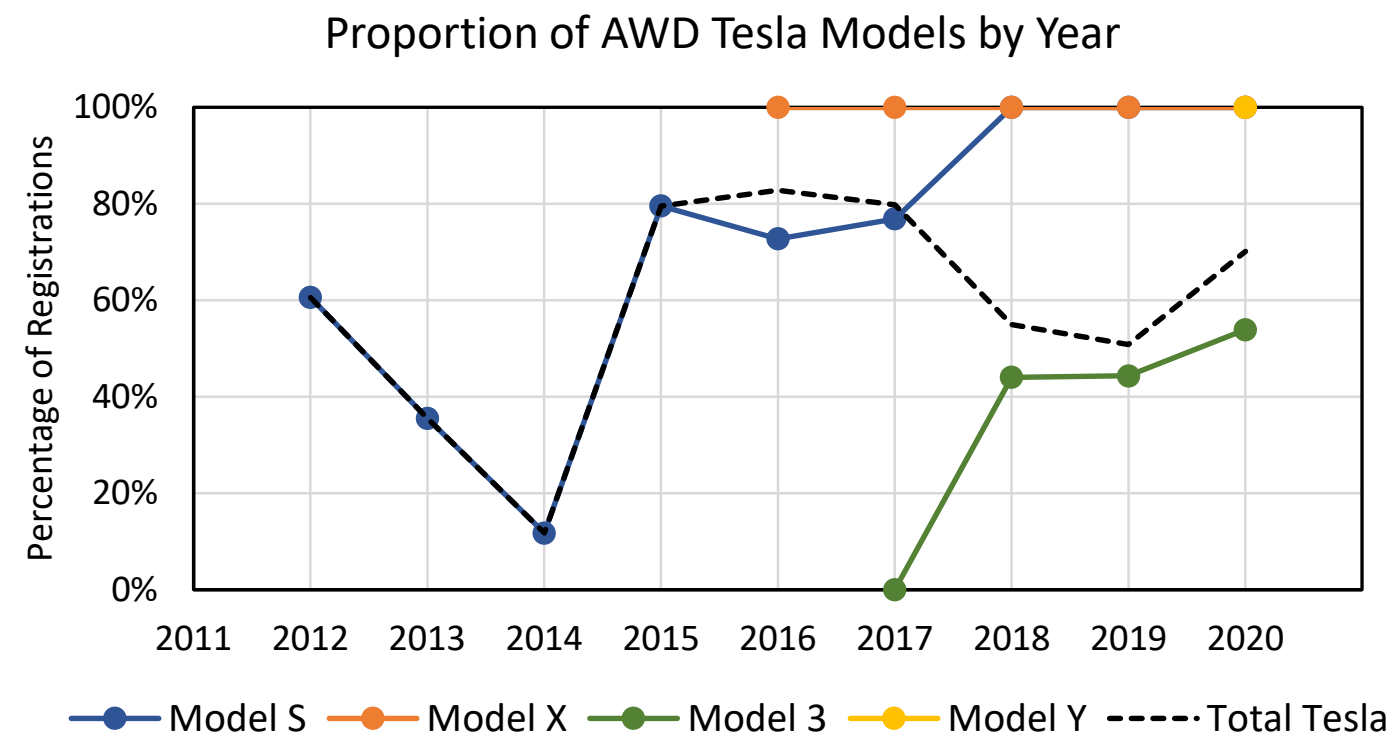

\section{FIGURE 8 Proportion of AWD Tesla Models by Year}

Figure 8 displays the proportion of Tesla models that were AWD by year and model. While the Model X and Model Y have only released AWD models through 2020, the Model 3 released no AWD models in its first year of production. All Model S models are now AWD, and the proportion of AWD Model 3s has increased since their original release. For the Model 3, the estimated fraction for AWD is similar to that estimated by Model3VINs: 44\% in MY2018-2019 here as opposed to $46 \%$ in their analysis based on VINs registered with NHTSA (Model3VINs.com 2019). Their analysis does include international sales, and does not include VINs registered after September 18, 2019, but there could be an impact due to regional preferences for AWD, as with the Model S, as described in the next section.

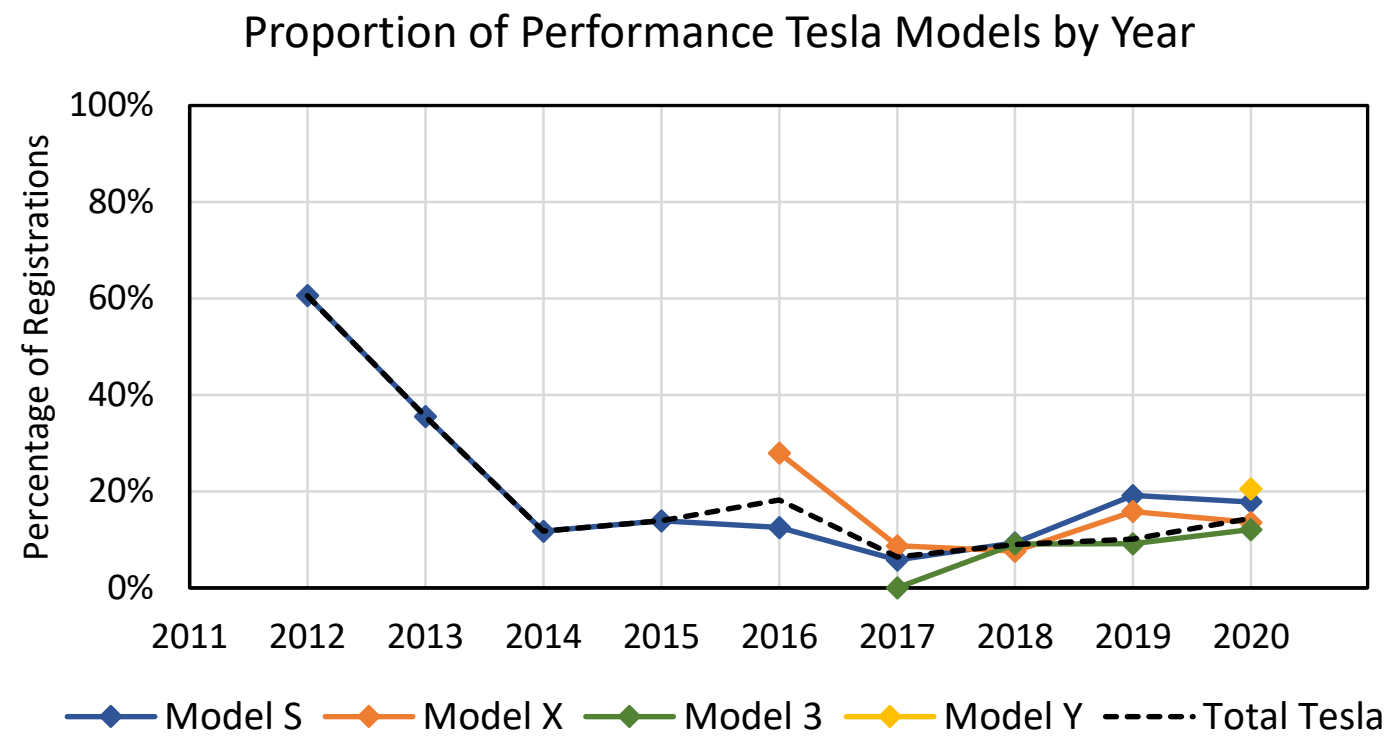

FIGURE 9 Proportion of Performance Tesla Models by Year 
Figure 9 displays the annual proportion of Tesla models that are performance models. Unlike the trends for AWD vehicles shown in Figure 8, the majority of Tesla models sold are not performance trim variants. In 2020, performance variants comprised between $12 \%$ and $21 \%$ of models sold. Performance designated models have not made substantial increases annually despite the yearly increases in performance capabilities such as driving range and fuel economy (see Table 3). The Tesla Model X is also available with 2 or 3 rows of seating. Examining VINs for this model shows that the third-row option was exceedingly popular in its first year of release (2016), with $94 \%$ of customers choosing this option, before falling to around $70 \%$ of sales in each year since then.

As Tesla expands its offerings, the trim variant distribution of various models mold to different niches. The Model X and Model S now clearly fill high-end luxury niches, while the cheaper Model 3 and Model Y contain a larger variety of battery and performance options.

\subsection{GEOGRAPHIC VARIATIONS}

In this section, we consider the state-by-state variations in all-wheel drive drivetrains and performance vehicle registrations for Tesla vehicles, PHEV/BEV share for the BMW i3, battery size for the Nissan Leaf, extra emissions hardware for the Chevrolet Volt, and assembly location for the Volvo XC60.

\subsubsection{Tesla All-Wheel Drive}

There does appear to be a clear regionality in the choice of AWD drivetrains. From Figure 2, we can see that the states for which we have registration data are disproportionately northern states. For several years, the Tesla Model S (MY2012-2017) and Tesla Model 3 (MY2018-2020) have included both all-wheel drive (AWD) and real-wheel drive (RWD) variants. Since having an AWD vehicle is considered advantageous for driving in snowier areas, we tracked how registrations of AWD vehicles compared to RWD vehicles based on location. We show here that the distribution of vehicles with AWD drivetrains is impacted by weather, specifically snowfall. By using climate data from the National Oceanic and Atmospheric Administration, we estimate the correlation of a buyer choosing the AWD drivetrain and the amount of annual snowfall (Arguez et al. 2011). Figure 10a shows the share of Tesla Model S (MY2015-17) vehicles that have AWD for each state. Likewise, Figure 10b shows the share of Tesla Model 3 (MY2018-20) vehicles that have AWD for each state. While overall the Model 3 has a lower share of AWD, both vehicles show the same behavior. In general, snowier states in the north have higher shares of all-wheel drive than states with less snowfall. 


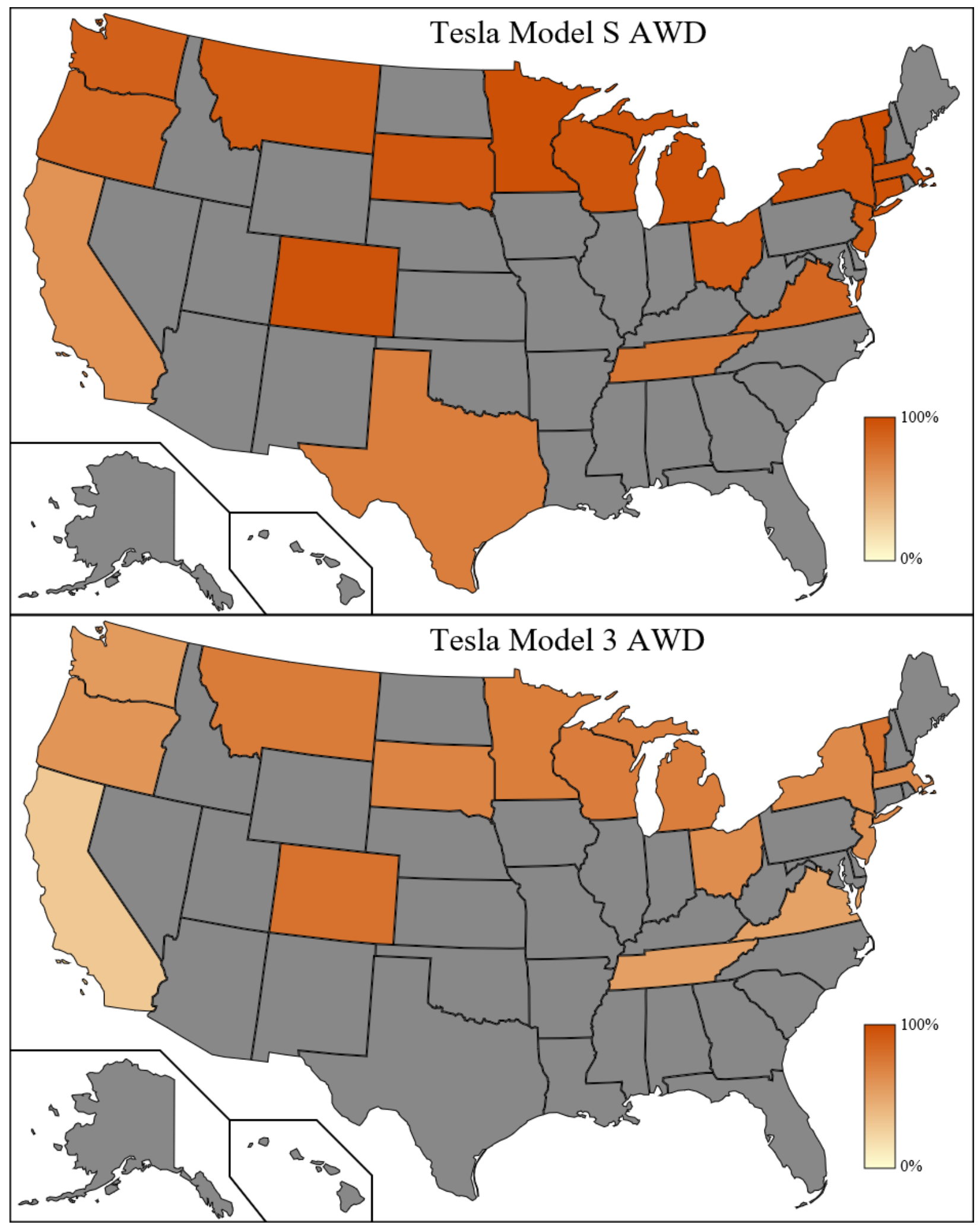

FIGURE 10 Share of MY2015-17 Tesla Model S and MY2018-20 Tesla Model 3 with AWD by state 
Single variable ordinary least squares linear regression was performed to discover the correlations between average annual snowfall and the percent of non-performance vehicles that were AWD for a given model at a local level. All Tesla performance vehicles are AWD, and so we compare the non-performance models with equivalent battery sizes, to minimize conflating multiple factors in vehicle purchase decisions. For the 15 states in Table 3 which had complete data at the ZIP or county level, we calculated the average annual snowfall using National Oceanic and Atmospheric Administration (NOAA) weather station normals for the nearest station (Arguez et al. 2011).

For all models examined, the proportion of AWD vehicles increase in snowier areas, as shown in Table 6. For the 2020 Tesla Model 3, for every foot of annual snowfall in an area, the predicted percentage of AWD vehicles increases by $4 \%$. This simple linear fit had a weighted $\mathrm{r}^{2}$ value of 0.15 , implying that $15 \%$ of the variation in AWD shares for a given zip code could be predicted using only average annual snowfall as the predictive variable, which is an excellent number for data as multifaceted as electric vehicle ownership.

TABLE 6 Predictive Model Coefficients for AWD for Certain Non-Performance Tesla Models

\begin{tabular}{|l|c|c|c|}
\hline Vehicle & $\begin{array}{c}\text { Intercept } \\
\text { (no-snow baseline } \\
\text { AWD share) }\end{array}$ & $\begin{array}{c}\text { Slope } \\
\text { (AWD share \% increase per inch of } \\
\text { average annual snow) }\end{array}$ & $\mathbf{R}^{\mathbf{2}}$ \\
\hline 2014 Tesla Model S & $14.1 \%$ & $0.18 \% /$ inch & 0.03 \\
\hline 2015 Tesla Model S & $85.6 \%$ & $0.17 \% /$ inch & 0.06 \\
\hline 2016 Tesla Model S & $79.9 \%$ & $0.23 \% /$ inch & 0.08 \\
\hline 2017 Tesla Model S & $81.4 \%$ & $0.25 \% /$ inch & 0.10 \\
\hline 2020 Tesla Model 3 & $50.4 \%$ & $0.34 \% /$ inch & 0.15 \\
\hline
\end{tabular}

In this analysis we do not adjust our baseline vehicle proportion based on geographic location, but do note that our sampled data is disproportionately snowy, and so we may be overestimating the share of AWD. Conveniently the drivetrain is distinguishable at the VIN level, and so we do not rely on international registration data to determine the AWD mix in the United States. Therefore, we do not have to worry about data from snowy northern European countries also skewing the analysis for AWD percentage. 


\subsubsection{Tesla Performance Vehicle}

Beyond the variation in AWD for Tesla models, we considered variations in the proportion of Tesla models that are performance models. Unlike the trends for AWD vehicles shown in Figure 8, the majority of Tesla models sold are not performance. California has the lowest share in this data set, which may be because of the incomplete sampling from the CVRP. Montana has the highest share of performance vehicles, which aligns with its reputation for being a haven for exotic cars due to lower taxes and registration fees (Demuro 2016). No clear systematic differences exist for other states.

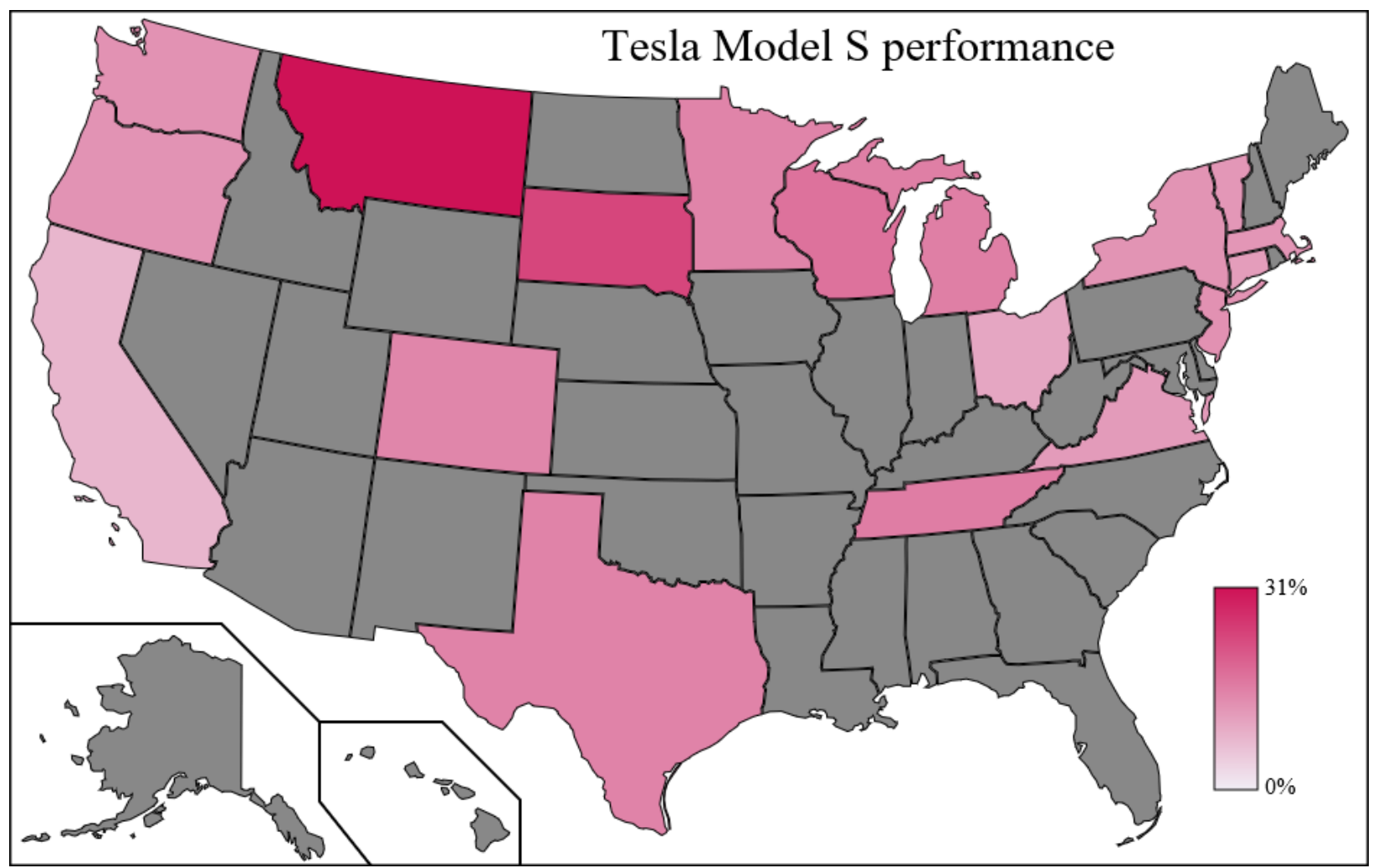

FIGURE 11 Share of MY2015-20 Tesla Model S with performance trim by state 


\subsubsection{BMW i3 REx}

Figure 12 shows the share of BMW i3 from MY2014 to MY2020 for each state with the PHEV range extender (REx). In general, as with the AWD of the Tesla, the share of BMW i3 REx is higher for cold-weather states. The choice of BEV over PHEV may be also encouraged by the availability of charging stations, as California, Florida, Texas, and Washington also were among the states with the most public electric vehicle chargers nationwide (AFDC 2021). However, New York also has a high density of charging stations but a high fraction of plug-in hybrid i3.

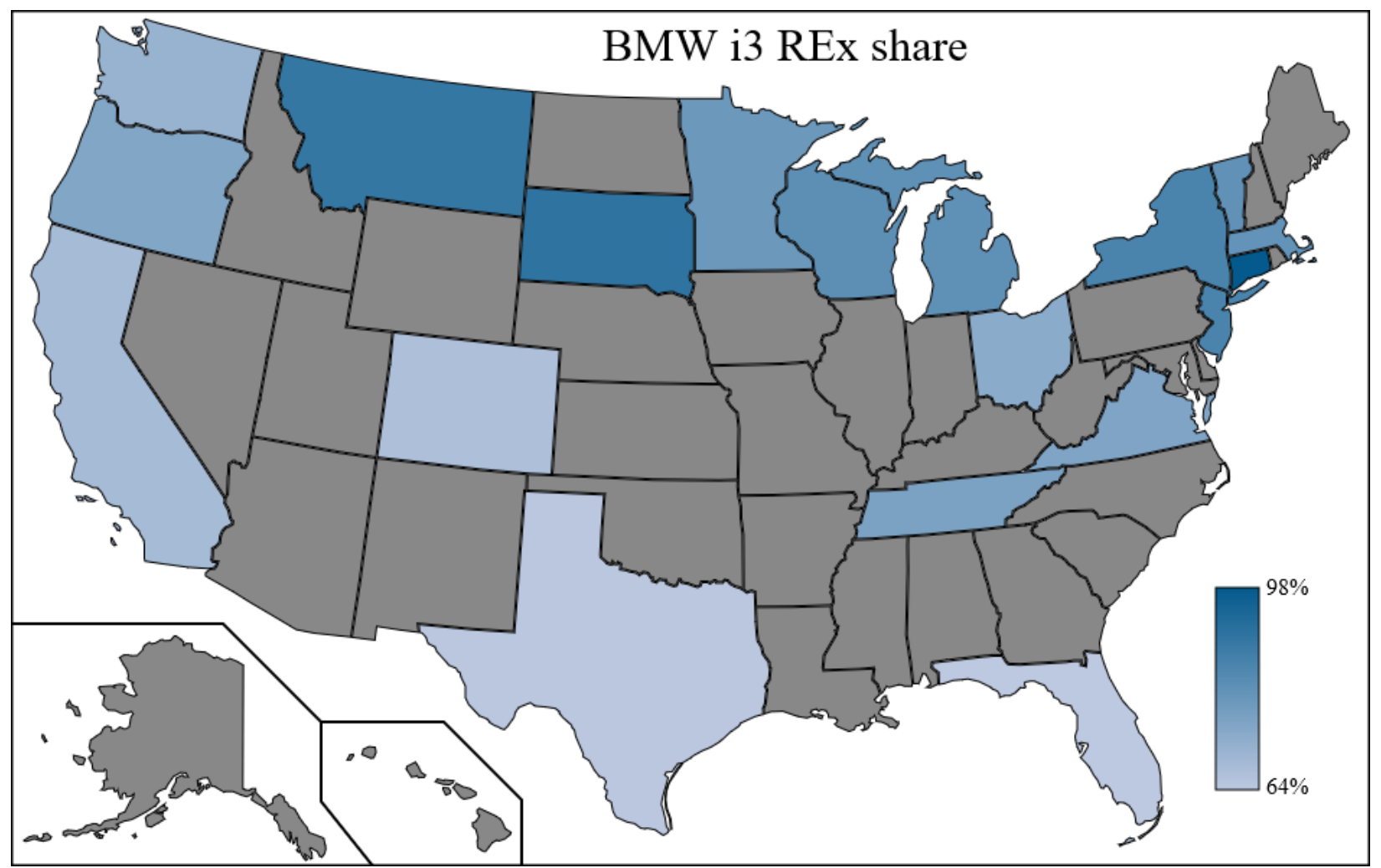

FIGURE 12 Share of MY2014-20 BMW i3 with range extender (REx) by state

While data cannot be determined by model year, the registration data available for Florida and Texas does allow for the total number of i3 and i3 REx to be distinguished. On the other hand, since only PHEV are required to have testing in Bernalillo County, New Mexico, this data is excluded from the analysis. 


\subsubsection{Nissan Leaf Battery Size}

In MY 2016, the Nissan offered the Leaf with both a $24 \mathrm{kWh}$ and $30 \mathrm{kWh}$ battery. Similarly, in MY2019 and MY2020, the Nissan Leaf had options for $40 \mathrm{kWh}$ and $62 \mathrm{kWh}$ batteries. The share of registered vehicles with the larger battery option is shown for each state in Figure 13. There is not a clear regional variation in the battery selection by state. Northeastern states appear to lean slightly toward smaller batteries, perhaps due to smaller typical daily driving distances (Zhou et al 2020).

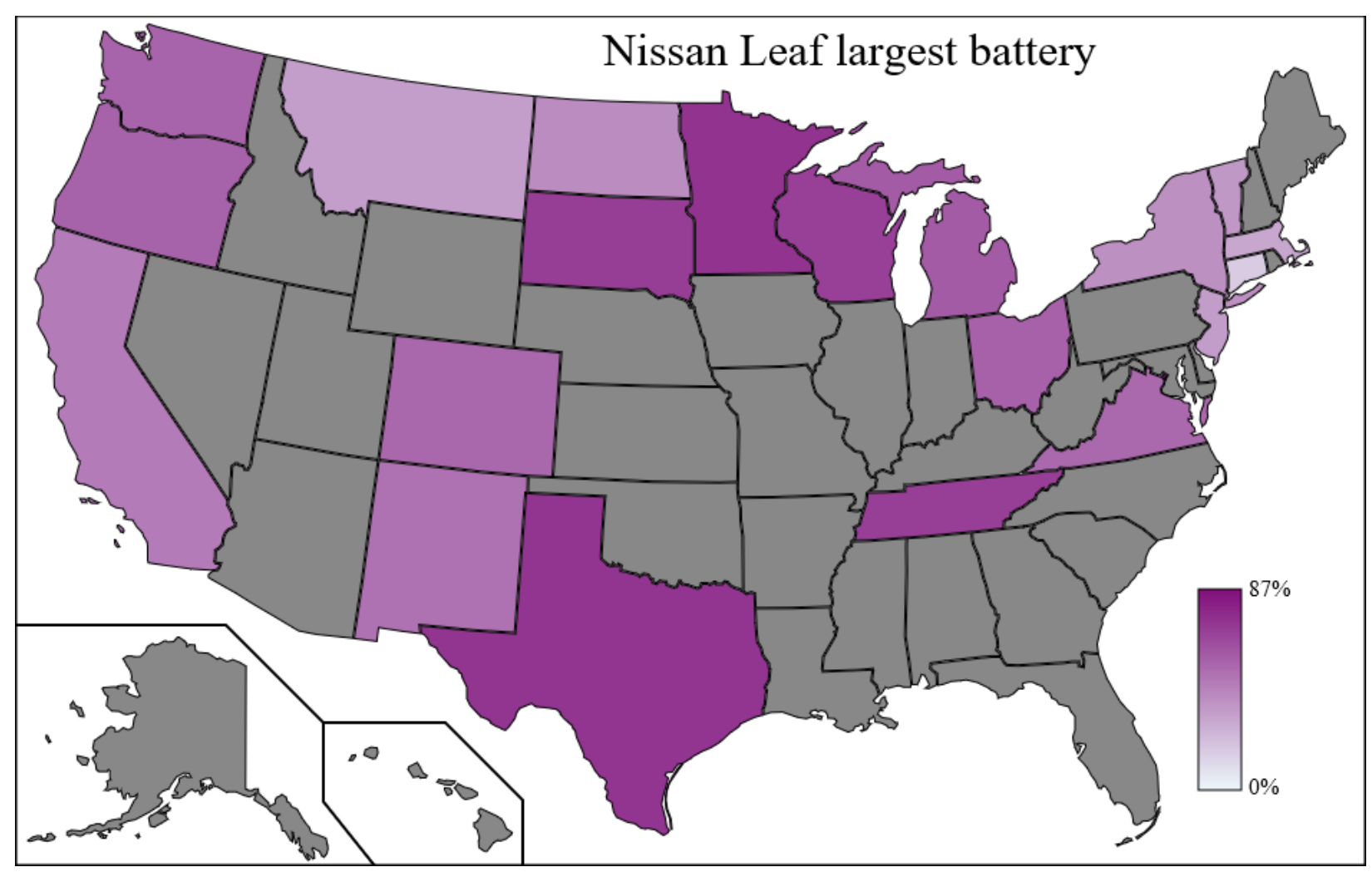

FIGURE 13 Share of MY2016, 2019 and 2020 Nissan Leaf in dataset with largest available battery 


\subsubsection{Chevrolet Volt Emission Package}

Starting in MY2012, the Chevrolet Volt was available with a low-emissions package, denoted by the $5^{\text {th }}$ digit of the VIN. The share for each state of MY2013 to MY2019 Volts having this package is shown in Figure 14. This package was standard in California (Millikin, 2011). Similarly, the northeastern states require an advanced low-emissions package for new vehicle registration (GM 2012). New York offers reduced tolls and high-occupancy vehicle lane access in exchange for having the low-emissions package (GM 2013; NYS TA, 2014).

The California Vehicle Rebate Program required this package, so practically all Volts from California in our data set have it. Comparison of the CVRP data with vehicle registrations from Atlas EV Hub shows that approximately three-quarters of registered Volts were included in the CVRP, though it is not possible to know if the remaining vehicles did not have the lowemissions package or simply did not participate in the rebate program.

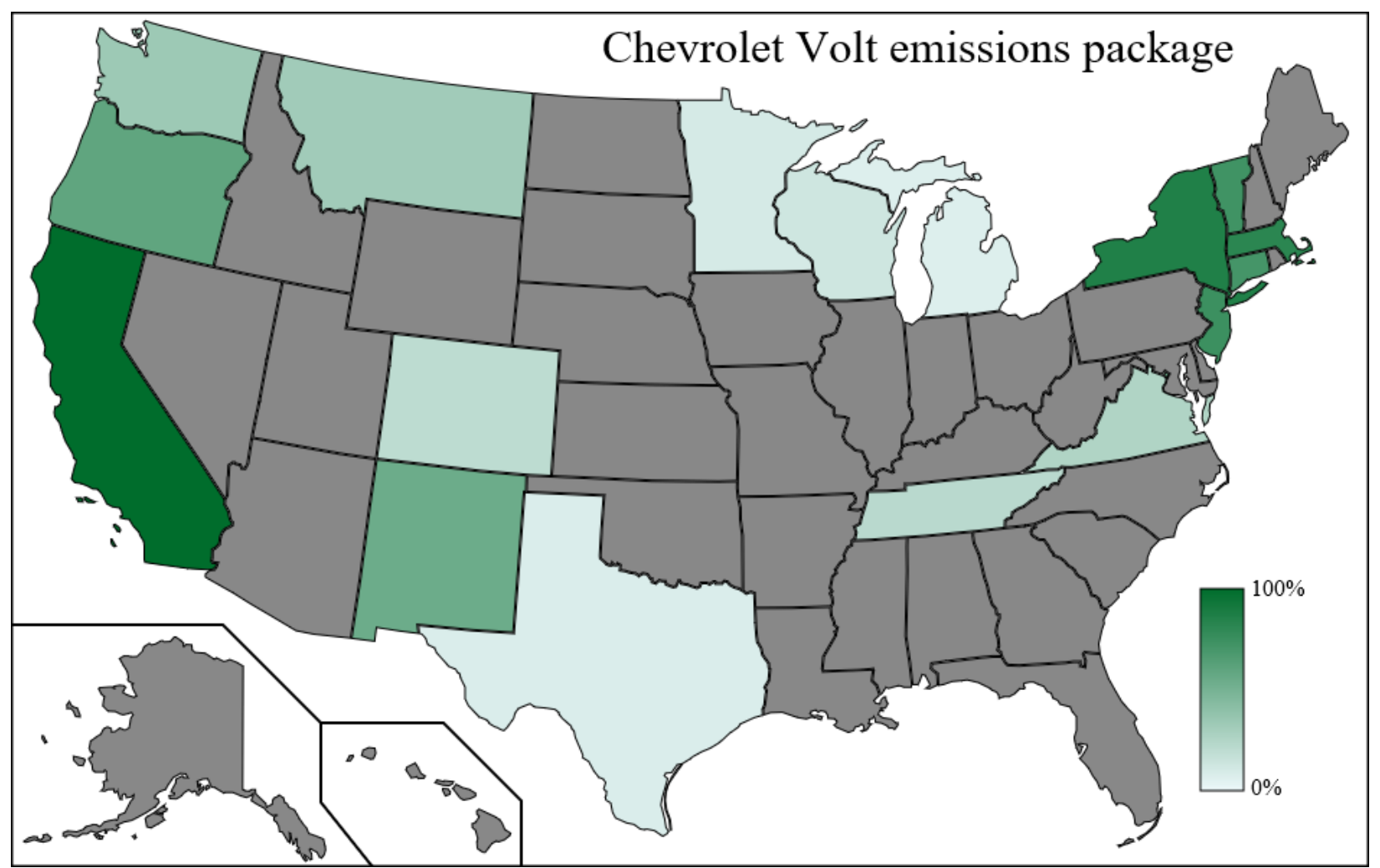

FIGURE 14 Share of MY2013-19 Chevrolet Volt in dataset with low-emissions package 


\subsubsection{Volvo XC60 Assembly Location}

The Volvo XC60 plug-in hybrid was manufactured in both Sweden and China for import to the United States for MY2018 and MY2019, before switching entirely to European manufacture in MY2020. In our dataset, approximately $60 \%$ of these vehicles were assembled in China: $40 \%$ of MY2018 and $80 \%$ of MY2019. A comparison by state shows no clear regionality within which these respective vehicles were ultimately sold and registered, as seen in Figure 15. The three most extremal points (Connecticut, Montana, and New Mexico) have very limited data in our dataset to draw statistical conclusions (a total of 11 vehicles across the three states).

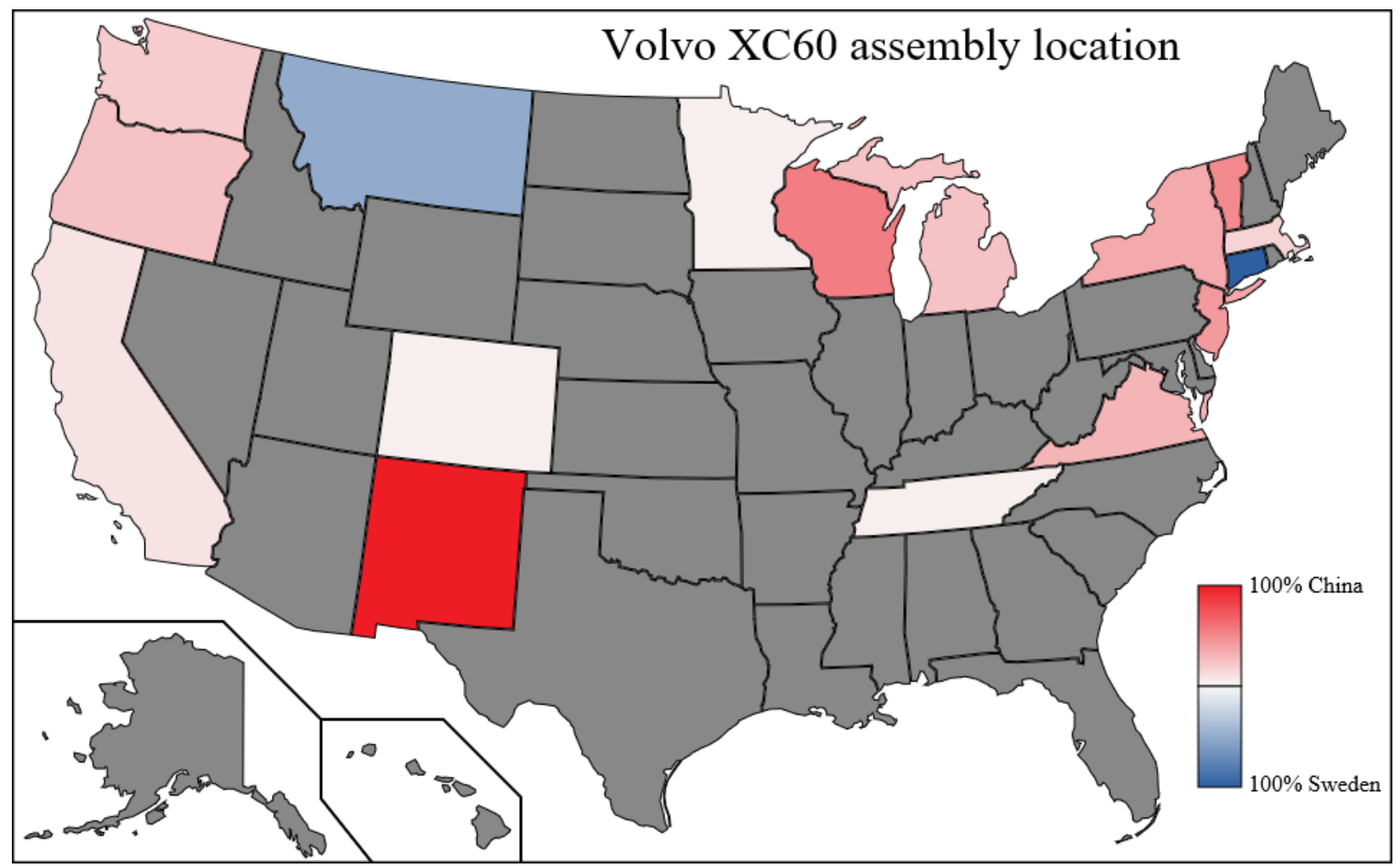

FIGURE 15 Share of MY2018-19 Volvo XC60 assembled in Sweden by state 


\section{SENSITIVITY ANALYSES}

\subsection{SAMPLING}

We generated confidence intervals for the VIN descriptors of each model by considering the number of sales of each particular trim variant and the total number of sales in a year. Mathematically, we have a total population $N$, from which we have selected $n$ vehicles. Of these $n$ vehicles, $s$ have a given trim, and we wish to find the fraction $S$ in the overall population with said trim. We assume a uniform distribution of all possible $S$ and find which values are most likely to result in a sample of $s$ trims out of $n$. To determine a confidence interval (or more precisely a credible interval), we use a hypergeometric distribution to find the smallest set of $\{S\}$ which contain $95 \%$ of the possible sampling pathways. This method was applied to the VIN descriptors as gathered from domestic registration data. The hypergeometric distribution was not applied to the international Tesla trim variant information because we do not know the complete population of international Tesla sales.

For most vehicle models, the $95 \%$ confidence interval is quite narrow. From a sampling perspective, we often have relatively large samples of vehicles in our registration data sets. The confidence intervals are further narrowed by the finite population adjustment inherent in the hypergeometric distribution. The largest confidence intervals are for those vehicles with few samples: for example, our sample of the 2016 Cadillac ELR shows $71 \%$ of vehicles with base trim, with $95 \%$ certainty it is between $65 \%$ and $76 \%$ (assuming vehicle variants in our sampled set are representative of the whole country). The confidence intervals are not perfectly symmetric about their central point; in general there tends to be a slight reversion to the mean due to our choice of ab initio prior distribution. The tables in Appendix A present all results with their associated $95 \%$ confidence intervals. Due to inherent uncertainty, we do not present any results to a greater precision than $1 \%$ of sales in a given model year in these tables.

\subsection{TESLA MIX SENSITIVITY ANALYSIS}

Because the international trim variant distribution is not a perfect match to that of the U.S., five different weightings were applied to trim variant distribution: absolute minimum, absolute maximum, current market weighting, potential market weighting, and even spread weighting. These weightings were created by comparing the trim variant distribution in the U.K., Norway, the Netherlands, and New Zealand. The absolute minimum and maximum weightings assumed that all vehicles within a given VIN descriptor were the vehicle with the lowest battery capacity or the highest battery capacity possible trim variant, respectively. If two variants had an equal battery capacity, they were then sorted by range. If they then had the same range, performance vehicles were ranked as "higher capacity". Finally, if all three of these qualifications were the same, the weights were split all evenly across the models. Although these estimations of the sales mix are not true reflections of the electric vehicle market, they provide clear bounds in between which the actual battery capacities and trim variant distributions must fall.

Note that the absolute minimum and absolute maximum are not equal to a naive estimate of all Tesla models being the lowest/highest possible capacity, but rather the lowest/highest 
within a given VIN descriptor. For example, the MY2018-2020 Model 3 with AWD (nearly half of the total market) still have the long range battery, as the standard range battery was not available with AWD.

Although the current market weighting is likely the most accurate of the weightings, this weighting scheme gives more power to sales in the Netherlands and Norway, countries with high market shares of electric vehicles that offer significant tax incentives that could potentially draw consumers to buy more expensive vehicles (IEA 2020a; Norsk 2021; Jüdell 2020). As of 2019, BEVs made up 54\% of the vehicle market in Norway (Norsk 2021). Since electric vehicles only made up 2.0\% of the United States vehicle market as of 2019 (IEA 2020a), the Norwegian and Dutch trim variants distributions may not be an accurate reflection of the domestic market. The U.K., however, had an electric vehicle market share of $2.9 \%$ in 2019.

Due to the idiosyncrasies of the Norwegian and Dutch EV markets and similarities between the U.K. and U.S. electric vehicle market shares, a second weighting scheme that gives more weight to data from the U.K. may also be an apt reflection of the domestic trim variant distribution. The fourth weighting scheme, known as the potential market weighting, weights each country by number of total registered vehicles (WHO 2020). This scenario gives stronger weighting to the U.K., which may better reflect the U.S. data. This weighting is not the baseline estimate due to its high representation of smaller datasets such as the U.K., and the possibility that the right-hand drive variant mix may differ from the left-hand drive mix in the United States. This side case has a very small potential impact on the total battery capacity, showing broad similarities in the market among each of the foreign countries considered in this analysis.

The fifth weighting scheme, labeled as the even spread, divides trim variants equally within each VIN descriptor, as would be estimated without additional data to distinguish trim variant mix. This weighting shows a modest increase in total battery capacity compared to our baseline case. This implies that consumers worldwide are moderately more likely to buy lowerrange models in order to save cost. This consumer behavior does not have a major impact when considering total installed battery capacity.

Aggregated analysis of battery capacity in PEV is shown in Table 7. Table 7 shows results for all PEV sold and for all Teslas sold in the United States since 2010. Full results by variant of each weighting scheme can be found in Appendix B.

TABLE 7 Impacts of Tesla Sensitivity Analyses on Total Battery Capacity

\begin{tabular}{|l|c|c|}
\hline Scenario name & $\begin{array}{c}\text { Total battery capacity } \\
\text { (Tesla) }\end{array}$ & $\begin{array}{c}\text { Total battery capacity } \\
\text { (all PEV) }\end{array}$ \\
\hline Baseline & $53.0 \mathrm{GWh}$ & $75.9 \mathrm{GWh}$ \\
\hline Absolute minimum & $49.7 \mathrm{GWh}$ & $72.5 \mathrm{GWh}$ \\
\hline Absolute maximum & $58.6 \mathrm{GWh}$ & $81.4 \mathrm{GWh}$ \\
\hline Population-weighted & $53.1 \mathrm{GWh}$ & $75.9 \mathrm{GWh}$ \\
\hline Even spread & $53.6 \mathrm{GWh}$ & $76.4 \mathrm{GWh}$ \\
\hline Nominal nameplate capacity & $51.6 \mathrm{GWh}$ & $74.4 \mathrm{GWh}$ \\
\hline Excluding California CVRP & $54.1 \mathrm{GWh}$ & $77.0 \mathrm{GWh}$ \\
\hline
\end{tabular}




\subsection{CALIFORNIA SAMPLING ANALYSIS}

Data from the Clean Vehicle Rebate Program in California comprises nearly half of all vehicles in the data set, and represents approximately one-quarter of all EV sold in the United States. However, these vehicles are only half of the PEV in California. As noted in Section 2.2, these vehicles may not be representative of all vehicles sold in California, underscored by the lower fraction of performance trim vehicles seen in Section 3.2.2. Therefore, we consider a side case excluding these vehicles from the estimation of the trim variant mix for Tesla vehicles. Those Tesla in the CVRP database on average have smaller batteries than the national average for other states with VIN information, and therefore excluding Californian data from the analysis changes the total nationwide estimate of battery capacity by $1.1 \mathrm{GWh}$.

The data from the CVRP database also underrepresents several high-end makes and short-range makes of PEVs, but because the present analysis is focused on understanding the trim mix within each make, this does not directly impact the results for estimating total installed battery capacity.

\subsection{BATTERY UNCERTAINTY ANALYSIS}

For most makes and models, the size of the battery is commonly believed to be equal to that presented by the automaker. However, for the Tesla models, it is likely that these batteries do not match their nameplate capacity (Bolli 2021; Hughes 2017; Lambert 2016) for vehicles before MY2018. Researchers have estimated that the Tesla Model S has historically had an energy capacity somewhat lower than its nominal nameplate capacity, but this is countered by the Tesla Model 3, which appears to have a battery larger than the $75 \mathrm{kWh}$ nominal battery. Starting with MY2019, Tesla no longer publicizes their total battery capacity, emphasizing instead all-electric range. In our baseline analysis, we use the most detailed battery capacity information that we have found, but we also quantified a side analysis where total battery capacity is equal to the nominal nameplate capacity. The net change in battery capacity is 1.4 GWh, with the side case using nominal battery sizes yielding a $2 \%$ lower total capacity. 


\section{CONCLUSION}

As the electric vehicle market continues to grow, it is highly likely that the diversity of options available to consumers will continue to expand. We identified fourteen models of electric vehicles where nameplate alone is not sufficient to fully characterize the vehicles. As noted above, in MY2021, Audi, BMW, Ford, and Volkswagen all released new models with multiple variants.

For the majority of the vehicles sampled, the average range and fuel efficiency has increased since the vehicle first appeared on the market. These within-model trends parallel the broader market trends for electric vehicles, where plug-in electric vehicles are improving their fuel efficiency and driving range. These trends are promising as larger volumes of PEVs continue to populate the road.

This report tracks sales trends by trim level, with these trends reflecting the decisions of manufacturers as well as consumer choice. Electric vehicle sales have traditionally been supplyconstrained (McDonald 2020), and so automakers may choose to prioritize more profitable vehicles than in the typical mass market (Guess 2018). Therefore, the vehicles purchased by early PEV adopters may skew more toward longer-range vehicles or higher-performance vehicles than the mass market.

The total installed battery capacity of PEV sold in the United States as of the end of 2020 is $75.9 \mathrm{GWh}$, and Tesla vehicles contain $53.0 \mathrm{GWh}$ of that total. Because Tesla is such a large electric vehicle manufacturer, this information can inform many decisions about battery recycling, including locations of where these vehicles are currently in use and forecasting the date of eventual scrappage. As these vehicles age and begin to be retired and scrapped, understanding the distribution of these batteries will be necessary to optimize second-life use and recycling.

The methodology used in this report lays important groundwork for future estimation of trim variant mixes of electric vehicles, and could be expanded to conventional powertrains as well. Further refinement of these estimations could be made if data from more U.S. states were available. Estimations would be made even more precise if there was U.S. data available that contained either trim labels or vehicle attributes, either through vehicle registration or reporting of more detailed sales information by vehicle OEMs. 


\section{APPENDIX A: DETAILED ESTIMATED TRIM VARIANT DISTRIBUTIONS}

Tables A1 through A14 show the specific sales shares for each variant of fourteen different vehicle models. For each vehicle, battery size, all-electric range, fuel economy, and curb weight are listed, along with the VIN descriptor (as described in Table 2) linked to that vehicle. Table 5 in Section 3 shows the sales-weighted values for each of these metrics. The sales share for each trim represents the expected fraction of all vehicles sold in that year, assuming that each vehicle for which we have registration information at the VIN level is randomly sampled from the full country. The $95 \%$ confidence interval is presented in absolute terms; for example, for the 2016 Audi A3 e-tron (Table A1), 12\% of vehicles have the "ultra" trim, and it is $95 \%$ likely that falls between $11 \%$ and $13 \%$ when accounting for sampling, or $12 \% \pm 1 \%$. The $95 \%$ confidence interval is not shown when there is only one vehicle trim available in that model year.

Because the Chevrolet Volt and Volvo XC60 show strong regional variations, it is unlikely that the vehicles in our registration data represent a uniform sampling nationwide. Further, these trims do not vary in their vehicle characteristics (battery size, all-electric range, fuel economy, or curb weight). Therefore, we do not present these models in this appendix.

TABLE A1 Audi A3 e-tron Trim Variant Distribution

\begin{tabular}{|c|c|c|c|c|c|c|c|c|}
\hline Year & Trim Variant & $\begin{array}{l}\text { Battery } \\
(\mathbf{k W h})\end{array}$ & $\begin{array}{l}\text { Range } \\
(\mathbf{m i})\end{array}$ & $\begin{array}{l}\text { Fuel } \\
\text { Economy } \\
\text { (Wh/mi) }\end{array}$ & $\begin{array}{l}\text { Curb } \\
\text { Weight } \\
\text { (lb) }\end{array}$ & $\begin{array}{l}\text { VIN } \\
\text { Descriptors }\end{array}$ & $\begin{array}{l}\text { Sales } \\
\text { Share }\end{array}$ & $\begin{array}{l}95 \% \\
\text { Confidence } \\
\text { Interval }\end{array}$ \\
\hline \multirow{2}{*}{2016} & Audi A3 e-tron & 8.8 & 16 & 400 & 3620 & $\begin{array}{l}\text { GUP, GUT, } \\
\text { GUS }\end{array}$ & $88 \%$ & $(-1 \%,+1 \%)$ \\
\hline & Audi A3 e-tron ultra & 8.8 & 17 & 380 & 3620 & $\begin{array}{l}\text { GUM, } \\
\text { GUN, GUV }\end{array}$ & $12 \%$ & $(-1 \%,+1 \%)$ \\
\hline
\end{tabular}

TABLE A2 BMW 530e Trim Variant Distribution

\begin{tabular}{|c|c|c|c|c|c|c|c|c|}
\hline Year & Trim Variant & $\begin{array}{l}\text { Battery } \\
(\mathbf{k W h})\end{array}$ & $\begin{array}{l}\text { Range } \\
(\mathbf{m i})\end{array}$ & $\begin{array}{l}\text { Fuel } \\
\text { Economy } \\
\text { (Wh/mi) }\end{array}$ & $\begin{array}{l}\text { Curb } \\
\text { Weight } \\
\text { (lb) }\end{array}$ & $\begin{array}{l}\text { VIN } \\
\text { Descriptor }\end{array}$ & $\begin{array}{l}\text { Sales } \\
\text { Share }\end{array}$ & $\begin{array}{l}95 \% \\
\text { Confidence } \\
\text { Interval }\end{array}$ \\
\hline \multirow{2}{*}{2018} & BMW 530e & 9.2 & 16 & 460 & 4270 & JJA9 & $48 \%$ & $(-1 \%,+1 \%)$ \\
\hline & BMW 530e xDrive & 9.2 & 15 & 490 & 4390 & JJB1 & $52 \%$ & $(-1 \%,+1 \%)$ \\
\hline \multirow{2}{*}{2019} & BMW 530e & 9.2 & 16 & 460 & 4270 & KJA9 & $55 \%$ & $(-2 \%,+2 \%)$ \\
\hline & BMW 530e xDrive & 9.2 & 15 & 490 & 4390 & KJB1 & $45 \%$ & $(-2 \%,+2 \%)$ \\
\hline \multirow{2}{*}{2020} & BMW 530e & 12 & 21 & 470 & 4270 & LJA9 & $31 \%$ & $(-6 \%,+6 \%)$ \\
\hline & BMW 530e xDrive & 12 & 19 & 520 & 4390 & LJB1 & $69 \%$ & $(-6 \%,+6 \%)$ \\
\hline
\end{tabular}


TABLE A3 BMW i3 Trim Variant Distribution

\begin{tabular}{|c|c|c|c|c|c|c|c|c|}
\hline Year & Trim Variant & $\begin{array}{l}\text { Battery } \\
(k W h)\end{array}$ & $\begin{array}{l}\text { Range } \\
\text { (mi) }\end{array}$ & $\begin{array}{l}\text { Fuel } \\
\text { Economy } \\
(\mathrm{Wh} / \mathbf{m i})\end{array}$ & $\begin{array}{l}\text { Curb } \\
\text { Weight } \\
\text { (lb) }\end{array}$ & $\begin{array}{l}\text { VIN } \\
\text { Descriptor }\end{array}$ & $\begin{array}{l}\text { Sales } \\
\text { Share }\end{array}$ & $\begin{array}{l}95 \% \\
\text { Confidence } \\
\text { Interval }\end{array}$ \\
\hline \multirow{2}{*}{2014} & BMW i3 & 21.6 & 81 & 270 & 2860 & $\mathrm{E} 1 \mathrm{Z2}$ & $33 \%$ & $(-1 \%,+1 \%)$ \\
\hline & BMW i3 REx & 21.6 & 72 & 290 & 3130 & $\mathrm{E} 1 \mathrm{Z4}$ & $67 \%$ & $(-1 \%,+1 \%)$ \\
\hline \multirow{2}{*}{2015} & BMW i3 & 21.6 & 81 & 270 & 2860 & $\mathrm{~F} 1 \mathrm{Z} 2$ & $23 \%$ & $(-1 \%,+1 \%)$ \\
\hline & BMW i3 REx & 21.6 & 72 & 290 & 3130 & F1Z4 & $77 \%$ & $(-1 \%,+1 \%)$ \\
\hline \multirow{2}{*}{2016} & BMW i3 & 21.6 & 81 & 270 & 2860 & $\mathrm{G} 1 \mathrm{Z2}$ & $19 \%$ & $(-1 \%,+2 \%)$ \\
\hline & BMW i3 REx & 21.6 & 72 & 290 & 3130 & G1Z4 & $81 \%$ & $(-2 \%,+1 \%)$ \\
\hline \multirow{2}{*}{2017} & BMW i3 & 21.6 & 81 & 270 & 2960 & H1Z6 & $26 \%$ & $(-1 \%,+1 \%)$ \\
\hline & BMW i3 REx & 21.6 & 72 & 290 & 3230 & $\mathrm{H} 1 \mathrm{Z8}$ & $74 \%$ & $(-1 \%,+1 \%)$ \\
\hline \multirow{4}{*}{2018} & BMW i3 & 33.2 & 114 & 286 & 2960 & $\mathrm{~J} 7 \mathrm{Z} 2$ & $23 \%$ & $(-1 \%,+1 \%)$ \\
\hline & BMW i3 S & 33.2 & 107 & 300 & 3010 & $\mathrm{~J} 7 \mathrm{Z6}$ & $9 \%$ & $(-1 \%,+1 \%)$ \\
\hline & BMW i3 REx & 33.2 & 97 & 310 & 3230 & $\mathrm{~J} 7 \mathrm{Z4}$ & $52 \%$ & $(-2 \%,+1 \%)$ \\
\hline & BMW i3 S Rex & 33.2 & 97 & 310 & 3280 & $\mathrm{~J} 7 \mathrm{Z8}$ & $16 \%$ & $(-1 \%,+1 \%)$ \\
\hline \multirow{4}{*}{2019} & BMW i3 & 42.2 & 153 & 298 & 2970 & $\mathrm{~K} 8 \mathrm{P} 2$ & $26 \%$ & $(-1 \%,+2 \%)$ \\
\hline & BMW i3 S & 42.2 & 153 & 298 & 3040 & K8P6 & $8 \%$ & $(-1 \%,+1 \%)$ \\
\hline & BMW i3 REx & 42.2 & 126 & 320 & 3280 & $\mathrm{~K} 8 \mathrm{P} 4$ & $48 \%$ & $(-2 \%,+2 \%)$ \\
\hline & BMW i3 S Rex & 42.2 & 126 & 320 & 3310 & K8P8 & $17 \%$ & $(-1 \%,+1 \%)$ \\
\hline \multirow{4}{*}{2020} & BMW i3 & 42.2 & 153 & 298 & 2970 & L8P2 & $24 \%$ & $(-5 \%,+6 \%)$ \\
\hline & BMW i3 S & 42.2 & 153 & 298 & 3040 & L8P6 & $21 \%$ & $(-5 \%,+5 \%)$ \\
\hline & BMW i3 REx & 42.2 & 126 & 320 & 3280 & L8P4 & $41 \%$ & $(-6 \%,+6 \%)$ \\
\hline & BMW i3 S Rex & 42.2 & 126 & 320 & 3310 & L8P8 & $14 \%$ & $(-4 \%,+5 \%)$ \\
\hline
\end{tabular}

TABLE A4 BMW i8 Trim Variant Distribution

\begin{tabular}{|c|c|c|c|c|c|c|c|c|}
\hline Year & Trim Variant & $\begin{array}{l}\text { Battery } \\
(k W h)\end{array}$ & $\begin{array}{l}\text { Range } \\
\text { (mi) }\end{array}$ & $\begin{array}{l}\text { Fuel } \\
\text { Economy } \\
\text { (Wh/mi) }\end{array}$ & $\begin{array}{l}\text { Curb } \\
\text { Weight } \\
\text { (lb) }\end{array}$ & $\begin{array}{l}\text { VIN } \\
\text { Descriptor }\end{array}$ & $\begin{array}{l}\text { Sales } \\
\text { Share }\end{array}$ & $\begin{array}{l}95 \% \\
\text { Confidence } \\
\text { Interval }\end{array}$ \\
\hline \multirow{2}{*}{2019} & BMW i8 Coupe & 7.1 & 18 & 490 & 3500 & $\mathrm{~K} 24$ & $25 \%$ & $(-3 \%,+3 \%)$ \\
\hline & BMW i8 Roadster & 7.1 & 18 & 490 & 3670 & K26 & $75 \%$ & $(-3 \%,+3 \%)$ \\
\hline \multirow{2}{*}{2020} & BMW i8 Coupe & 7.1 & 18 & 490 & 3500 & L24 & $53 \%$ & $\begin{array}{l}(-24 \%) \\
+23 \%)\end{array}$ \\
\hline & BMW i8 Roadster & 7.1 & 18 & 490 & 3670 & L26 & $47 \%$ & $\begin{array}{l}(-23 \% \\
+24 \%)\end{array}$ \\
\hline
\end{tabular}

\section{TABLE A5 Cadillac ELR Trim Variant Distribution}

\begin{tabular}{|c|c|c|c|c|c|c|c|c|}
\hline Year & Trim Variant & $\begin{array}{l}\text { Battery } \\
\text { (kWh) }\end{array}$ & $\begin{array}{l}\text { Range } \\
\text { (mi) }\end{array}$ & $\begin{array}{l}\text { Fuel } \\
\text { Economy } \\
(\mathrm{Wh} / \mathrm{mi})\end{array}$ & $\begin{array}{l}\text { Curb } \\
\text { Weight } \\
\text { (lb) }\end{array}$ & $\begin{array}{l}\text { VIN } \\
\text { Descriptor }\end{array}$ & $\begin{array}{l}\text { Sales } \\
\text { Share }\end{array}$ & $\begin{array}{l}95 \% \\
\text { Confidence } \\
\text { Interval }\end{array}$ \\
\hline 2014 & Cadillac ELR & 16.5 & 37 & 410 & 4050 & $\mathrm{GR}^{*}$ & $100 \%$ & \\
\hline \multirow{2}{*}{2016} & Cadillac ELR & 17.1 & 40 & 390 & 4070 & GRL & $71 \%$ & $(-5 \%,+5 \%)$ \\
\hline & Cadillac ELR Sport & 17.1 & 36 & 430 & 4070 & GRM & $29 \%$ & $(-5 \%,+5 \%)$ \\
\hline
\end{tabular}


TABLE A6 Nissan Leaf Trim Variant Distribution

\begin{tabular}{|c|c|c|c|c|c|c|c|c|}
\hline Year & Trim Variant & $\begin{array}{l}\text { Battery } \\
(\mathbf{k W h})\end{array}$ & $\begin{array}{l}\text { Range } \\
(\mathbf{m i})\end{array}$ & $\begin{array}{l}\text { Fuel } \\
\text { Economy } \\
\text { (Wh/mi) }\end{array}$ & $\begin{array}{l}\text { Curb } \\
\text { Weight } \\
\text { (lb) }\end{array}$ & $\begin{array}{l}\text { VIN } \\
\text { Descriptor }\end{array}$ & $\begin{array}{l}\text { Sales } \\
\text { Share }\end{array}$ & $\begin{array}{l}95 \% \\
\text { Confidence } \\
\text { Interval }\end{array}$ \\
\hline 2011 & Nissan Leaf & 24 & 73 & 340 & 3370 & BAC & $100 \%$ & \\
\hline 2012 & Nissan Leaf & 24 & 73 & 340 & 3390 & CAC & $100 \%$ & \\
\hline 2013 & Nissan Leaf & 24 & 75 & 290 & 3260 & DAC & $100 \%$ & \\
\hline 2014 & Nissan Leaf & 24 & 84 & 300 & 3260 & EAC & $100 \%$ & \\
\hline 2015 & Nissan Leaf & 24 & 84 & 296 & 3260 & FAC & $100 \%$ & \\
\hline \multirow{2}{*}{2016} & Nissan Leaf ( $24 \mathrm{~kW}$-hr battery pack) & 24 & 84 & 296 & 3260 & GAC & $37 \%$ & $(-1 \%,+1 \%)$ \\
\hline & Nissan Leaf (30 kW-hr battery pack) & 30 & 107 & 300 & 3310 & GBC & $63 \%$ & $(-1 \%,+1 \%)$ \\
\hline 2017 & Nissan Leaf & 30 & 107 & 300 & 3320 & $\mathrm{HBC}$ & $100 \%$ & \\
\hline 2018 & Nissan Leaf & 40 & 151 & 300 & 3400 & JAC & $100 \%$ & \\
\hline \multirow{2}{*}{2019} & Nissan Leaf (40 kW-hr battery pack) & 40 & 150 & 302 & 3430 & KAC & $62 \%$ & $(-1 \%,+1 \%)$ \\
\hline & Nissan Leaf (62 kW-hr battery pack) & 62 & 226 & 310 & 3780 & $\mathrm{KBC}$ & $38 \%$ & $(-1 \%,+1 \%)$ \\
\hline \multirow{5}{*}{2020} & Nissan Leaf 40-S & 40 & 149 & 304 & 3540 & LAB & $12 \%$ & $(-1 \%,+1 \%)$ \\
\hline & Nissan Leaf 40-SV & 40 & 149 & 304 & 3540 & LAC & $34 \%$ & $(-2 \%,+2 \%)$ \\
\hline & Nissan Leaf 62-S & 62 & 226 & 313 & 3880 & LBB & $9 \%$ & $(-1 \%,+1 \%)$ \\
\hline & Nissan Leaf 62-SL & 62 & 226 & 323 & 3930 & LBC & $20 \%$ & $(-2 \%,+2 \%)$ \\
\hline & Nissan Leaf 62-SV & 62 & 226 & 323 & 3930 & LBD & $25 \%$ & $(-2 \%,+2 \%)$ \\
\hline
\end{tabular}

TABLE A7 Porsche Cayenne Trim Variant Distribution

\begin{tabular}{|c|c|c|c|c|c|c|c|c|}
\hline Year & Trim Variant & $\begin{array}{l}\text { Battery } \\
(\mathbf{k W h})\end{array}$ & $\begin{array}{l}\text { Range } \\
(\mathbf{m i})\end{array}$ & $\begin{array}{l}\text { Fuel } \\
\text { Economy } \\
\text { (Wh/mi) }\end{array}$ & $\begin{array}{l}\text { Curb } \\
\text { Weight } \\
\text { (lb) }\end{array}$ & $\begin{array}{l}\text { VIN } \\
\text { Descriptor }\end{array}$ & $\begin{array}{l}\text { Sales } \\
\text { Share }\end{array}$ & $\begin{array}{l}95 \% \\
\text { Confidence } \\
\text { Interval }\end{array}$ \\
\hline 2015 & Cayenne S e-Hybrid & 10.8 & 14 & 690 & 5180 & FAE & $100 \%$ & \\
\hline 2016 & Cayenne S e-Hybrid & 10.8 & 14 & 690 & 5180 & GAE & $100 \%$ & \\
\hline 2017 & Cayenne S e-Hybrid & 10.8 & 14 & 710 & 5180 & HAE & $100 \%$ & \\
\hline 2018 & Cayenne S e-Hybrid & 10.8 & 14 & 700 & 5180 & JAE & $100 \%$ & \\
\hline 2019 & Cayenne e-Hybrid & 14.1 & 13 & 720 & 5050 & $\mathrm{KAE}$ & $100 \%$ & \\
\hline \multirow{4}{*}{2020} & Cayenne e-Hybrid & 14.1 & 14 & 710 & 5160 & LAE & $82 \%$ & $(-7 \%,+6 \%)$ \\
\hline & Cayenne e-Hybrid Coupe & 14.1 & 14 & 710 & 5270 & LBE & $6 \%$ & $(-3 \%,+5 \%)$ \\
\hline & Cayenne Turbo S E-Hybrid & 14.1 & 12 & 760 & 5680 & LAH & $9 \%$ & $(-4 \%,+5 \%)$ \\
\hline & Cayenne Turbo S E-Hybrid Coupe & 14.1 & 12 & 760 & 5670 & LBH & $3 \%$ & $(-2 \%,+3 \%)$ \\
\hline
\end{tabular}


TABLE A8 Porsche Panamera Trim Variant Distribution

\begin{tabular}{|c|c|c|c|c|c|c|c|c|}
\hline Year & Trim Variant & $\begin{array}{l}\text { Battery } \\
(\mathrm{kWh})\end{array}$ & $\begin{array}{l}\text { Range } \\
\text { (mi) }\end{array}$ & $\begin{array}{l}\text { Fuel } \\
\text { Economy } \\
(\mathbf{W h} / \mathbf{m i})\end{array}$ & $\begin{array}{l}\text { Curb } \\
\text { Weight } \\
\text { (lb) }\end{array}$ & $\begin{array}{l}\text { VIN } \\
\text { Descriptor }\end{array}$ & $\begin{array}{l}\text { Sales } \\
\text { Share }\end{array}$ & $\begin{array}{l}95 \% \\
\text { Confidence } \\
\text { Interval }\end{array}$ \\
\hline 2014 & Panamera S E-Hybrid & 9.4 & 16 & 520 & 4620 & EAD & $100 \%$ & \\
\hline 2015 & Panamera S E-Hybrid & 9.4 & 16 & 520 & 4620 & FAD & $100 \%$ & \\
\hline 2016 & Panamera S E-Hybrid & 9.4 & 16 & 510 & 4620 & GAD & $100 \%$ & \\
\hline \multirow{6}{*}{2018} & Panamera Turbo S e-Hybrid & 14.1 & 14 & 670 & 5090 & JAH & $16 \%$ & $(-3 \%,+3 \%)$ \\
\hline & Panamera Turbo S e-Hybrid Executive & 14.1 & 14 & 670 & 5310 & JBH & $4 \%$ & $(-1 \%,+2 \%)$ \\
\hline & Panamera Turbo S e-Hybrid Sport Tourismo & 14.1 & 14 & 670 & 5130 & $\mathrm{JCH}$ & $5 \%$ & $(-1 \%,+2 \%)$ \\
\hline & Panamera 4 e-Hybrid & 14.1 & 16 & 590 & 4780 & JAE & $68 \%$ & $(-4 \%,+3 \%)$ \\
\hline & Panamera 4 e-Hybrid Executive & 14.1 & 16 & 590 & 4960 & JBE & $3 \%$ & $(-1 \%,+2 \%)$ \\
\hline & Panamera 4 e-Hybrid Sport Tourismo & 14.1 & 16 & 590 & 4830 & JCE & $4 \%$ & $(-1 \%,+2 \%)$ \\
\hline \multirow{6}{*}{2019} & Panamera Turbo S e-Hybrid & 14.1 & 14 & 660 & 5090 & KAH & $9 \%$ & $(-5 \%,+6 \%)$ \\
\hline & Panamera Turbo S e-Hybrid Executive & 14.1 & 14 & 660 & 5310 & $\mathrm{KBH}$ & $2 \%$ & $(-2 \%,+3 \%)$ \\
\hline & Panamera Turbo S e-Hybrid Sport Tourismo & 14.1 & 14 & 660 & 5130 & $\mathrm{KCH}$ & $4 \%$ & $(-3 \%,+4 \%)$ \\
\hline & Panamera 4 e-Hybrid & 14.1 & 14 & 650 & 4780 & $\mathrm{KAE}$ & $79 \%$ & $(-7 \%,+6 \%)$ \\
\hline & Panamera 4 e-Hybrid Executive & 14.1 & 14 & 650 & 4960 & $\mathrm{KBE}$ & $3 \%$ & $(-2 \%,+4 \%)$ \\
\hline & Panamera 4 e-Hybrid Sport Tourismo & 14.1 & 14 & 650 & 4830 & $\mathrm{KCE}$ & $4 \%$ & $(-3 \%,+4 \%)$ \\
\hline \multirow{6}{*}{2020} & Panamera Turbo S e-Hybrid & 14.1 & 14 & 660 & 5090 & LAH & $2 \%$ & $(-2 \%,+5 \%)$ \\
\hline & Panamera Turbo S e-Hybrid Executive & 14.1 & 14 & 660 & 5310 & $\mathrm{LBH}$ & $6 \%$ & $(-5 \%,+8 \%)$ \\
\hline & Panamera Turbo S e-Hybrid Sport Tourismo & 14.1 & 14 & 660 & 5130 & $\mathrm{LCH}$ & $2 \%$ & $(-2 \%,+5 \%)$ \\
\hline & Panamera 4 e-Hybrid & 14.1 & 14 & 650 & 4780 & LAE & $85 \%$ & $(-9 \%,+6 \%)$ \\
\hline & Panamera 4 e-Hybrid Executive & 14.1 & 14 & 650 & 5060 & LBE & $2 \%$ & $(-2 \%,+5 \%)$ \\
\hline & Panamera 4 e-Hybrid Sport Tourismo & 14.1 & 14 & 650 & 5000 & LCE & $4 \%$ & $(-4 \%,+7 \%)$ \\
\hline
\end{tabular}

\section{TABLE A9 Porsche Taycan Trim Variant Distribution}

\begin{tabular}{|c|c|c|c|c|c|c|c|c|}
\hline Year & Trim Variant & $\begin{array}{l}\text { Battery } \\
\text { (kWh) }\end{array}$ & $\begin{array}{l}\text { Range } \\
\text { (mi) }\end{array}$ & $\begin{array}{l}\text { Fuel } \\
\text { Economy } \\
(\mathrm{Wh} / \mathrm{mi})\end{array}$ & $\begin{array}{l}\text { Curb } \\
\text { Weight } \\
\text { (lb) }\end{array}$ & $\begin{array}{l}\text { VIN } \\
\text { Descriptor }\end{array}$ & $\begin{array}{l}\text { Sales } \\
\text { Share }\end{array}$ & $\begin{array}{l}95 \% \\
\text { Confidence } \\
\text { Interval }\end{array}$ \\
\hline \multirow{2}{*}{2020} & Taycan 4S Perf Battery Plus & 93.4 & 203 & 488 & 4950 & LAC & $46 \%$ & $(-5 \%,+5 \%)$ \\
\hline & Taycan Turbo / Turbo S & 93.4 & 192 & 499 & 5130 & LAB & $54 \%$ & $(-5 \%,+5 \%)$ \\
\hline
\end{tabular}




\section{TABLE A10 Smart Fortwo Trim Variant Distribution}

\begin{tabular}{|c|c|c|c|c|c|c|c|c|}
\hline Year & Trim Variant & $\begin{array}{l}\text { Battery } \\
\text { (kWh) }\end{array}$ & $\begin{array}{l}\text { Range } \\
\text { (mi) }\end{array}$ & $\begin{array}{l}\text { Fuel } \\
\text { Economy } \\
\text { (Wh/mi) }\end{array}$ & $\begin{array}{l}\text { Curb } \\
\text { Weight } \\
\text { (lb) }\end{array}$ & $\begin{array}{l}\text { VIN } \\
\text { Descriptor }\end{array}$ & $\begin{array}{l}\text { Sales } \\
\text { Share }\end{array}$ & $\begin{array}{l}95 \% \\
\text { Confidence } \\
\text { Interval }\end{array}$ \\
\hline \multirow{2}{*}{2011} & Smart Fortwo Electric Drive Cabriolet & 17.6 & 63 & 390 & 1960 & BK9 & $10 \%$ & $(-1 \%,+1 \%)$ \\
\hline & Smart Fortwo Electric Drive Coupe & 17.6 & 63 & 390 & 1960 & BJ9 & $90 \%$ & $(-1 \%,+1 \%)$ \\
\hline \multirow{2}{*}{2013} & Smart Fortwo Electric Drive Convertible & 17.6 & 68 & 320 & 2110 & DK9 & $6 \%$ & $(-1 \%,+1 \%)$ \\
\hline & Smart Fortwo Electric Drive Coupe & 17.6 & 68 & 320 & 2110 & DJ9 & $94 \%$ & $(-1 \%,+1 \%)$ \\
\hline \multirow{2}{*}{2014} & Smart Fortwo Electric Drive Convertible & 17.6 & 68 & 320 & 2140 & EK9 & $10 \%$ & $(-1 \%,+1 \%)$ \\
\hline & Smart Fortwo Electric Drive Coupe & 17.6 & 68 & 320 & 2090 & EJ9 & $90 \%$ & $(-1 \%,+1 \%)$ \\
\hline \multirow{2}{*}{2015} & Smart Fortwo Electric Drive Convertible & 17.6 & 68 & 315 & 2140 & FK9 & $3 \%$ & $(-0 \%,+1 \%)$ \\
\hline & Smart Fortwo Electric Drive Coupe & 17.6 & 68 & 315 & 2090 & FJ9 & $97 \%$ & $(-1 \%,+0 \%)$ \\
\hline \multirow{2}{*}{2016} & Smart Fortwo Electric Drive Convertible & 17.6 & 68 & 315 & 2140 & FK9 & $0 \%$ & \\
\hline & Smart Fortwo Electric Drive Coupe & 17.6 & 68 & 315 & 2090 & GJ9 & $100 \%$ & \\
\hline \multirow{2}{*}{2017} & Smart Fortwo Electric Drive Convertible & 17.6 & 57 & 330 & 2380 & HK9 & $13 \%$ & $(-2 \%,+2 \%)$ \\
\hline & Smart Fortwo Electric Drive Coupe & 17.6 & 58 & 310 & 2360 & HJ9 & $87 \%$ & $(-2 \%,+2 \%)$ \\
\hline \multirow{2}{*}{2018} & Smart Fortwo Electric Drive Convertible & 17.6 & 57 & 330 & 2380 & JK9 & $13 \%$ & $(-1 \%,+1 \%)$ \\
\hline & Smart Fortwo Electric Drive Coupe & 17.6 & 58 & 310 & 2360 & JJ9 & $87 \%$ & $(-1 \%,+1 \%)$ \\
\hline \multirow{2}{*}{2019} & Smart Fortwo Electric Drive Convertible & 17.6 & 57 & 330 & 2380 & KK9 & $7 \%$ & $(-2 \%,+3 \%)$ \\
\hline & Smart Fortwo Electric Drive Coupe & 17.6 & 58 & 310 & 2360 & KJ9 & $93 \%$ & $(-3 \%,+2 \%)$ \\
\hline
\end{tabular}

\section{TABLE A11 Tesla Model 3 Trim Variant Distribution}

\begin{tabular}{|c|c|c|c|c|c|c|c|c|}
\hline Year & Trim Variant & $\begin{array}{l}\text { Battery } \\
(\mathbf{k W h})\end{array}$ & $\begin{array}{l}\text { Range } \\
\text { (mi) }\end{array}$ & $\begin{array}{l}\text { Fuel } \\
\text { Economy } \\
\text { (Wh/mi) }\end{array}$ & $\begin{array}{l}\text { Curb } \\
\text { Weight } \\
\text { (lb) }\end{array}$ & $\begin{array}{l}\text { VIN } \\
\text { Descriptor }\end{array}$ & $\begin{array}{l}\text { Sales } \\
\text { Share }\end{array}$ & $\begin{array}{l}95 \% \\
\text { Confidence } \\
\text { Interval }\end{array}$ \\
\hline 2017 & Model 3 Long Range & 79.5 & 310 & 268 & 3840 & H3EA & $100 \%$ & \\
\hline \multirow{4}{*}{2018} & Model 3 Mid Range & 65.0 & 360 & 275 & 3690 & \multirow{2}{*}{ J3EA } & $9 \%$ & $(-0 \%,+0 \%)$ \\
\hline & Model 3 Long Range & 79.5 & 310 & 259 & 3840 & & $48 \%$ & $(-0 \%,+0 \%)$ \\
\hline & Model 3 Long Range AWD & 79.5 & 310 & 289 & 4070 & \multirow{2}{*}{ J3EB } & $34 \%$ & $(-0 \%,+0 \%)$ \\
\hline & Model 3 Long Range AWD Performance & 79.5 & 310 & 289 & 4100 & & $9 \%$ & $(-0 \%,+0 \%)$ \\
\hline \multirow{6}{*}{2019} & Model 3 Standard Range & 53.6 & 220 & 257 & 3550 & \multirow{4}{*}{ K3EA } & $39 \%$ & $(-0 \%,+0 \%)$ \\
\hline & Model 3 Standard Range Plus & 53.6 & 240 & 254 & 3550 & & $13 \%$ & $(-2 \%,+2 \%)$ \\
\hline & Model 3 Mid Range & 65.0 & 264 & 275 & 3690 & & $0 \%$ & $(-1 \%,+1 \%)$ \\
\hline & Model 3 Long Range & 79.5 & 310 & 259 & 3840 & & $4 \%$ & $(-1 \%,+1 \%)$ \\
\hline & Model 3 Long Range AWD & 79.5 & 310 & 289 & 4070 & \multirow{2}{*}{ K3EB } & $35 \%$ & $(-0 \%,+0 \%)$ \\
\hline & Model 3 Long Range AWD Performance & 79.5 & 310 & 289 & 4100 & & $9 \%$ & $(-0 \%,+0 \%)$ \\
\hline \multirow{8}{*}{2020} & Model 3 Standard Range & 53.6 & 220 & 257 & 3550 & \multirow{4}{*}{ L3EA } & $12 \%$ & $(-0 \%,+0 \%)$ \\
\hline & Model 3 Standard Range Plus & 53.6 & 250 & 240 & 3550 & & $34 \%$ & $(-0 \%,+0 \%)$ \\
\hline & Model 3 Mid Range & 65.0 & 264 & 275 & 3690 & & $0 \%$ & $(-0 \%,+0 \%)$ \\
\hline & Model 3 Long Range & 80.5 & 330 & 259 & 3870 & & $0 \%$ & $(-0 \%,+0 \%)$ \\
\hline & Model 3 Long Range AWD & 80.5 & 322 & 280 & 4100 & L3EB & $42 \%$ & $(-0 \%,+0 \%)$ \\
\hline & $\begin{array}{l}\text { Model } 3 \text { Long Range Performance AWD } \\
\text { (18in) }\end{array}$ & 80.5 & 322 & 280 & 4100 & \multirow{3}{*}{ L3EC } & $4 \%$ & $(-0 \%,+0 \%)$ \\
\hline & $\begin{array}{l}\text { Model } 3 \text { Long Range Performance AWD } \\
\text { (19in) }\end{array}$ & 80.5 & 204 & 291 & 4100 & & $4 \%$ & $(-0 \%,+0 \%)$ \\
\hline & $\begin{array}{l}\text { Model } 3 \text { Long Range Performance AWD } \\
\text { (20in) }\end{array}$ & 80.5 & 299 & 299 & 4100 & & $4 \%$ & $(-0 \%,+0 \%)$ \\
\hline
\end{tabular}


TABLE A12 Tesla Model S Trim Variant Distribution

\begin{tabular}{|c|c|c|c|c|c|c|c|c|}
\hline Year & Trim Variant & $\begin{array}{l}\text { Battery } \\
\text { (kWh) }\end{array}$ & $\begin{array}{l}\text { Range } \\
\text { (mi) }\end{array}$ & $\begin{array}{l}\text { Fuel } \\
\text { Economy } \\
(\mathbf{W h} / \mathbf{m i})\end{array}$ & $\begin{array}{l}\text { Curb } \\
\text { Weight } \\
\text { (lb) }\end{array}$ & $\begin{array}{l}\text { VIN } \\
\text { Descriptors }\end{array}$ & $\begin{array}{l}\text { Sales } \\
\text { Share }\end{array}$ & $\begin{array}{l}95 \% \\
\text { Confidence } \\
\text { Interval }\end{array}$ \\
\hline \multirow{2}{*}{2012} & Model S & 81.5 & 265 & 380 & 4650 & $\begin{array}{l}\mathrm{CSCN} \\
\mathrm{CSDN}\end{array}$ & $39 \%$ & $(-1 \%,+1 \%)$ \\
\hline & $\begin{array}{l}\text { Model S: } \\
\text { performance model not in DOE/EPA database }\end{array}$ & 81.5 & 265 & 380 & 4650 & $\begin{array}{l}\text { CSCP, } \\
\text { CSDP }\end{array}$ & $61 \%$ & $(-1 \%,+1 \%)$ \\
\hline \multirow{4}{*}{2013} & Model S (40 kW-hr battery pack) & $61^{*}$ & 139 & 360 & 4410 & $\begin{array}{l}\text { DSAC, } \\
\text { DSBC }\end{array}$ & $4 \%$ & $(-0 \%,+0 \%)$ \\
\hline & Model S (60 kW-hr battery pack) & 61 & 208 & 350 & 4410 & $\mathrm{DS} * \mathrm{G}$ & $22 \%$ & $(-0 \%,+0 \%)$ \\
\hline & Model S (85 kW-hr battery pack) & 81.5 & 265 & 380 & 4650 & $\mathrm{DS} * \mathrm{~N}$ & $38 \%$ & $(-0 \%,+0 \%)$ \\
\hline & $\begin{array}{l}\text { Model S ( } 85 \mathrm{~kW}-\mathrm{hr} \text { battery pack): } \\
\text { performance model not in DOE/EPA database }\end{array}$ & 81.5 & 265 & 380 & 4650 & $\mathrm{DS} * \mathrm{P}$ & $36 \%$ & $(-0 \%,+0 \%)$ \\
\hline \multirow{3}{*}{2014} & Model S (60 kW-hr battery pack) & 61 & 208 & 350 & 4410 & ESS1 & $15 \%$ & $(-0 \%,+0 \%)$ \\
\hline & Model S (85 kW-hr battery pack) & 81.5 & 265 & 380 & 4650 & ESH1 & $74 \%$ & $(-0 \%,+0 \%)$ \\
\hline & Model S AWD (85 kW-hr battery pack) & 81.5 & 242 & 380 & 4940 & $\mathrm{ESH} 2$ & $12 \%$ & $(-0 \%,+0 \%)$ \\
\hline \multirow{8}{*}{2015} & Model S (60 kW-hr battery pack) & 61 & 208 & 350 & 4410 & FSS1, FSE1 & $5 \%$ & $(-0 \%,+0 \%)$ \\
\hline & Model S (85 kW-hr battery pack) & 81.5 & 265 & 308 & 4630 & $\begin{array}{l}\text { FSH1, } \\
\text { FSE1 }\end{array}$ & $13 \%$ & $(-0 \%,+0 \%)$ \\
\hline & Model S (90 kW-hr battery pack) & 85.8 & 265 & 380 & 4630 & $\begin{array}{l}\text { FSV1, } \\
\text { FSE1 }\end{array}$ & $3 \%$ & $(-0 \%,+0 \%)$ \\
\hline & Model S AWD - 70D & 71.2 & 240 & 330 & 4720 & FSS2, FSE2 & $18 \%$ & $(-0 \%,+0 \%)$ \\
\hline & Model S AWD - 85D & 81.5 & 270 & 340 & 4850 & $\begin{array}{l}\text { FSH2, } \\
\text { FSE2 }\end{array}$ & $43 \%$ & $(-0 \%,+0 \%)$ \\
\hline & Model S AWD - 90D & 85.8 & 270 & 340 & 4850 & $\begin{array}{l}\text { FSV2, } \\
\text { FSE2 }\end{array}$ & $4 \%$ & $(-0 \%,+0 \%)$ \\
\hline & Model S AWD - P85D & 81.5 & 253 & 360 & 4960 & $\begin{array}{l}\text { FSH4, } \\
\text { FSE4 }\end{array}$ & $11 \%$ & $(-0 \%,+0 \%)$ \\
\hline & Model S AWD - P90D & 85.8 & 253 & 360 & 4960 & $\begin{array}{l}\text { FSV4, } \\
\text { FSE4 }\end{array}$ & $3 \%$ & $(-0 \%,+0 \%)$ \\
\hline \multirow{13}{*}{2016} & Model S (60 kW-hr battery pack) & $75^{*}$ & 210 & 340 & 4470 & \multirow{5}{*}{ GSE1 } & $3 \%$ & $(-0 \%,+0 \%)$ \\
\hline & Model S (70 kW-hr battery pack) & 71.2 & 234 & 380 & 4560 & & $7 \%$ & $(-0 \%,+0 \%)$ \\
\hline & Model S (75 kW-hr battery pack) & 75 & 249 & 340 & 4470 & & $13 \%$ & $(-0 \%,+0 \%)$ \\
\hline & Model S (85 kW-hr battery pack) & 81.5 & 265 & 380 & 4550 & & $2 \%$ & $(-0 \%,+0 \%)$ \\
\hline & Model S (90 kW-hr battery pack) & 85.8 & 265 & 380 & 4630 & & $2 \%$ & $(-0 \%,+0 \%)$ \\
\hline & Model S AWD - 60D & $75^{*}$ & 218 & 320 & 4770 & \multirow{5}{*}{ GSE2 } & $1 \%$ & $(-0 \%,+0 \%)$ \\
\hline & Model S AWD - 70D & 71.2 & 240 & 330 & 4720 & & $8 \%$ & $(-0 \%,+0 \%)$ \\
\hline & Model S AWD - 75D & 75 & 259 & 330 & 4770 & & $11 \%$ & $(-0 \%,+0 \%)$ \\
\hline & Model S AWD - 85D & 81.5 & 270 & 340 & 4850 & & $7 \%$ & $(-0 \%,+0 \%)$ \\
\hline & Model S AWD - 90D & 85.8 & 294 & 330 & 4870 & & $33 \%$ & $(-0 \%,+0 \%)$ \\
\hline & Model S AWD - P85D & 81.5 & 253 & 360 & 4840 & \multirow{3}{*}{ GSE4 } & $2 \%$ & $(-0 \%,+0 \%)$ \\
\hline & Model S AWD - P90D & 85.8 & 270 & 350 & 4870 & & $9 \%$ & $(-0 \%,+0 \%)$ \\
\hline & Model S AWD - P100D & 102.4 & 315 & 350 & 4940 & & $1 \%$ & $(-0 \%,+0 \%)$ \\
\hline
\end{tabular}


TABLE A12 (Cont.)

\begin{tabular}{|c|c|c|c|c|c|c|c|c|}
\hline Year & Trim Variant & $\begin{array}{l}\text { Battery } \\
(\mathbf{k W h})\end{array}$ & $\begin{array}{l}\text { Range } \\
\text { (mi) }\end{array}$ & $\begin{array}{l}\text { Fuel } \\
\text { Economy } \\
(\mathrm{Wh} / \mathrm{mi})\end{array}$ & $\begin{array}{l}\text { Curb } \\
\text { Weight } \\
\text { (lb) }\end{array}$ & $\begin{array}{l}\text { VIN } \\
\text { Descriptors }\end{array}$ & $\begin{array}{l}\text { Sales } \\
\text { Share }\end{array}$ & $\begin{array}{l}95 \% \\
\text { Confidence } \\
\text { Interval }\end{array}$ \\
\hline \multirow{8}{*}{2017} & Model S (60 kW-hr battery pack) & $75^{*}$ & 210 & 340 & 4470 & \multirow{2}{*}{ HSE1 } & $3 \%$ & $(-0 \%,+0 \%)$ \\
\hline & Model S (75 kW-hr battery pack) & 75 & 249 & 340 & 4470 & & $20 \%$ & $(-1 \%,+1 \%)$ \\
\hline & Model S AWD - 60D & $75^{*}$ & 218 & 320 & 4770 & \multirow{4}{*}{ HSE2 } & $2 \%$ & $(-0 \%,+0 \%)$ \\
\hline & Model S AWD - 75D & 75 & 259 & 330 & 4770 & & $41 \%$ & $(-1 \%,+1 \%)$ \\
\hline & Model S AWD - 90D & 85.8 & 294 & 320 & 4850 & & $16 \%$ & $(-0 \%,+0 \%)$ \\
\hline & Model S AWD - 100D & 102.4 & 335 & 330 & 4880 & & $13 \%$ & $(-0 \%,+0 \%)$ \\
\hline & Model S AWD - P90D & 85.8 & 270 & 350 & 4870 & \multirow{2}{*}{ HSE4 } & $0 \%$ & $(-0 \%,+0 \%)$ \\
\hline & Model S AWD - P100D & 102.4 & 315 & 350 & 4940 & & $6 \%$ & $(-0 \%,+0 \%)$ \\
\hline \multirow{4}{*}{2018} & Model S 75kWh & 75 & 249 & 342 & 4470 & JSE1 & $0 \%$ & $(-0 \%,+0 \%)$ \\
\hline & Model S 75D & 75 & 259 & 326 & 4770 & \multirow{2}{*}{ JSE2 } & $67 \%$ & $(-1 \%,+1 \%)$ \\
\hline & Model S 100D & 102.4 & 335 & 332 & 4880 & & $24 \%$ & $(-1 \%,+1 \%)$ \\
\hline & Model S P100D & 102.4 & 315 & 346 & 4940 & JSE4 & $9 \%$ & $(-0 \%,+0 \%)$ \\
\hline \multirow{7}{*}{2019} & Model S 75D & 75 & 259 & 326 & 4770 & \multirow{4}{*}{ KSE2 } & $25 \%$ & $(-2 \%,+2 \%)$ \\
\hline & Model S 100D & 102.4 & 335 & 332 & 4880 & & $28 \%$ & $(-2 \%,+2 \%)$ \\
\hline & Model S Standard Range & 75 & 285 & 308 & 4770 & & $3 \%$ & $(-1 \%,+1 \%)$ \\
\hline & Model S Long Range & 102.4 & 370 & 303 & 4880 & & $25 \%$ & $(-2 \%,+2 \%)$ \\
\hline & Model S P100D & 102.4 & 315 & 346 & 4940 & \multirow{3}{*}{ KSE4 } & $5 \%$ & $(-1 \%,+1 \%)$ \\
\hline & Model S Performance (19in Wheels) & 102.4 & 345 & 324 & 4940 & & $7 \%$ & $(-1 \%,+1 \%)$ \\
\hline & Model S Performance (21in Wheels) & 102.4 & 325 & 347 & 4940 & & $7 \%$ & $(-1 \%,+1 \%)$ \\
\hline \multirow{5}{*}{2020} & Model S Standard Range & 75 & 287 & 308 & 4770 & \multirow{3}{*}{ LSE2 } & $0 \%$ & $(-0 \%,+0 \%)$ \\
\hline & Model S Long Range & 102.4 & 373 & 303 & 4880 & & $64 \%$ & $(-2 \%,+2 \%)$ \\
\hline & Model S Long Range Plus & 102.4 & 402 & 289 & 4880 & & $18 \%$ & $(-2 \%,+2 \%)$ \\
\hline & Model S Performance (19in Wheels) & 102.4 & 348 & 324 & 4940 & \multirow{2}{*}{ LSE4 } & $9 \%$ & $(-1 \%,+1 \%)$ \\
\hline & Model S Performance (21in Wheels) & 102.4 & 326 & 347 & 4940 & & $9 \%$ & $(-1 \%,+1 \%)$ \\
\hline
\end{tabular}

* Software-limited battery 
TABLE A13 Tesla Model X Trim Variant Distribution

\begin{tabular}{|c|c|c|c|c|c|c|c|c|}
\hline Year & Trim Variant & $\begin{array}{l}\text { Battery } \\
\text { (kWh) }\end{array}$ & $\begin{array}{l}\text { Range } \\
\text { (mi) }\end{array}$ & $\begin{array}{l}\text { Fuel } \\
\text { Economy } \\
\text { (Wh/mi) }\end{array}$ & $\begin{array}{l}\text { Curb } \\
\text { Weight } \\
\text { (lb) }\end{array}$ & $\begin{array}{l}\text { VIN } \\
\text { Descriptor }\end{array}$ & $\begin{array}{l}\text { Sales } \\
\text { Share }\end{array}$ & $\begin{array}{l}\mathbf{9 5 \%} \\
\text { Confidence } \\
\text { Interval }\end{array}$ \\
\hline \multirow{5}{*}{2016} & Model X AWD - 60D & $75^{*}$ & 200 & 360 & 5190 & \multirow{3}{*}{ GXE2 } & $1 \%$ & $(-0 \%,+0 \%)$ \\
\hline & Model X AWD - 75D & 75 & 238 & 360 & 5190 & & $13 \%$ & $(-0 \%,+0 \%)$ \\
\hline & Model X AWD - 90D & 85.8 & 257 & 370 & 5270 & & $58 \%$ & $(-1 \%,+1 \%)$ \\
\hline & Model X AWD - P90D & 85.8 & 250 & 350 & 5380 & \multirow{2}{*}{ GXE4 } & $24 \%$ & $(-1 \%,+1 \%)$ \\
\hline & Model X AWD - P100D & 102.4 & 289 & 360 & 5480 & & $4 \%$ & $(-0 \%,+0 \%)$ \\
\hline \multirow{6}{*}{2017} & Model X AWD - 60D & $75^{*}$ & 200 & 360 & 5190 & \multirow{4}{*}{ HXE2 } & $1 \%$ & $(-0 \%,+0 \%)$ \\
\hline & Model X AWD - 75D & 75 & 238 & 360 & 5190 & & $37 \%$ & $(-1 \%,+1 \%)$ \\
\hline & Model X AWD - 90D & 85.8 & 257 & 370 & 5270 & & $25 \%$ & $(-1 \%,+1 \%)$ \\
\hline & Model X AWD - 100D & 102.4 & 295 & 387 & 5420 & & $29 \%$ & $(-1 \%,+1 \%)$ \\
\hline & Model X AWD - P90D & 85.8 & 250 & 380 & 5380 & \multirow{2}{*}{ HXE4 } & $1 \%$ & $(-0 \%,+0 \%)$ \\
\hline & Model X AWD - P100D & 102.4 & 289 & 390 & 5530 & & $8 \%$ & $(-0 \%,+1 \%)$ \\
\hline \multirow{3}{*}{2018} & Model X 75D & 75 & 238 & 362 & 5310 & \multirow{2}{*}{ JXE2 } & $39 \%$ & $(-1 \%,+1 \%)$ \\
\hline & Model X 100D & 102.4 & 295 & 387 & 5420 & & $54 \%$ & $(-1 \%,+1 \%)$ \\
\hline & Model X P100D & 102.4 & 289 & 395 & 5530 & JXE4 & $8 \%$ & $(-0 \%,+0 \%)$ \\
\hline \multirow{5}{*}{2019} & Model X 75D & 75 & 238 & 362 & 5310 & \multirow{3}{*}{ KXE2 } & $17 \%$ & $(-1 \%,+1 \%)$ \\
\hline & Model X 100D & 102.4 & 295 & 387 & 5420 & & $27 \%$ & $(-1 \%,+1 \%)$ \\
\hline & Model X Long Range & 102.4 & 325 & 350 & 5420 & & $40 \%$ & $(-1 \%,+2 \%)$ \\
\hline & Model X P100D & 102.4 & 289 & 395 & 5530 & \multirow{2}{*}{ KXE4 } & $3 \%$ & $(-1 \%,+1 \%)$ \\
\hline & Model X Performance (22in Wheels) & 102.4 & 270 & 428 & 5530 & & $13 \%$ & $(-1 \%,+1 \%)$ \\
\hline \multirow{5}{*}{2020} & Model X Standard Range & 75 & 258 & 333 & 5310 & \multirow{3}{*}{ LXE2 } & $0 \%$ & $(-0 \%,+0 \%)$ \\
\hline & Model X Long Range & 102.4 & 328 & 350 & 5420 & & $60 \%$ & $(-2 \%,+2 \%)$ \\
\hline & Model X Long Range Plus & 102.4 & 351 & 322 & 5420 & & $26 \%$ & $(-1 \%,+1 \%)$ \\
\hline & Model X Performance (20in Wheels) & 102.4 & 305 & 376 & 5530 & \multirow{2}{*}{ LXE4 } & $7 \%$ & $(-1 \%,+1 \%)$ \\
\hline & Model X Performance (22in Wheels) & 102.4 & 272 & 428 & 5530 & & $7 \%$ & $(-1 \%,+1 \%)$ \\
\hline
\end{tabular}

* Software-limited battery

TABLE A14 Tesla Model Y Trim Variant Distribution

\begin{tabular}{|c|c|c|c|c|c|c|c|c|}
\hline Year & Trim Variant & $\begin{array}{l}\text { Battery } \\
\text { (kWh) }\end{array}$ & $\begin{array}{l}\text { Range } \\
\text { (mi) }\end{array}$ & $\begin{array}{l}\text { Fuel } \\
\text { Economy } \\
\text { (Wh/mi) }\end{array}$ & $\begin{array}{l}\text { Curb } \\
\text { Weight } \\
\text { (lb) }\end{array}$ & $\begin{array}{l}\text { VIN } \\
\text { Descriptor }\end{array}$ & $\begin{array}{l}\text { Sales } \\
\text { Share }\end{array}$ & $\begin{array}{l}95 \% \\
\text { Confidence } \\
\text { Interval }\end{array}$ \\
\hline \multirow{3}{*}{2020} & Model Y Long Range AWD & 74 & 316 & 279 & 4420 & LYEE & $66 \%$ & $(-0 \%,+0 \%)$ \\
\hline & Model Y Performance AWD & 74 & 315 & 280 & 4420 & \multirow{2}{*}{ LYEF } & $17 \%$ & $(-0 \%,+0 \%)$ \\
\hline & Model Y Performance AWD (21in wheels) & 74 & 291 & 304 & 4420 & & $17 \%$ & $(-0 \%,+0 \%)$ \\
\hline
\end{tabular}




\section{APPENDIX B: SHARE OF TESLA MODELS BY TRIM VARIANT}

This Appendix contains tables listing the distribution of Tesla models by trim variant in accordance with the current market weighting described in the Tesla sensitivity analysis, along with the trim distribution for each of the main sensitivity cases from Section 4.

\section{TABLE B1 Tesla Model S Trim Variant Distribution}

\begin{tabular}{|c|c|c|c|c|c|c|c|c|}
\hline Year & Trim Variant & $\begin{array}{c}\text { VIN } \\
\text { Descriptor }\end{array}$ & $\begin{array}{l}\text { VIN } \\
\text { Descriptor } \\
\text { Proportion }\end{array}$ & Baseline & $\begin{array}{l}\text { Absolute } \\
\text { Minimum }\end{array}$ & $\begin{array}{l}\text { Absolute } \\
\text { Maximum }\end{array}$ & $\begin{array}{l}\text { Population } \\
\text { Weighted }\end{array}$ & $\begin{array}{l}\text { Even } \\
\text { Spread }\end{array}$ \\
\hline \multirow[b]{2}{*}{2012} & Model S & $\mathrm{CS}-\mathrm{C} / \mathrm{G} / \mathrm{N}$ & $39.4 \%$ & $39.4 \%$ & $39.4 \%$ & $39.4 \%$ & $39.4 \%$ & $39.4 \%$ \\
\hline & $\begin{array}{l}\text { Model S: performance model not } \\
\text { listed in DOE/EPA database }\end{array}$ & CS-P & $60.6 \%$ & $60.6 \%$ & $60.6 \%$ & $60.6 \%$ & $60.6 \%$ & $60.6 \%$ \\
\hline \multirow{4}{*}{2013} & Model S (40 kW-hr battery pack) & DS-C & $4.1 \%$ & $4.1 \%$ & $4.1 \%$ & $4.1 \%$ & $4.1 \%$ & $4.1 \%$ \\
\hline & Model S (60 kW-hr battery pack) & DS-G & $22.4 \%$ & $22.4 \%$ & $22.4 \%$ & $22.4 \%$ & $22.4 \%$ & $22.4 \%$ \\
\hline & Model S (85 kW-hr battery pack) & DS-N & $38.0 \%$ & $38.0 \%$ & $38.0 \%$ & $38.0 \%$ & $38.0 \%$ & $38.0 \%$ \\
\hline & $\begin{array}{l}\text { Model S ( } 85 \mathrm{~kW}-\mathrm{hr} \text { battery pack): } \\
\text { performance model not listed in } \\
\text { DOE/EPA database }\end{array}$ & DS-P & $35.5 \%$ & $35.5 \%$ & $35.5 \%$ & $35.5 \%$ & $35.5 \%$ & $35.5 \%$ \\
\hline \multirow{3}{*}{2014} & Model S (60 kW-hr battery pack) & ESS1 & $14.5 \%$ & $14.5 \%$ & $14.5 \%$ & $14.5 \%$ & $14.5 \%$ & $14.5 \%$ \\
\hline & Model S (85 kW-hr battery pack) & ESH1 & $73.8 \%$ & $73.8 \%$ & $73.8 \%$ & $73.8 \%$ & $73.8 \%$ & $73.8 \%$ \\
\hline & $\begin{array}{l}\text { Model S AWD ( } 85 \mathrm{~kW} \text {-hr battery } \\
\text { pack) }\end{array}$ & $\mathrm{ESH} 2$ & $11.7 \%$ & $11.7 \%$ & $11.7 \%$ & $11.7 \%$ & $11.7 \%$ & $11.7 \%$ \\
\hline \multirow{16}{*}{2015} & \multirow{2}{*}{ Model S (60 kW-hr battery pack) } & FSS1 & $3.5 \%$ & $3.5 \%$ & $3.5 \%$ & $3.5 \%$ & $3.5 \%$ & $3.5 \%$ \\
\hline & & FSE1 & $8.8 \%$ & $1.7 \%$ & $8.8 \%$ & $0.0 \%$ & $5.9 \%$ & $2.9 \%$ \\
\hline & \multirow{2}{*}{ Model S (85 kW-hr battery pack) } & FSH1 & $8.1 \%$ & $8.1 \%$ & $8.1 \%$ & $8.1 \%$ & $8.1 \%$ & $8.1 \%$ \\
\hline & & FSE1 & $8.8 \%$ & $4.5 \%$ & $0.0 \%$ & $0.0 \%$ & $2.4 \%$ & $2.9 \%$ \\
\hline & \multirow{2}{*}{ Model S (90 kW-hr battery pack) } & FSV1 & $0.1 \%$ & $0.1 \%$ & $0.1 \%$ & $0.1 \%$ & $0.1 \%$ & $0.1 \%$ \\
\hline & & FSE1 & $8.8 \%$ & $2.6 \%$ & $0.0 \%$ & $8.8 \%$ & $0.6 \%$ & $2.9 \%$ \\
\hline & \multirow{2}{*}{ Model S AWD - 70D } & FSS2 & $13.2 \%$ & $13.2 \%$ & $13.2 \%$ & $13.2 \%$ & $13.2 \%$ & $13.2 \%$ \\
\hline & & FSE2 & $23.0 \%$ & $5.2 \%$ & $23.0 \%$ & $0.0 \%$ & $5.9 \%$ & $7.7 \%$ \\
\hline & \multirow{2}{*}{ Model S AWD - 85D } & FSH2 & $28.2 \%$ & $28.2 \%$ & $28.2 \%$ & $28.2 \%$ & $28.2 \%$ & $28.2 \%$ \\
\hline & & FSE2 & $23.0 \%$ & $14.7 \%$ & $0.0 \%$ & $0.0 \%$ & $11.5 \%$ & $7.7 \%$ \\
\hline & \multirow{2}{*}{ Model S AWD - 90D } & FSV2 & $1.2 \%$ & $1.2 \%$ & $1.2 \%$ & $1.2 \%$ & $1.2 \%$ & $1.2 \%$ \\
\hline & & FSE2 & $23.0 \%$ & $3.1 \%$ & $0.0 \%$ & $23.0 \%$ & $5.6 \%$ & $7.7 \%$ \\
\hline & \multirow{2}{*}{ Model S AWD - P85D } & FSH4 & $7.3 \%$ & $7.3 \%$ & $7.3 \%$ & $7.3 \%$ & $7.3 \%$ & $7.3 \%$ \\
\hline & & FSE4 & $5.8 \%$ & $3.9 \%$ & $5.8 \%$ & $0.0 \%$ & $4.8 \%$ & $2.9 \%$ \\
\hline & \multirow{2}{*}{ Model S AWD - P90D } & FSV4 & $0.9 \%$ & $0.9 \%$ & $0.9 \%$ & $0.9 \%$ & $0.9 \%$ & $0.9 \%$ \\
\hline & & FSE4 & $5.8 \%$ & $1.8 \%$ & $0.0 \%$ & $5.8 \%$ & $1.0 \%$ & $2.9 \%$ \\
\hline
\end{tabular}


TABLE B1 (Cont.)

\begin{tabular}{|c|c|c|c|c|c|c|c|c|}
\hline Year & Trim Variant & $\begin{array}{c}\text { VIN } \\
\text { Descriptor }\end{array}$ & $\begin{array}{c}\text { VIN } \\
\text { Descriptor } \\
\text { Proportion }\end{array}$ & Baseline & $\begin{array}{l}\text { Absolute } \\
\text { Minimum }\end{array}$ & $\begin{array}{l}\text { Absolute } \\
\text { Maximum }\end{array}$ & $\begin{array}{l}\text { Population } \\
\text { Weighted }\end{array}$ & $\begin{array}{l}\text { Even } \\
\text { Spread }\end{array}$ \\
\hline \multirow{13}{*}{2016} & Model S (60 kW-hr battery pack) & \multirow{5}{*}{ GSE1 } & \multirow{5}{*}{$27.2 \%$} & $3.2 \%$ & $27.2 \%$ & $0.0 \%$ & $3.9 \%$ & $5.4 \%$ \\
\hline & Model S (70 kW-hr battery pack) & & & $7.4 \%$ & $0.0 \%$ & $0.0 \%$ & $11.5 \%$ & $5.4 \%$ \\
\hline & Model S (75 kW-hr battery pack) & & & $13.0 \%$ & $0.0 \%$ & $0.0 \%$ & $9.1 \%$ & $5.4 \%$ \\
\hline & Model S ( $85 \mathrm{~kW}$-hr battery pack) & & & $1.9 \%$ & $0.0 \%$ & $0.0 \%$ & $1.4 \%$ & $5.4 \%$ \\
\hline & Model S (90 kW-hr battery pack) & & & $1.8 \%$ & $0.0 \%$ & $27.2 \%$ & $1.3 \%$ & $5.4 \%$ \\
\hline & Model S AWD - 60D & \multirow{5}{*}{ GSE2 } & \multirow{5}{*}{$60.3 \%$} & $1.2 \%$ & $60.3 \%$ & $0.0 \%$ & $1.6 \%$ & $12.1 \%$ \\
\hline & Model S AWD - 70D & & & $7.7 \%$ & $0.0 \%$ & $0.0 \%$ & $7.3 \%$ & $12.1 \%$ \\
\hline & Model S AWD - 75D & & & $11.5 \%$ & $0.0 \%$ & $0.0 \%$ & $8.2 \%$ & $12.1 \%$ \\
\hline & Model S AWD - 85D & & & $7.3 \%$ & $0.0 \%$ & $0.0 \%$ & $10.6 \%$ & $12.1 \%$ \\
\hline & Model S AWD - 90D & & & $32.5 \%$ & $0.0 \%$ & $60.3 \%$ & $32.5 \%$ & $12.1 \%$ \\
\hline & Model S AWD - P85D & \multirow{3}{*}{ GSE4 } & \multirow{3}{*}{$12.5 \%$} & $2.4 \%$ & $12.5 \%$ & $0.0 \%$ & $4.3 \%$ & $4.2 \%$ \\
\hline & Model S AWD - P90D & & & $8.9 \%$ & $0.0 \%$ & $0.0 \%$ & $6.5 \%$ & $4.2 \%$ \\
\hline & Model S AWD - P100D & & & $1.3 \%$ & $0.0 \%$ & $12.5 \%$ & $1.7 \%$ & $4.2 \%$ \\
\hline \multirow{8}{*}{2017} & Model S (60 kW-hr battery pack) & \multirow{2}{*}{ HSE1 } & \multirow{2}{*}{$23.1 \%$} & $2.7 \%$ & $23.1 \%$ & $0.0 \%$ & $4.0 \%$ & $11.6 \%$ \\
\hline & Model S (75 kW-hr battery pack) & & & $20.5 \%$ & $0.0 \%$ & $23.1 \%$ & $19.1 \%$ & $11.6 \%$ \\
\hline & Model S AWD - 60D & \multirow{4}{*}{ HSE2 } & \multirow{4}{*}{$71.1 \%$} & $2.1 \%$ & $71.1 \%$ & $0.0 \%$ & $3.8 \%$ & $17.8 \%$ \\
\hline & Model S AWD - 75D & & & $40.8 \%$ & $0.0 \%$ & $0.0 \%$ & $33.1 \%$ & $17.8 \%$ \\
\hline & Model S AWD - 90D & & & $15.6 \%$ & $0.0 \%$ & $0.0 \%$ & $19.7 \%$ & $17.8 \%$ \\
\hline & Model S AWD - 100D & & & $12.6 \%$ & $0.0 \%$ & $71.1 \%$ & $14.5 \%$ & $17.8 \%$ \\
\hline & Model S AWD - P90D & \multirow{2}{*}{ HSE4 } & \multirow{2}{*}{$5.8 \%$} & $0.1 \%$ & $5.8 \%$ & $0.0 \%$ & $0.2 \%$ & $2.9 \%$ \\
\hline & Model S AWD - P100D & & & $5.7 \%$ & $0.0 \%$ & $5.8 \%$ & $5.6 \%$ & $2.9 \%$ \\
\hline \multirow{4}{*}{2018} & Model S 75kWh & JSE1 & $0.0 \%$ & $0.0 \%$ & $0.0 \%$ & $0.0 \%$ & $0.0 \%$ & $0.0 \%$ \\
\hline & Model S 75D & \multirow{2}{*}{ JSE2 } & \multirow{2}{*}{$90.6 \%$} & $66.8 \%$ & $90.6 \%$ & $0.0 \%$ & $60.9 \%$ & $45.3 \%$ \\
\hline & Model S 100D & & & $23.8 \%$ & $0.0 \%$ & $90.6 \%$ & $29.7 \%$ & $45.3 \%$ \\
\hline & Model S P100D & JSE4 & $9.3 \%$ & $9.3 \%$ & $9.3 \%$ & $9.3 \%$ & $9.3 \%$ & $9.3 \%$ \\
\hline \multirow{7}{*}{2019} & Model S 75D & \multirow{4}{*}{ KSE2 } & \multirow{4}{*}{$80.8 \%$} & $25.0 \%$ & $80.8 \%$ & $0.0 \%$ & $22.2 \%$ & $20.2 \%$ \\
\hline & Model S 100D & & & $27.8 \%$ & $0.0 \%$ & $0.0 \%$ & $26.2 \%$ & $20.2 \%$ \\
\hline & Model S Standard Range & & & $2.5 \%$ & $0.0 \%$ & $0.0 \%$ & $3.3 \%$ & $20.2 \%$ \\
\hline & Model S Long Range & & & $25.5 \%$ & $0.0 \%$ & $80.8 \%$ & $29.3 \%$ & $20.2 \%$ \\
\hline & Model S P100D & \multirow{3}{*}{ KSE4 } & \multirow{3}{*}{$19.2 \%$} & $5.3 \%$ & $19.2 \%$ & $0.0 \%$ & $6.2 \%$ & $6.4 \%$ \\
\hline & $\begin{array}{l}\text { Model S Performance (19in } \\
\text { Wheels) }\end{array}$ & & & $6.9 \%$ & $0.0 \%$ & $19.2 \%$ & $6.4 \%$ & $6.4 \%$ \\
\hline & $\begin{array}{l}\text { Model S Performance ( } 21 \text { in } \\
\text { Wheels) }\end{array}$ & & & $6.9 \%$ & $0.0 \%$ & $0.0 \%$ & $6.4 \%$ & $6.4 \%$ \\
\hline \multirow{5}{*}{2020} & Model S Standard Range & \multirow{3}{*}{ LSE2 } & \multirow{3}{*}{$82.2 \%$} & $0.0 \%$ & $82.2 \%$ & $0.0 \%$ & $0.0 \%$ & $27.4 \%$ \\
\hline & Model S Long Range & & & $63.8 \%$ & $0.0 \%$ & $0.0 \%$ & $71.4 \%$ & $27.4 \%$ \\
\hline & Model S Long Range Plus & & & $18.4 \%$ & $0.0 \%$ & $82.2 \%$ & $10.7 \%$ & $27.4 \%$ \\
\hline & $\begin{array}{l}\text { Model S Performance (19in } \\
\text { Wheels) }\end{array}$ & \multirow{2}{*}{ LSE4 } & & $8.9 \%$ & $0.0 \%$ & $17.8 \%$ & $8.9 \%$ & $8.9 \%$ \\
\hline & $\begin{array}{l}\text { Model S Performance (21in } \\
\text { Wheels) }\end{array}$ & & $17.8 \%$ & $8.9 \%$ & $17.8 \%$ & $0.0 \%$ & $8.9 \%$ & $8.9 \%$ \\
\hline
\end{tabular}


TABLE B2 Tesla Model X Trim Variant Distribution

\begin{tabular}{|c|c|c|c|c|c|c|c|c|}
\hline Year & EPA Label & $\begin{array}{c}\text { VIN } \\
\text { Descriptor }\end{array}$ & $\begin{array}{c}\text { VIN } \\
\text { Descriptor } \\
\text { Proportion }\end{array}$ & Baseline & $\begin{array}{l}\text { Absolute } \\
\text { Minimum }\end{array}$ & $\begin{array}{l}\text { Absolute } \\
\text { Maximum }\end{array}$ & $\begin{array}{l}\text { Population } \\
\text { Weighted }\end{array}$ & $\begin{array}{c}\text { Even } \\
\text { Spread }\end{array}$ \\
\hline \multirow{5}{*}{2016} & Model X AWD - 60D & \multirow{3}{*}{ GXE2 } & \multirow{3}{*}{$72.1 \%$} & $1.1 \%$ & $72.1 \%$ & $0.0 \%$ & $0.9 \%$ & $24.0 \%$ \\
\hline & Model X AWD - 75D & & & $13.4 \%$ & $0.0 \%$ & $0.0 \%$ & $4.8 \%$ & $24.0 \%$ \\
\hline & Model X AWD - 90D & & & $57.5 \%$ & $0.0 \%$ & $72.1 \%$ & $66.5 \%$ & $24.0 \%$ \\
\hline & Model X AWD - P90D & \multirow{2}{*}{ GXE4 } & \multirow{2}{*}{$27.9 \%$} & $24.1 \%$ & $27.9 \%$ & $0.0 \%$ & $7.2 \%$ & $14.0 \%$ \\
\hline & Model X AWD - P100D & & & $3.9 \%$ & $0.0 \%$ & $27.9 \%$ & $20.8 \%$ & $14.0 \%$ \\
\hline \multirow{6}{*}{2017} & Model X AWD - 60D & \multirow{4}{*}{ HXE2 } & \multirow{4}{*}{$91.3 \%$} & $0.6 \%$ & $91.3 \%$ & $0.0 \%$ & $1.4 \%$ & $22.8 \%$ \\
\hline & Model X AWD - 75D & & & $36.6 \%$ & $0.0 \%$ & $0.0 \%$ & $26.7 \%$ & $22.8 \%$ \\
\hline & Model X AWD - 90D & & & $24.8 \%$ & $0.0 \%$ & $0.0 \%$ & $33.8 \%$ & $22.8 \%$ \\
\hline & Model X AWD - 100D & & & $29.2 \%$ & $0.0 \%$ & $91.3 \%$ & $29.4 \%$ & $22.8 \%$ \\
\hline & Model X AWD - P90D & \multirow{2}{*}{ HXE4 } & \multirow{2}{*}{$8.7 \%$} & $0.5 \%$ & $8.7 \%$ & $0.0 \%$ & $0.6 \%$ & $4.4 \%$ \\
\hline & Model X AWD - P100D & & & $8.2 \%$ & $0.0 \%$ & $8.7 \%$ & $8.1 \%$ & $4.4 \%$ \\
\hline \multirow{3}{*}{2018} & Model X 75D & \multirow{2}{*}{ JXE2 } & \multirow{2}{*}{$92.4 \%$} & $38.6 \%$ & $100.0 \%$ & $0.0 \%$ & $37.0 \%$ & $46.2 \%$ \\
\hline & Model X 100D & & & $53.8 \%$ & $0.0 \%$ & $92.4 \%$ & $55.4 \%$ & $46.2 \%$ \\
\hline & Model X P100D & JXE4 & $7.6 \%$ & $7.6 \%$ & $0.0 \%$ & $7.6 \%$ & $7.6 \%$ & $7.6 \%$ \\
\hline \multirow{5}{*}{2019} & Model X 75D & \multirow{3}{*}{ KXE2 } & \multirow{3}{*}{$84.2 \%$} & $16.7 \%$ & $84.2 \%$ & $0.0 \%$ & $13.5 \%$ & $28.1 \%$ \\
\hline & Model X 100D & & & $27.1 \%$ & $0.0 \%$ & $0.0 \%$ & $25.6 \%$ & $28.1 \%$ \\
\hline & Model X Long Range & & & $40.3 \%$ & $0.0 \%$ & $84.2 \%$ & $45.1 \%$ & $28.1 \%$ \\
\hline & Model X P100D & \multirow[b]{2}{*}{ KXE4 } & \multirow[b]{2}{*}{$15.8 \%$} & $3.1 \%$ & $0.0 \%$ & $15.8 \%$ & $4.5 \%$ & $7.9 \%$ \\
\hline & $\begin{array}{l}\text { Model X Performance (22in } \\
\text { Wheels) }\end{array}$ & & & $12.8 \%$ & $15.8 \%$ & $0.0 \%$ & $11.3 \%$ & $7.9 \%$ \\
\hline \multirow{5}{*}{2020} & Model X Standard Range & \multirow{3}{*}{ LXE2 } & \multirow{3}{*}{$86.5 \%$} & $0.0 \%$ & $86.5 \%$ & $0.0 \%$ & $0.0 \%$ & $28.8 \%$ \\
\hline & Model X Long Range & & & $60.2 \%$ & $0.0 \%$ & $0.0 \%$ & $76.6 \%$ & $28.8 \%$ \\
\hline & Model X Long Range Plus & & & $26.3 \%$ & $0.0 \%$ & $86.5 \%$ & $9.9 \%$ & $28.8 \%$ \\
\hline & $\begin{array}{l}\text { Model X Performance (20in } \\
\text { Wheels) }\end{array}$ & \multirow{2}{*}{ LXE4 } & \multirow{2}{*}{$13.5 \%$} & $6.8 \%$ & $0.0 \%$ & $13.5 \%$ & $6.8 \%$ & $6.8 \%$ \\
\hline & $\begin{array}{l}\text { Model X Performance (22in } \\
\text { Wheels) }\end{array}$ & & & $6.8 \%$ & $13.5 \%$ & $0.0 \%$ & $6.8 \%$ & $6.8 \%$ \\
\hline
\end{tabular}




\section{TABLE B3 Tesla Model 3 Trim Variant Distribution}

\begin{tabular}{|c|c|c|c|c|c|c|c|c|}
\hline Year & Trim Variant & $\begin{array}{c}\text { VIN } \\
\text { Descriptor }\end{array}$ & $\begin{array}{c}\text { VIN } \\
\text { Descriptor } \\
\text { Proportion }\end{array}$ & Baseline & $\begin{array}{l}\text { Absolute } \\
\text { Minimum }\end{array}$ & $\begin{array}{l}\text { Absolute } \\
\text { Maximum }\end{array}$ & $\begin{array}{l}\text { Population } \\
\text { Weighted }\end{array}$ & $\begin{array}{l}\text { Even } \\
\text { Spread }\end{array}$ \\
\hline 2017 & Model 3 Long Range & H3EA & $100.0 \%$ & $100.0 \%$ & $100.0 \%$ & $100.0 \%$ & $100.0 \%$ & $100.0 \%$ \\
\hline \multirow{4}{*}{2018} & Model 3 Mid Range & \multirow{2}{*}{ J3EA } & \multirow{2}{*}{$56.0 \%$} & $8.6 \%$ & $56.0 \%$ & $0.0 \%$ & $8.6 \%$ & $28.0 \%$ \\
\hline & Model 3 Long Range & & & $47.3 \%$ & $0.0 \%$ & $56.0 \%$ & $47.3 \%$ & $28.0 \%$ \\
\hline & Model 3 Long Range AWD & \multirow[b]{2}{*}{$\mathrm{J} 3 \mathrm{~EB}$} & \multirow[b]{2}{*}{$44.0 \%$} & $34.9 \%$ & $44.0 \%$ & $0.0 \%$ & $23.2 \%$ & $22.0 \%$ \\
\hline & $\begin{array}{l}\text { Model } 3 \text { Long Range AWD } \\
\text { Performance }\end{array}$ & & & $9.1 \%$ & $0.0 \%$ & $44.0 \%$ & $20.8 \%$ & $22.0 \%$ \\
\hline \multirow{6}{*}{2019} & Model 3 Standard Range & \multirow{4}{*}{ K3EA } & \multirow{4}{*}{$55.7 \%$} & $38.8 \%$ & $55.7 \%$ & $0.0 \%$ & $47.5 \%$ & $13.9 \%$ \\
\hline & Model 3 Standard Range Plus & & & $13.1 \%$ & $0.0 \%$ & $0.0 \%$ & $7.0 \%$ & $13.9 \%$ \\
\hline & Model 3 Mid Range & & & $0.0 \%$ & $0.0 \%$ & $0.0 \%$ & $0.0 \%$ & $13.9 \%$ \\
\hline & Model 3 Long Range & & & $3.7 \%$ & $0.0 \%$ & $55.7 \%$ & $1.2 \%$ & $13.9 \%$ \\
\hline & Model 3 Long Range AWD & \multirow[b]{2}{*}{ K3EB } & \multirow[b]{2}{*}{$44.3 \%$} & $35.2 \%$ & $44.3 \%$ & $0.0 \%$ & $23.3 \%$ & $22.2 \%$ \\
\hline & $\begin{array}{l}\text { Model } 3 \text { Long Range AWD } \\
\text { Performance }\end{array}$ & & & $9.2 \%$ & $0.0 \%$ & $44.3 \%$ & $21.0 \%$ & $22.2 \%$ \\
\hline \multirow{8}{*}{2020} & Model 3 Standard Range & \multirow{4}{*}{ L3EA } & \multirow{4}{*}{$46.1 \%$} & $12.0 \%$ & $46.1 \%$ & $0.0 \%$ & $11.3 \%$ & $15.4 \%$ \\
\hline & Model 3 Standard Range Plus & & & $34.1 \%$ & $0.0 \%$ & $0.0 \%$ & $34.8 \%$ & $15.4 \%$ \\
\hline & Model 3 Mid Range & & & $0.0 \%$ & $0.0 \%$ & $0.0 \%$ & $0.0 \%$ & $0.0 \%$ \\
\hline & Model 3 Long Range & & & $0.0 \%$ & $0.0 \%$ & $46.1 \%$ & $0.0 \%$ & $15.4 \%$ \\
\hline & Model 3 Long Range AWD & L3EB & $41.9 \%$ & $41.9 \%$ & $41.9 \%$ & $41.9 \%$ & $41.9 \%$ & $41.9 \%$ \\
\hline & $\begin{array}{l}\text { Model } 3 \text { Long Range Performance } \\
\text { AWD (18in) }\end{array}$ & \multirow{3}{*}{ L3EC } & \multirow{3}{*}{$12.1 \%$} & $4.0 \%$ & $0.0 \%$ & $12.1 \%$ & $4.0 \%$ & $4.0 \%$ \\
\hline & $\begin{array}{l}\text { Model } 3 \text { Long Range Performance } \\
\text { AWD (19in) }\end{array}$ & & & $4.0 \%$ & $0.0 \%$ & $0.0 \%$ & $4.0 \%$ & $4.0 \%$ \\
\hline & $\begin{array}{l}\text { Model } 3 \text { Long Range Performance } \\
\text { AWD (20in) }\end{array}$ & & & $4.0 \%$ & $12.1 \%$ & $0.0 \%$ & $4.0 \%$ & $4.0 \%$ \\
\hline
\end{tabular}

TABLE B4 Tesla Model Y Trim Variant Distribution

\begin{tabular}{|c|c|c|c|c|c|c|c|c|}
\hline Year & Trim Variant & $\begin{array}{c}\text { VIN } \\
\text { Descriptor }\end{array}$ & $\begin{array}{c}\text { VIN } \\
\text { Descriptor } \\
\text { Proportion }\end{array}$ & Baseline & $\begin{array}{l}\text { Absolute } \\
\text { Minimum }\end{array}$ & $\begin{array}{l}\text { Absolute } \\
\text { Maximum }\end{array}$ & $\begin{array}{l}\text { Population } \\
\text { Weighted }\end{array}$ & $\begin{array}{c}\text { Even } \\
\text { Spread }\end{array}$ \\
\hline \multirow{3}{*}{2020} & Model Y Long Range AWD & LYEE & $79.5 \%$ & $79.5 \%$ & $79.5 \%$ & $79.5 \%$ & $79.5 \%$ & $79.5 \%$ \\
\hline & Model Y Performance AWD & \multirow[b]{2}{*}{ LYEF } & \multirow[b]{2}{*}{$20.5 \%$} & $10.3 \%$ & $0.0 \%$ & $20.5 \%$ & $10.3 \%$ & $10.3 \%$ \\
\hline & $\begin{array}{l}\text { Model Y Performance AWD ( } 21 \text { in } \\
\text { Wheels) }\end{array}$ & & & $10.3 \%$ & $20.5 \%$ & $0.0 \%$ & $10.3 \%$ & $10.3 \%$ \\
\hline
\end{tabular}




\section{REFERENCES}

Alliance for Automotive Innovation, 2021. Advanced Technology Vehicle Sales Dashboard. Updated April 7, 2021. https://www.autosinnovate.org/resources/electric-vehicle-salesdashboard

ANL (Argonne National Laboratory), 2021. Light Duty Electric Drive Vehicles Monthly Sales Update. Updated August 18, 2021. https://www.anl.gov/es/light-duty-electric-drive-vehicles$\underline{\text { monthly-sales-updates }}$

Arguez, Anthony, Imke Durre, Scott Applequist, Russell S. Vose, Michael F. Squires, Xungang Yin, Richard R. Heim, Jr., and Timothy W. Owen. "NOAA's 1981-2010 U.S. Climate Normals: An Overview", Bulletin of the American Meteorological Society 93, 11 (2012): 1687-1697, accessed Mar 24, 2021, https://doi.org/10.1175/BAMS-D-11-00197.1

Atlas EV Hub, 2021. "State EV Registration Download," Atlas EV Hub, Accessed March 8, 2021. https://www.atlasevhub.com/materials/state-ev-registration-data/\#data

Berman, Bradley, 2020. "Washington State passes bill to become a ZEV state, pushes for ban of gas cars," electrek. March 11, 2020. https://electrek.co/2020/03/11/washington-state-passes-billto-become-a-zev-state-pushes-for-ban-of-gas-cars/

BloombergNEF, 2020. Electric Vehicle Outlook 2020. Accessed February 17, 2021. https://bnef.turtl.co/story/evo-2020/page/3/1?teaser=yes

Bolli, Patrick, 2021. "Welche effektiv nutzbare Akku Kapazität hat mein Tesla?” Updated February 5, 2021. https://teslawissen.ch/effektiv-nutzbare-akku-kapazitaet/

Boudette, Neal E., 2019. “Tesla Sales Slump as '19 Starts Is Hinted At in State Data," New York Times. March 22, 2019. https://www.nytimes.com/2019/03/22/business/tesla-sales.html

Brooker, Aaron, Jeffrey Gonder, Sean Loop, and Jacob Ward, “ADOPT: A Historically Validated Light Duty Vehicle Consumer Choice Model," SAE Technical Paper 2015-01-0974, doi:10.4271/2015-01-0974. https://www.nrel.gov/docs/fy15osti/63608.pdf

CARB (California Air Resources Board), 2019. States that have Adopted California's Vehicle Standards under Section 177 of the Federal Clean Air Act. Updated August 19, 2019. https://ww2.arb.ca.gov/sites/default/files/2019-03/177-states.pdf

CarGurus.com, 2021. “2017 BMW i3 94 Ah RWD for Sale Nationwide,” Car Gurus. Accessed March 18, 2021. https://www.cargurus.com/Cars/1-Used-2017-BMW-i3-94-Ah-RWD-t69520

Cars.com, 2021. "New and Used BMW i3 for Sale," Cars.com. Accessed March 18, 2021. https://www.cars.com/for-sale/searchresults.action/

?mdId=56067\&mkId=20005\&yrId=30031936 
CARSP (Canadian Association of Road Safety Professionals), 2021. Canadian Vehicle Specifications. Accessed March 23, 2021. http://www.carsp.ca/research/resources/safetysources/canadian-vehicle-specifications/

Car and Driver, 2021. Car and Driver. Accessed February 22, 2021. https://www.caranddriver.com/new-cars/

City of Albuquerque, 2021. Vehicle emissions database. Updated March 23, 2021. http://data.cabq.gov/airquality/vehicleemisions

Cohen, Ariel, 2020. Plugging Into the Future: The Electric Vehicle Market Outlook. October 26, 2020. https://www.forbes.com/sites/arielcohen/2020/10/26/plugging-into-the-future-the-electricvehicle-market-outlook/?sh=4bc215db9812

Cole, Jay, 2017. "19,130 BMW i3 Rex Recalled In US Due to Fire Risk...Thanks To Its Gas Extender," Inside EVs. February 18, 2017. https://insideevs.com/news/332573/19130-bmw-i3rex-recalled-in-us-due-to-fire-riskthanks-to-its-gas-extender/

Demuro, Doug, 2016. "Here's Why So Many Exotic Cars Have Montana License Plates," Autotrader. August 31, 2016. https://www.autotrader.com/car-news/heres-why-so-many-exoticcars-have-montana-license-plates-256721

DOE (U.S. Department of Energy), 2021. Alternative Fuels Data Center - Electric Vehicle Charging Station Locations. Accessed August 21, 2021. https://afdc.energy.gov/fuels/electricity_locations.html\#/find/nearest?fuel=ELEC

DOE (U.S. Department of Energy) and EPA (U.S. Department of Energy and Environmental Protection Agency), 2021. FuelEconomy.gov. Updated April 16, 2021. https://www.fueleconomy.gov/feg/download.shtml

Durbin, Dee-Ann, 2015. "Tesla's long-delayed Model X SUV hits the road as sales of luxury SUVs are booming," US News and World Report. September 30, 2015. https://www.usnews.com/news/business/articles/2015/09/29/teslas-first-suv-the-model-x-isfinally-hitting-the-road

Dyer, Danny and Rebecca L. Pierce, 1993. "On the choice of the prior distribution in hypergeometric sampling," Communications in Statistics-Theory and Methods. 22(8), 21252146. doi:10.1080/03610929308831139. https://doi.org/10.1080/03610929308831139

Edvardsen, Lasse, 2020. General Tesla Registration Stats. Accessed February 3, 2020. https://teslastats.no/

Electric Vehicle Database, 2021. Electric Vehicle Database. Accessed February 22, 2021. https://ev-database.org/

EV Specifications, 2021. EV Specifications. Accessed February 3, 2021. https://www.evspecifications.com/en/brand/b1e92 
GM (General Motors), 2012. "Emission Requirements for 2013 Model Year GM Vehicles," Bulletin GM 12-14, May 16, 2012. http://www.zl1registry.com/pdfs/2013-model-emissionsbulletin.pdf

GM (General Motors), 2013. "Chevrolet Volt - 2014: Product Information.” https://media.chevrolet.com/media/us/en/chevrolet/vehicles/volt/2014.html

Gohlke, David and Joann Zhou, 2021. Assessment of Light-Duty Plug-in Electric Vehicles in the United States, 2010-2020. Report ANL/ESD-21/2, doi: 10.2172/1785708. https://www.osti.gov/biblio/1785708

GOV.UK, 2020. Data on all licensed and registered vehicles, produced by Department for Transport. Accessed February 9, 2021. https://www.gov.uk/government/statistical-datasets/all-vehicles-veh01

Greene, David, and Changzheng Liu, 2012. Consumer Vehicle Choice Model Documentation. Report EPA-420-B-12-052. https://nepis.epa.gov/Exe/ZyPDF.cgi/P100EZ37.PDF?Dockey=P100EZ37.PDF

Guess, Megan, 2018. "Musk: Shipping base-price Model 3 at this point would cause Tesla to lose money," ARS Technica. May 22, 2018. https://arstechnica.com/cars/2018/05/muskshipping-base-price-model-3-at-this-point-would-cause-tesla-to-lose-money/

Gurskiy, Denis, 2019. “How Tesla Tire Size Impacts Tesla Range,” Clean Technica. October 12, 2019. https://cleantechnica.com/2019/10/12/how-tesla-tire-size-impacts-tesla-range/

Hughes, Jason, 2017. "Pics and Info: Inside the Tesla 100kWh Battery Pack.” January 24, 2017. http://skie.net/skynet/projects/tesla/view_post/ 20_Pics+and+Info $\% 3 \mathrm{~A}+$ Inside+the+Tesla+100kWh+Battery+Pack

IEA, 2020a. Electric Vehicles. Accessed February 17, 2021. https://www.iea.org/reports/electricvehicles

IEA, 2020b. Global EV Outlook 2020. Accessed February 17, 2021. https://www.iea.org/reports/global-ev-outlook-2020

Jüdell, Frank, 2020; "Everything You Need to Know About EV Incentives In The Netherlands," Wallbox. Accessed February 17, 2021. https://blog.wallbox.com/en/netherlands-ev-incentives/

KBA (Kraftfahrt-Bundesamt), 2020. Bestand am 1. Januar 2020 nach Marken, Herstellern. Accessed February 3, 2021. https://www.kba.de/DE/Statistik/Fahrzeuge/Bestand/ MarkenHersteller/marken_hersteller_node.html

Lambert, Fred, 2016. "Tesla's hacked Battery Management System exposes the real usable capacity of its battery packs," electrek. December 14, 2016. https://electrek.co/2016/12/14/teslabattery-capacity/ 
Lambert, Fred, 2019a. “Tesla discontinues Model 3 Mid Range battery pack," electrek. March 17, 2019. https://electrek.co/2019/03/17/tesla-discontinues-model-3-mid-range-battery-pack/

Lambert, Fred, 2019b. "Tesla unveils Model Y electric SUV with 300 miles range and 7-seats," electrek, March 14, 2019. https://electrek.co/2019/03/14/tesla-model-y-electric-suv-unveil/

Lambert, Fred, 2020. "Tesla (TSLA) still holds impressive 18\% market share of global EV sales, but that's about to change," electrek. October 30, 2020. https://electrek.co/2020/10/30/tesla-tslamarket-share-global-ev-sales-change/

Lambert, Fred, 2021a. "Tesla Model 3 is still the best-selling electric car in the world and it's not even close." electrek, February 4, 2021. https://electrek.co/2021/02/04/tesla-model-3-still-bestselling-electric-car-world-not-even-close/

Lambert, Fred, 2021b. "Telsa owns 79\% of the electric car market in the US, and that needs to change," electrek. February 16, 2021. https://electrek.co/2021/02/16/tesla-owns-electric-car$\underline{\text { market-us/ }}$

MAPC (Metropolitan Area Planning Council), 2016. Massachusetts Vehicle Census (20092014). Updated January 1, 2015. https://datacommon.mapc.org/browser/Transportation/

McDonald, Loren, 2020. "2019 US EV Sales Decreased an Estimated 7\% to 9\%--6 Reasons Why," EV Adoption. January 20, 2020. https://evadoption.com/2019-us-ev-sales-decreased-anestimated-7-to-9-6-reasons-why/

Millikin, Mike, 2011. "Chevy Volt gets a Low Emissions Package for California; HOV lanes access," Green Car Congress. November 17, 2011.

https://www.greencarcongress.com/2011/11/volt-20111117.html

MLIT (Ministry of Land, Infrastructure, Transport, and Tourism), 2019. "Vehicle

Safety/Pollution Recall Campaign in Japan, 2771.” January 10, 2019.

https://www.mlit.go.jp/common/001272966.pdf

Model3VINs.com, 2019. "Model 3 VIN Registrations, Weekly," Model3VINs. September 22, 2019. http://www.model3vins.com/

Model 3 VINs (@Model3VINs), 2020. “Q1 loss secured \$TSLA,” Twitter, February 6, 2020, 11:05 p.m. https://twitter.com/Model3VINs/status/1225631766326571008

ND DOT (North Dakota Department of Transportation), 2021. Online Title Status Search. Accessed March 19, 2021. https://apps.nd.gov/dot/mv/mvrenewal/titleStatus.htm

NHTSA (National Highway Traffic Safety Administration), 2008. Vehicle Identification Number Requirements. Federal Register, Vol. 73, no. 84, pg. 23367. April 30, 2008. https://www.govinfo.gov/content/pkg/FR-2008-04-30/pdf/08-1197.pdf

NHTSA, 2015. New Manufacturers Handbook. Updated December 7, 2015. https://www.nhtsa.gov/staticfiles/laws_regs/pdf/Manufacturer_Information_12022015.pdf 
NHTSA, 2021a. Product Information Catalog and Vehicle Listing (vPIC). Accessed August 2, 2021. https://vpic.nhtsa.dot.gov/

NHTSA, 2021b. Safety Issues \& Recalls. Accessed February 25, 2021.

https://www.nhtsa.gov/recalls

Norsk elbilforening, 2021. "Norwegian EV policy," Norsk elbilforening. Accessed February 17, 2021. https://elbil.no/english/norwegian-ev-policy/

NREL (National Renewable Energy Laboratory), 2020. "Electric Vehicle Registrations by State," National Renewable Energy Laboratory, Accessed February 12, 2021.

https://afdc.energy.gov/data/10962

NYS DMV (New York State, Department of Motor Vehicles), 2021. Vehicle, Snowmobile, and Boat Registrations. Updated April 1, 2021. https://data.ny.gov/Transportation/Vehicle-

Snowmobile-and-Boat-Registrations/w4pv-hbkt

NYS Thruway Authority (New York State Thruway Authority), 2014. Green Pass Discount Plan. Updated November 7, 2014. https://www.thruway.ny.gov/ezpass/greentag.html

NZTA (New Zealand Transport Agency), 2021. Motor Vehicle Register API. Accessed February 11, 2021. https://opendata-nzta.opendata.arcgis.com/datasets/motor-vehicle-registerapi

OH BMV (Ohio Bureau of Motor Vehicles), 2021. Vehicle/Watercraft Title Search. Accessed March 19, 2021, https://bmvonline.dps.ohio.gov/Search/Title.

Open Data DC, 2021. "DMW Vehicle Inspections 2014 to 2020," Open Data DC. Accessed February 15, 2021. https://opendata.dc.gov/datasets/dmv-vehicle-inspections-2014-to-2020

Randall, Tom and Dean Halford, 2019. "Tesla Model 3 Tracker," Bloomberg. December 31, 2019. https://www.bloomberg.com/graphics/tesla-model-3-vin-tracker/

RDW (Rijksdienst voor het Wegverkeer), 2021. Open Data RDW: Gekentekende_voertuigen. Accessed January 22, 2021. https://opendata.rdw.n1/en/Voertuigen/Open-Data-RDW-

Gekentekende_voertuigen/m9d7-ebf2/data

Shahan, Zachary, 2018. 'Exclusive: Tesla Registers 17 LHD Model 3 VINs - Comin' To Europe, Baby!" Clean Technica, August 31, 2018. https://cleantechnica.com/2018/08/31/teslaregisters-17-lhd-model-3-vins-comin-to-europe-baby-cleantechnica-exclusive/

SD Cars (South Dakota Department of Revenue Division of Motor Vehicles), 2021, Check Vehicle Information. Accessed March 19, 2021. https://apps.sd.gov/RV66Renewals/checkvin/NewCheckVIN.aspx

Tesla, 2014. "Right Hand Drive Model S Arrives in the UK," Tesla, June 9, 2014. https://www.tesla.com/blog/right-hand-drive-model-s-arrives-uk 
Tesla, 2018. “Tesla Third Quarter 2018 Update," Tesla, October 2, 2018. https://teslacdn.thron.com/static/1QFVCG_TSLA_Update_Letter_2018-3Q_NSDHT5.pdf

Tesla, 2019. “Tesla Second Quarter 2019 Update,” Tesla, July 2, 2019. https://teslacdn.thron.com/static/DBTY1V_TSLA_Update_Letter_2019-2Q_TXNPXB.pdf

Tesla, 2021. "Tesla Q4 2020 Vehicle Production \& Deliveries," Tesla, Accessed February 9, 20201. https://ir.tesla.com/press-release/tesla-q4-2020-vehicle-production-deliveries

Tesla Info, 2021. "Tesla VIN decoder," Tesla Info. Accessed March 6, 2021. https://teslainfo.com/vin-decoder.php

VinAudit, 2021. VIN Directory. Accessed March 23, 2021. https://www.vinaudit.com/vindir/

WA DOL (Washington State Department of Licensing), 2021. "Electric Vehicle Population Data," State of Washington, Updated March 15, 2021.

https://data.wa.gov/Transportation/Electric-Vehicle-Population-Data/f6w7-q2d2/data

Wei, Wei, Sankaran Ramakrishnan, Zachary A. Needell, and Jessika E. Trancik, 2021. "Personal vehicle electrification and charging solutions for high-energy days," Nature Energy, 6(1), 105114, doi:10.1038/s41560-020-00752-y, https://doi.org/10.1038/s41560-020-00752-y.

WHO (World Health Organization), 2020. "Registered Vehicles Data by Country," Global Health Observatory data repository. Updated January 22, 2020.

https://apps.who.int/gho/data/view.main.51210

Williams, B., J. Anderson, C. Santulli, and G. Arreola, 2015. "Clean Vehicle Rebate Project Participation Rates: The First Five Years (March 2010 - March 2015)," Center for Sustainable Energy, San Diego CA, October 2015. https://cleanvehiclerebate.org/eng/content/cvrpparticipation-thru-2015-03

Xu, Panpan, Qiang Dai, Hongpeng Gao, Haodong Liu, Minghao Zhang, Mingqian Li, Yan Chen, Ke An, Ying Shirley Meng, Ping Liu, Yanran Li, Jeffery S. Spangenburger, Linda Gaines, Jun $\mathrm{Lu}$, and Zheng Chen, 2020. "Efficient Direct Recycling of Lithium-Ion Battery Cathodes by Targeted Healing," Joule. 4(12), 2609-2626, doi:10.1016/j.joule.2020.10.008. https://doi.org/10.1016/j.joule.2020.10.008.

Zhou, Yan, Spencer Aeschliman, and David Gohlke, 2020. Affordability of Household Transportation Fuel Costs by Region and Socioeconomic Factors. Report ANL/ESD-20/11, doi: 10.2172/1760477. https://www.osti.gov/biblio/1760477 



\section{Argonne}

\section{Energy Systems Division}

Argonne National Laboratory

9700 South Cass Avenue, Bldg. 362

Lemont, IL 60439-4832

www.anl.gov 